Supporting Information

\title{
Discovery of Aryl Sulfonamides as Isoform-Selective Inhibitors of Nav1.7 with Efficacy in Rodent Pain Models
}

Thilo Focken, ${ }^{\dagger, *}$ Shifeng Liu, ${ }^{\dagger, \|}$ Navjot Chahal, ${ }^{\dagger}$ Maxim Dauphinais, ${ }^{\dagger, \S}$ Michael E. Grimwood, ${ }^{\dagger}$ Sultan Chowdhury, ${ }^{\dagger}$ Ivan Hemeon, ${ }^{\dagger}$ Paul Bichler, ${ }^{\dagger}$ David Bogucki, ${ }^{\dagger}$ Matthew Waldbrook, ${ }^{\dagger}$ Girish Bankar, ${ }^{\dagger}$ Luis E. Sojo, ${ }^{\dagger}$ Clint Young, $^{\dagger}$ Sophia Lin, ${ }^{\dagger}$ Noah Shuart, ${ }^{\dagger}$ Rainbow Kwan, ${ }^{\dagger}$ Jodie Pang, ${ }^{\ddagger}$ Jae H. Chang, ${ }^{\ddagger}$ Brian S. Safina, ${ }^{\ddagger}$ Daniel P. Sutherlin, ${ }^{\ddagger}$ J.

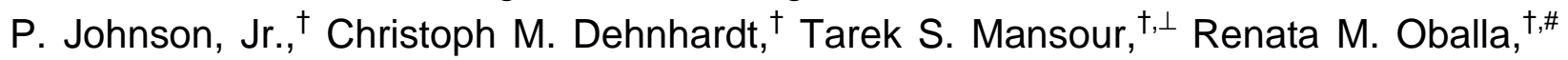
Charles J. Cohen, ${ }^{\dagger}$ and C. Lee Robinette ${ }^{\dagger}$

${ }^{\dagger}$ Xenon Pharmaceuticals Inc., 200-3650 Gilmore Way, Burnaby, BC V5G 4W8, Canada

‡ Genentech, Inc., 1 DNA Way, South San Francisco, CA 94080, United States

Present Addresses:

"Hangzhou Yingchuang Pharma, Longtan Road No. 20, Yuhang District, Hangzhou, Zhejiang, 31121, P.R.China. $\$$ Department of Chemistry, Université de Montréal, PO Box 6128, Station Downtown, Montreal, QC H3C 3J7, Canada. ${ }^{\perp}$ Sabila Biosciences LLC, 5 Overlook Road, New City, NY 10956, United States. " Inception Sciences Canada, 887 Great Northern Way, Suite 210, Vancouver, BC V5T 4T5, Canada.

\section{Table of Contents}

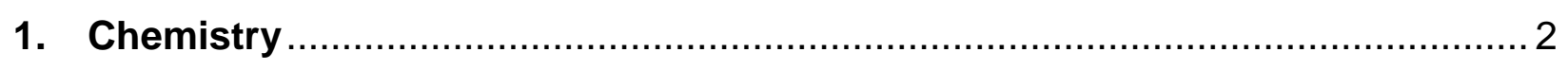

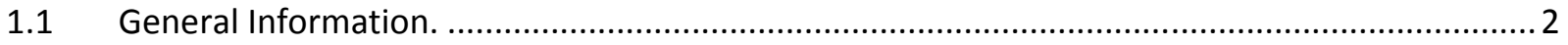

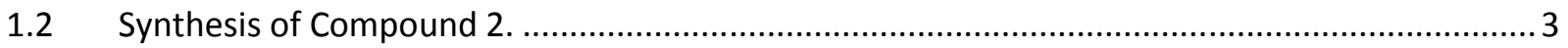

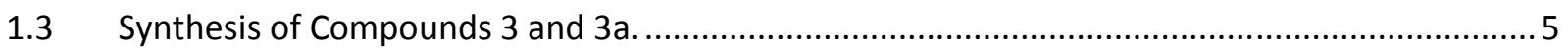

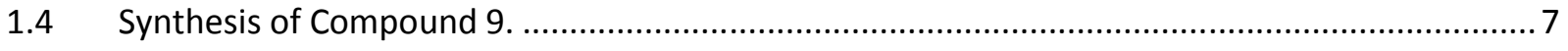

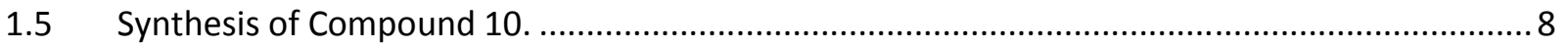

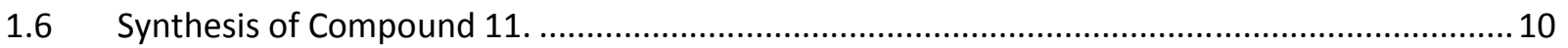

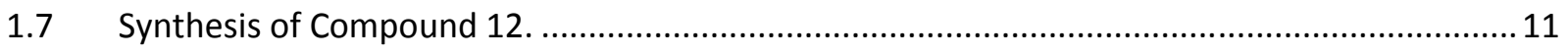

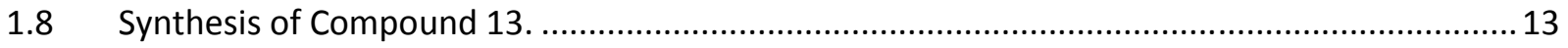

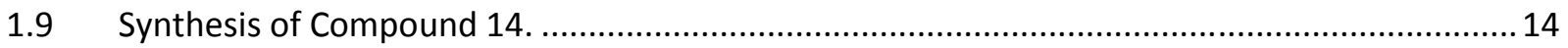




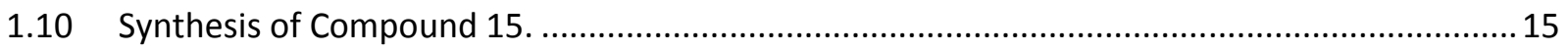

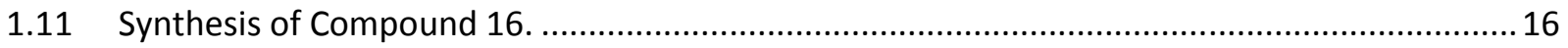

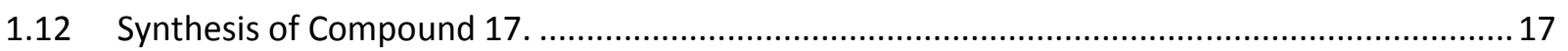

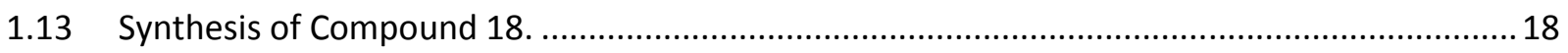

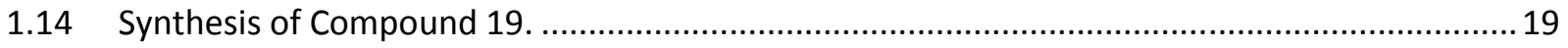

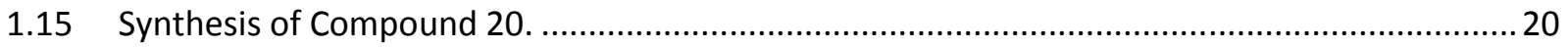

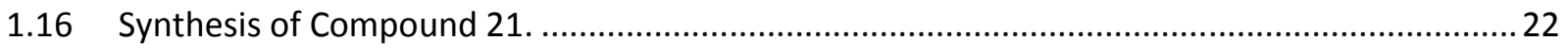

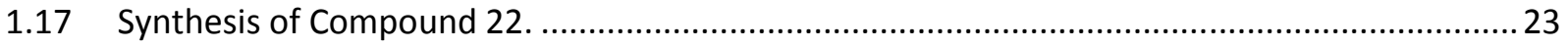

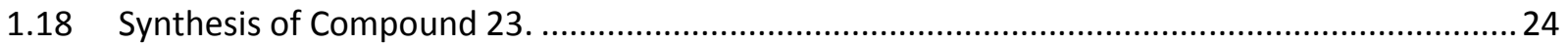

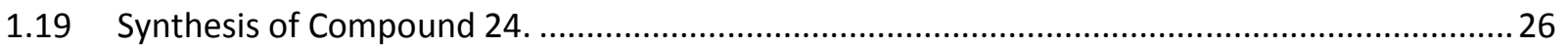

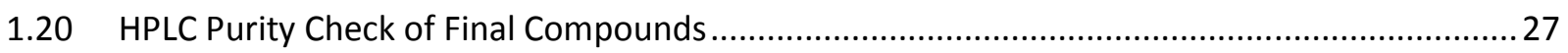

2. Voltage-Clamp Whole Cell Recordings and Cell Lines .................................. 28

3. In Vitro Predicated Hepatic Clearance Data with Hepatocytes........................ 31

4. In Vitro MDCK Cell Permeability............................................................... 31

5. In Vitro Pgp (MDR1) and BCRP Transport Assays ..................................... 31

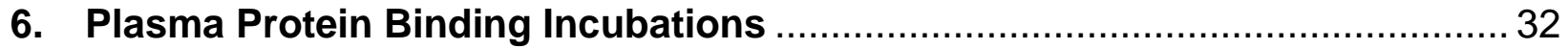

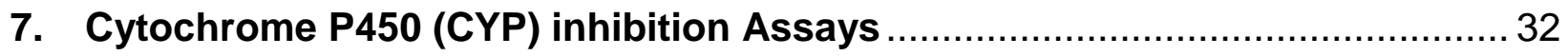

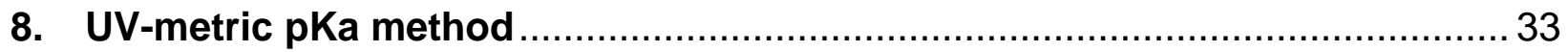

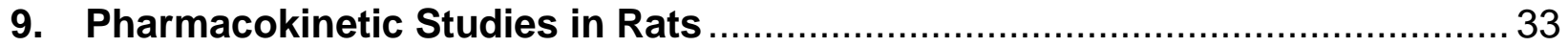

10. Formalin- and Aconitine-Induced Pain Model in Rats .................................... 34

11. CFA-Induced Cold Allodynia Pain Model in Mice ........................................... 34

12. Analysis of Plasma and Brain Samples..................................................... 34

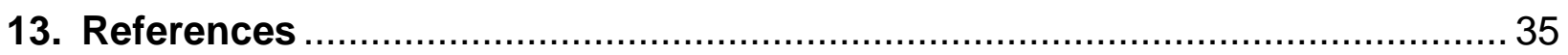

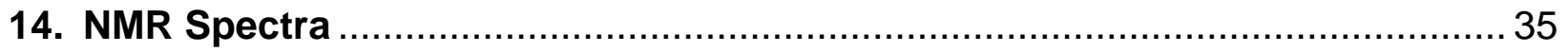

\section{Chemistry}

\subsection{General Information.}

Unless otherwise stated, commercially available reagents and solvents were used without purification. Yields were not optimized. Melting points were determined on a Büchi hot-stage apparatus and are uncorrected. NMR spectra were recorded on a Bruker Avance 300 spectrometer with chemical shifts $(\delta)$ reported in parts-per-million 
(ppm) relative to the residual signal of the deuterated solvent. ${ }^{1} \mathrm{H} N M R,{ }^{19} \mathrm{~F}$ and ${ }^{13} \mathrm{C}$ NMR data are reported as follows: chemical shift, multiplicity $(s=$ singlet, $d=$ doublet, $t$ = triplet, $\mathrm{q}=$ quartet, $\mathrm{qn}=$ quintet, $\mathrm{m}=$ multiplet and $\mathrm{br}=$ broad), coupling constant in $\mathrm{Hz}$, and number of protons, fluorine or carbon atoms. Mass spectra were obtained using a Waters 2795/Micromass Quattro LC/MS system (Waters Corporation). Purity was determined by HPLC analysis on Agilent 1100, 1200, or 1260 systems (Agilent Technologies) using a XBridge C-18 column ( $5 \mu \mathrm{m}, 4.6 \times 50 \mathrm{~mm}$, Waters Corporation) with a $5-95 \%$ gradient over 5 min of $\mathrm{CH}_{3} \mathrm{CN}$ in water containing $0.1 \%$ TFA at a flow rate of $1.0 \mathrm{~mL} / \mathrm{min}$ at $25 \stackrel{\circ}{\circ}$. Peaks were detected at a wavelength of 254 or $280 \mathrm{~nm}$ with an Agilent photodiode array detector. All compounds reported herein with biological data exhibited spectral data consistent with their proposed structures and had purities $>95 \%$ as determined by HPLC unless otherwise stated. Preparative HPLC was performed on Water HPLC systems using a XBridge Prep C18 column $(5 \mu \mathrm{m}, 30 \times 50 \mathrm{~mm}$, Waters Corporation), a XSelect CSH Prep column ( $5 \mu \mathrm{m}, 30 \times 50 \mathrm{~mm}$, Waters Corporation), or a Gemini-NX C18 column ( $5 \mu \mathrm{m}, 150 \times 50 \mathrm{~mm}$, Phenomenex) with a 5-95\% gradient of $\mathrm{CH}_{3} \mathrm{CN}$ in water containing $0.1 \%$ TFA or formic acid, respectively. Elemental analyses were performed by Canadian Microanalysis Services Ltd. (Delta, BC, Canada). Chemical names were generated using ChemBioDraw version 14 by CambridgeSoft.

\subsection{Synthesis of Compound 2.}

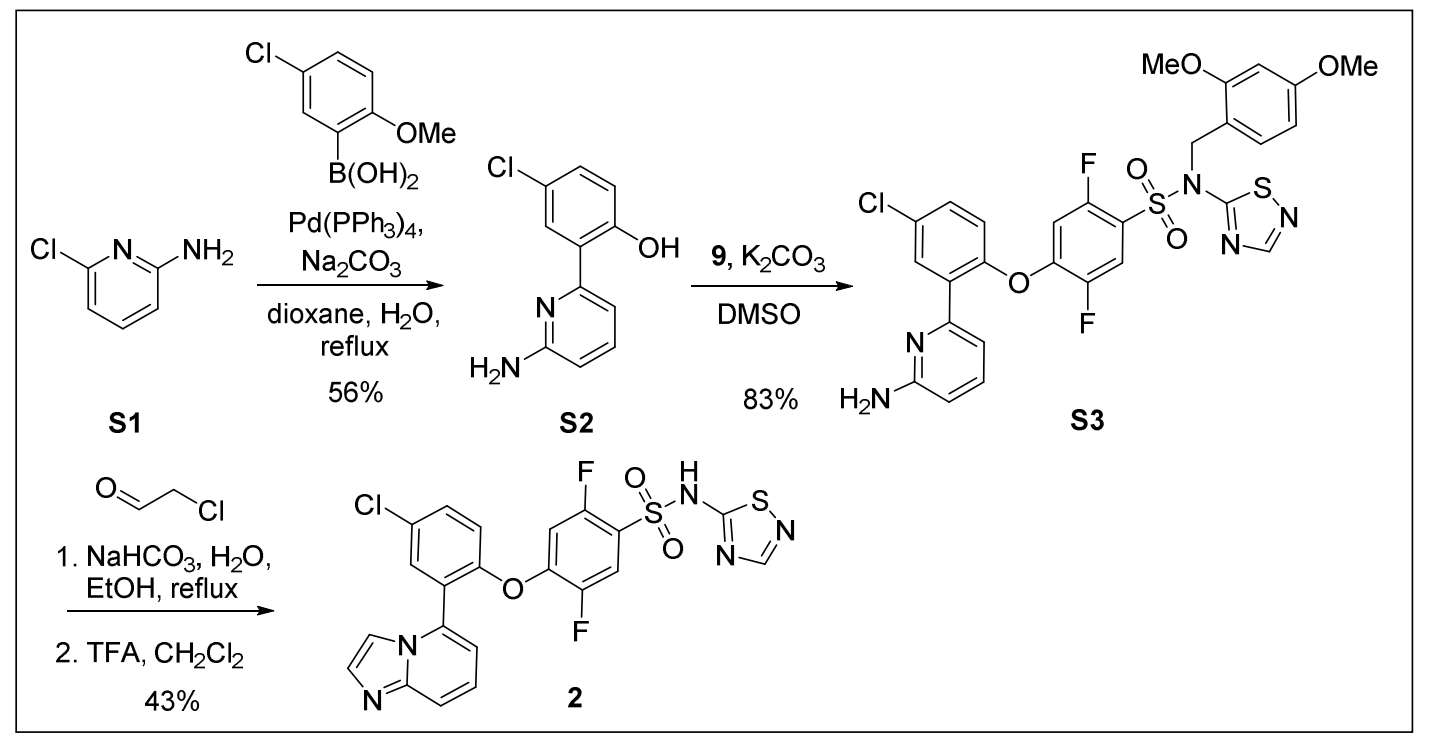

2-(6-Aminopyridin-2-yl)-4-chlorophenol (S2). To a stirred mixture of 2-amino-6chloropyridine $(0.26 \mathrm{~g}, 2.0 \mathrm{mmol})$, 5-chloro-2-hydroxyphenylboronic acid (0.35 g, 2.0 mmol) and $2 \mathrm{M}$ aqueous $\mathrm{Na}_{2} \mathrm{CO}_{3}(3 \mathrm{~mL}, 6 \mathrm{mmol})$ in dioxane $(6 \mathrm{~mL})$ was added $\mathrm{Pd}\left(\mathrm{PPh}_{3}\right)_{4}(0.10 \mathrm{~g}, 0.086 \mathrm{mmol})$. The mixture was heated at $85{ }^{\circ} \mathrm{C}$ for $16 \mathrm{~h}$, allowed to cool to ambient temperature and diluted with EtOAc $(50 \mathrm{~mL})$ and water $(20 \mathrm{~mL})$. The organic layer was separated, washed with brine, and dried over anhydrous $\mathrm{Na}_{2} \mathrm{SO}_{4}$. 
After concentration in vacuo, the residue was purified by column chromatography (25$50 \%$ ethyl acetate in hexanes) to afford the title compound as a yellowish solid in $56 \%$ yield $(0.25 \mathrm{~g}) .{ }^{1} \mathrm{H}$ NMR $\left(300 \mathrm{MHz}, \mathrm{CDCl}_{3}\right) \delta 7.67(\mathrm{~d}, J=2.4 \mathrm{~Hz}, 1 \mathrm{H}), 7.57(\mathrm{dd}, J=7.8$, $7.8 \mathrm{~Hz}, 1 \mathrm{H}), 7.22-7.13(\mathrm{~m}, 2 \mathrm{H}), 6.89(\mathrm{~d}, J=8.7 \mathrm{~Hz}, 1 \mathrm{H}), 6.46(\mathrm{~d}, J=8.4 \mathrm{~Hz}, 1 \mathrm{H}), 4.53$ $(\mathrm{s}, 2 \mathrm{H}),(\mathrm{OH}$ not observed).

4-(2-(6-Aminopyridin-2-yl)-4-chlorophenoxy)-N-(2,4-dimethoxybenzyl)-2,5-difluoro- $N$ (1,2,4-thiadiazol-5-yl)benzenesulfonamide (S3). To a stirred mixture of $9(0.41 \mathrm{~g}, 0.93$ $\mathrm{mmol})$ and $\mathrm{K}_{2} \mathrm{CO}_{3}(0.38 \mathrm{~g}, 2.8 \mathrm{mmol})$ in anhydrous DMSO $(4 \mathrm{~mL})$ was added phenol S2 $(0.19 \mathrm{~g}, 0.93 \mathrm{mmol})$. The reaction mixture was stirred at ambient temperature for $16 \mathrm{~h}$ and diluted with ethyl acetate $(50 \mathrm{~mL})$ and water $(20 \mathrm{~mL})$. The organic phase was washed with brine, dried over anhydrous $\mathrm{Na}_{2} \mathrm{SO}_{4}$, and concentrated in vacuo. The residue was purified by column chromatography (20-50\% EtOAc in hexanes) to afford the title compound as a yellowish oil in $83 \%$ yield $(0.49 \mathrm{~g}) .{ }^{1} \mathrm{H} \mathrm{NMR}\left(300 \mathrm{MHz}, \mathrm{CDCl}_{3}\right) \delta$ $8.16(\mathrm{~s}, 1 \mathrm{H}), 7.84(\mathrm{~d}, J=2.7 \mathrm{~Hz}, 1 \mathrm{H}), 7.51-7.34(\mathrm{~m}, 3 \mathrm{H}), 7.14(\mathrm{~d}, J=8.7 \mathrm{~Hz}, 1 \mathrm{H}), 7.01$ $(\mathrm{d}, J=8.7 \mathrm{~Hz}, 1 \mathrm{H}), 6.97(\mathrm{~d}, J=7.5 \mathrm{~Hz}, 1 \mathrm{H}), 6.42-6.26(\mathrm{~m}, 3 \mathrm{H}), 6.17(\mathrm{~d}, J=2.4 \mathrm{~Hz}, 1 \mathrm{H})$, $5.25(\mathrm{~s}, 2 \mathrm{H}), 4.39(\mathrm{~s}, 2 \mathrm{H}), 3.75(\mathrm{~s}, 3 \mathrm{H}), 3.63(\mathrm{~s}, 3 \mathrm{H})$; LRMS $\mathrm{m} / \mathrm{z}$ calcd for $\mathrm{C}_{28} \mathrm{H}_{23} \mathrm{ClF}_{2} \mathrm{~N}_{5} \mathrm{O}_{5} \mathrm{~S}_{2}(\mathrm{M}+\mathrm{H})^{+}$646.1, found 645.6.

4-(4-Chloro-2-(imidazo[1,2-a]pyridin-5-yl)phenoxy)-2,5-difluoro-N-(1,2,4-thiadiazol-5yl)benzenesulfonamide (2). To a stirred solution of $\mathbf{S 3}(2.43 \mathrm{~g}, 3.75 \mathrm{mmol})$ in $\mathrm{EtOH}(75$ $\mathrm{mL})$ and water $(9 \mathrm{~mL})$ was added $\mathrm{NaHCO}_{3}(0.41 \mathrm{~g}, 4.9 \mathrm{mmol})$ and chloroacetaldehyde $(50 \% \mathrm{w} / \mathrm{w}$ in water, $0.63 \mathrm{~mL}, 4.9 \mathrm{mmol})$ at ambient temperature. The mixture was heated at reflux for $16 \mathrm{~h}$, allowed to cool to ambient temperature and diluted with $\mathrm{CH}_{2} \mathrm{Cl}_{2}$ $(200 \mathrm{~mL})$ and water $(20 \mathrm{~mL})$. The organic layer washed with brine $(50 \mathrm{~mL})$, dried over anhydrous $\mathrm{Na}_{2} \mathrm{SO}_{4}$, and concentrated in vacuo. The residue was dissolved in $\mathrm{CH}_{2} \mathrm{Cl}_{2}$ $(50 \mathrm{~mL})$ and TFA $(2 \mathrm{~mL})$ was added. The reaction mixture was stirred for $5 \mathrm{~h}$ at ambient temperature and concentrated in vacuo. Purification of the residue by column chromatography $(0-10 \%$ methanol in EtOAc) afforded the title compound as a pale yellow solid in $43 \%$ yield $(0.84 \mathrm{~g}) .{ }^{1} \mathrm{H}$ NMR $\left(300 \mathrm{MHz}\right.$, DMSO- $\left.d_{6}\right) \delta 8.14(\mathrm{~s}, 1 \mathrm{H}), 7.93(\mathrm{~d}$, $J=1.5 \mathrm{~Hz}, 2 \mathrm{H}), 7.87-7.78(\mathrm{~m}, 2 \mathrm{H}), 7.76-7.66(\mathrm{~m}, 2 \mathrm{H}), 7.62-7.52(\mathrm{~m}, 1 \mathrm{H}), 7.42-7.30$ $\left(\mathrm{m}, 3 \mathrm{H}\right.$ ), (sulfonamide $\mathrm{NH}$ not observed); HRMS $\mathrm{m} / \mathrm{z}$ calcd for $\mathrm{C}_{21} \mathrm{H}_{13} \mathrm{ClF}_{2} \mathrm{~N}_{5} \mathrm{O}_{3} \mathrm{~S}_{2}$ $(\mathrm{M}+\mathrm{H})^{+} 520.0111$, found 520.0118 . 


\subsection{Synthesis of Compounds 3 and $3 a$.}

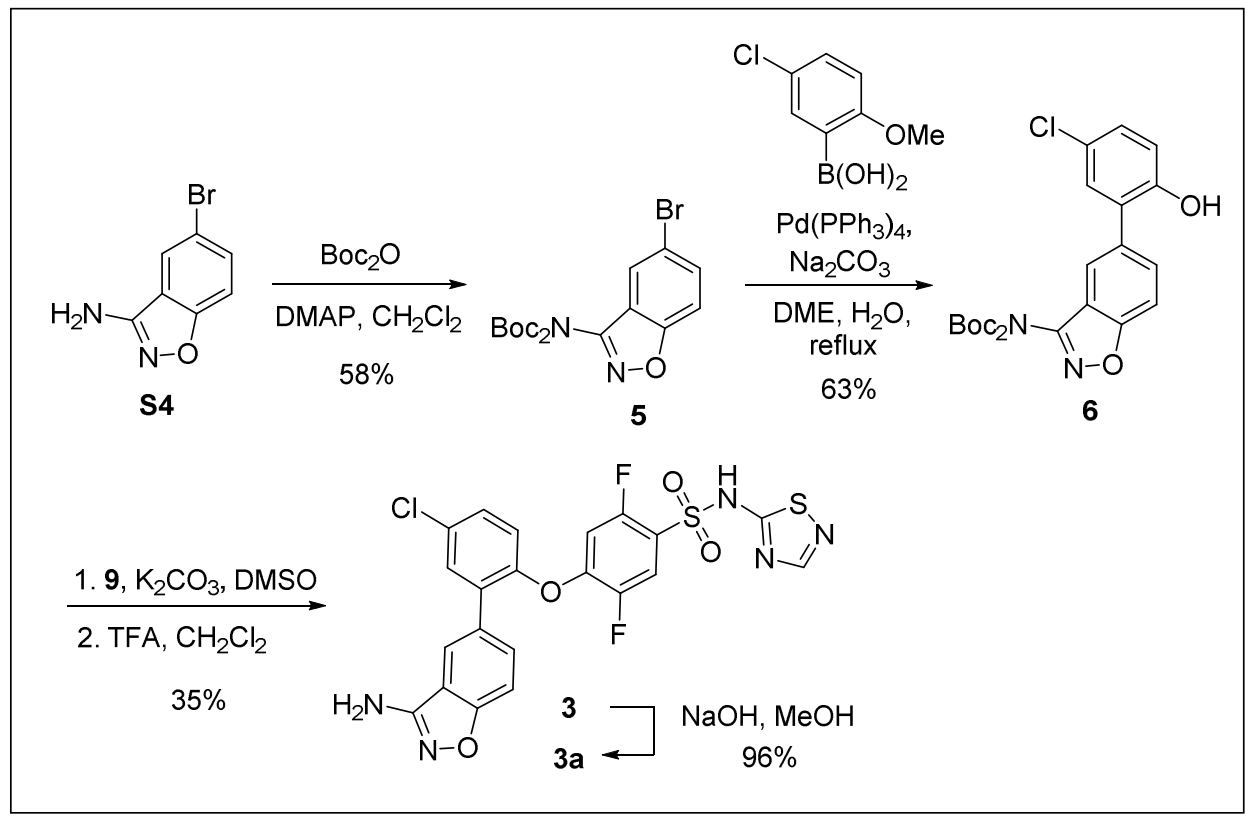

Di-tert-butyl (5-bromo-1,2-benzoxazol-3-yl)imido-dicarbonate (5). To a solution of 5bromobenzo[d]isoxazol-3-amine (S4) $(5.5 \mathrm{~g}, 26 \mathrm{mmol})$ in THF $(50 \mathrm{~mL})$ was added DMAP $(0.63 \mathrm{~g}, 5.2 \mathrm{mmol})$ and $\mathrm{Boc}_{2} \mathrm{O}(11.8 \mathrm{~g}, 54.5 \mathrm{mmol})$. The reaction mixture was stirred at ambient temperature for $18 \mathrm{~h}$ and concentrated in vacuo. The residue was diluted with EtOAc $(60 \mathrm{~mL})$, washed with water $(2 \times 30 \mathrm{~mL})$, and dried over anhydrous sodium sulfate. Evaporation in vacuo yielded a solid residue which was triturated in a mixture of $\mathrm{Et}_{2} \mathrm{O}$ and hexanes to afford 5 as a colorless solid in $58 \%$ yield $(6.2 \mathrm{~g}) .{ }^{1} \mathrm{H}$ $\operatorname{NMR}\left(300 \mathrm{MHz}\right.$, DMSO- $\left.d_{6}\right) \delta 7.68-7.63(\mathrm{~m}, 2 \mathrm{H}), 7.47(\mathrm{~d}, J=8.7 \mathrm{~Hz}, 1 \mathrm{H}), 1.40(\mathrm{~s}, 18 \mathrm{H})$; LRMS $\mathrm{m} / \mathrm{z}$ calcd for $\mathrm{C}_{17} \mathrm{H}_{22} \mathrm{BrN}_{2} \mathrm{O}_{5}(\mathrm{M}+\mathrm{H})^{+} 413.1$, found 412.9 .

Di-tert-butyl (5-(5-chloro-2-hydroxyphenyl)-1,2-benzoxazol-3-yl)imidodicarbonate (6). To a solution of $5(3.9 \mathrm{~g}, 9.3 \mathrm{mmol})$ in DME $(100 \mathrm{~mL})$ was added (5-chloro-2hydroxyphenyl)boronic acid $(1.6 \mathrm{~g}, 9.3 \mathrm{mmol}), \mathrm{Pd}\left(\mathrm{PPh}_{3}\right)_{4}(1.1 \mathrm{~g}, 0.9 \mathrm{mmol})$ and $2 \mathrm{M}$ aqueous $\mathrm{Na}_{2} \mathrm{CO}_{3}(9.3 \mathrm{~mL}, 18.6 \mathrm{mmol})$. The mixture was heated at reflux for $5 \mathrm{~h}$, allowed to cool to ambient temperature and concentrated in vacuo. The residue was diluted with EtOAc $(75 \mathrm{~mL})$, washed with water $(2 \times 40 \mathrm{~mL})$, dried over anhydrous sodium sulfate, and concentrated in vacuo. The residue was purified by column chromatography (10-50\% EtOAc in hexanes) to 6 as a colorless solid in $63 \%$ yield (2.69 g). ${ }^{1} \mathrm{H}$ NMR $\left(300 \mathrm{MHz}\right.$, DMSO- $\left.d_{6}\right) \delta 7.66(\mathrm{~m}, 2 \mathrm{H}), 7.47-7.45(\mathrm{~s}, 1 \mathrm{H}), 7.22-7.19(\mathrm{~m}, 3 \mathrm{H})$, 6.90-6.87 $(\mathrm{m}, 1 \mathrm{H}), 1.41(\mathrm{~s}, 18 \mathrm{H})$; LRMS $\mathrm{m} / \mathrm{z}$ calcd for $\mathrm{C}_{23} \mathrm{H}_{26} \mathrm{ClN}_{2} \mathrm{O}_{6}(\mathrm{M}+\mathrm{H})^{+} 461.1$, found 460.9 .

4-(2-(3-Aminobenzo[d]isoxazol-5-yl)-4-chlorophenoxy)-2,5-difluoro- $N$-(1,2,4-thiadiazol5-yl)benzenesulfonamide (3). Step 1. To a mixture of $6(2.07 \mathrm{~g}, 4.49 \mathrm{mmol})$ and $9(2.0$ 
$\mathrm{g}, 4.49 \mathrm{mmol})$ in anhydrous DMSO $(20 \mathrm{~mL})$ was added $\mathrm{K}_{2} \mathrm{CO}_{3}(0.75 \mathrm{~g}, 5.39 \mathrm{mmol})$ and the reaction mixture was stirred for $16 \mathrm{~h}$ at ambient temperature. The mixture was diluted with EtOAc $(200 \mathrm{~mL})$ and water $(50 \mathrm{~mL})$, and the aqueous layer was extracted with EtOAc $(3 \times 20 \mathrm{~mL})$. The combined organic phase was washed with brine $(20 \mathrm{~mL})$, dried over anhydrous $\mathrm{Na}_{2} \mathrm{SO}_{4}$, and concentrated in vacuo. Purification of the residue by column chromatography (10-25\% EtOAc in hexanes) afforded the adduct as a colorless solid in $55 \%$ yield $(2.23 \mathrm{~g})$. ${ }^{1} \mathrm{H}$ NMR $\left(300 \mathrm{MHz}\right.$, DMSO- $\left.d_{6}\right) \delta 8.15(\mathrm{~s}, 1 \mathrm{H}), 7.67-7.57(\mathrm{~m}$, $3 \mathrm{H}), 7.47-7.39(\mathrm{~m}, 3 \mathrm{H}), 7.13(\mathrm{~m}, 1 \mathrm{H}), 7.00(\mathrm{~m}, 1 \mathrm{H}), 6.32-6.30(\mathrm{~m}, 2 \mathrm{H}), 6.19(\mathrm{~s}, 1 \mathrm{H})$, $5.24(\mathrm{~s}, 2 \mathrm{H}), 3.73(\mathrm{~s}, 3 \mathrm{H}), 3.64(\mathrm{~s}, 3 \mathrm{H}), 1.36(\mathrm{~s}, 18 \mathrm{H})$; LRMS $\mathrm{m} / \mathrm{z}$ calcd for $\mathrm{C}_{40} \mathrm{H}_{39} \mathrm{ClF}_{2} \mathrm{~N}_{5} \mathrm{O}_{10} \mathrm{~S}_{2}(\mathrm{M}+\mathrm{H})^{+} 886.2$, found 885.6. Step 2. To a solution of the product from step 1 (1.70 g, $1.92 \mathrm{mmol})$ in $\mathrm{CH}_{2} \mathrm{Cl}_{2}(25 \mathrm{~mL})$ was added TFA $(10 \mathrm{~mL})$. The reaction mixture was stirred at ambient temperature for $4 \mathrm{~h}$ and concentrated in vacuo. The residue was taken up in $\mathrm{MeOH}(15 \mathrm{~mL})$ and filtered. After concentration of the filtrate in vacuo, the residue was triturated with $\mathrm{CH}_{2} \mathrm{Cl}_{2} / \mathrm{Et}_{2} \mathrm{O}(2: 1,15 \mathrm{~mL})$ to afford 3 as a colorless solid in $63 \%$ yield $(0.65 \mathrm{~g})$. ${ }^{1} \mathrm{H}$ NMR $\left(300 \mathrm{MHz}\right.$, DMSO- $\left.d_{6}\right) \delta 8.53(\mathrm{~s}, 1 \mathrm{H}), 7.99$ (s, 1H), 7.72 (dd, $J=9.7,6.6 \mathrm{~Hz}, 1 \mathrm{H}), 7.67-7.59(\mathrm{~m}, 2 \mathrm{H}), 7.54-7.43(\mathrm{~m}, 2 \mathrm{H}), 7.29$ (d, J $=8.6 \mathrm{~Hz}, 1 \mathrm{H}$ ), $7.14(\mathrm{dd}, J=10.3,6.5 \mathrm{~Hz}, 1 \mathrm{H}$ ), $6.48(\mathrm{~s}, 2 \mathrm{H})$, (sulfonamide $\mathrm{NH}$ not observed); ${ }^{19} \mathrm{~F}$ NMR (282 MHz, DMSO-d6) $\delta$-110.3 (d, $\left.J=15.8 \mathrm{~Hz}, 1 \mathrm{~F}\right),-135.3$ (d, $J=$ $15.8 \mathrm{~Hz}, 1 \mathrm{~F})$; HRMS $\mathrm{m} / \mathrm{z}$ calcd for $\mathrm{C}_{21} \mathrm{H}_{13} \mathrm{ClF}_{2} \mathrm{~N}_{5} \mathrm{O}_{4} \mathrm{~S}_{2}(\mathrm{M}+\mathrm{H})^{+} 536.0060$, found 536.0061 .

Sodium ((4-(2-(3-aminobenzo[d]isoxazol-5-yl)-4-chlorophenoxy)-2,5-difluorophenyl)sulfonyl) (1,2,4-thiadiazol-5-yl)amide (3a). To a suspension of $3(2.19 \mathrm{~g}, 4.1 \mathrm{mmol})$ in a $1: 1$ mixture of $\mathrm{MeOH}$ and water $(50 \mathrm{~mL})$ was added a solution of $\mathrm{NaOH}(0.17 \mathrm{~g}, 4.2$ $\mathrm{mmol})$ in water $(4.3 \mathrm{~mL})$. The reaction mixture was stirred at ambient temperature for $16 \mathrm{~h}$ and slowly turned into a clear solution The solution was filtered, concentrated in vacuo to a volume of approximately $5 \mathrm{~mL}$, and then lyophilized to give $3 \mathrm{a}$ as an offwhite solid in $96 \%$ yield $(2.19 \mathrm{~g})$. ${ }^{1} \mathrm{H}$ NMR $\left(300 \mathrm{MHz}\right.$, DMSO- $\left.d_{6}\right) \delta 8.00(\mathrm{~d}, J=1.0 \mathrm{~Hz}$, $1 \mathrm{H}), 7.90(\mathrm{~s}, 1 \mathrm{H}), 7.66(\mathrm{dd}, J=8.7,1.5 \mathrm{~Hz}, 1 \mathrm{H}), 7.61-7.54(\mathrm{~m}, 2 \mathrm{H}), 7.47(\mathrm{~d}, J=8.9 \mathrm{~Hz}$, $1 \mathrm{H}), 7.45$ (dd, $J=8.8,2.4 \mathrm{~Hz}, 1 \mathrm{H}), 7.16(\mathrm{~d}, J=8.7 \mathrm{~Hz}, 1 \mathrm{H}), 7.08(\mathrm{dd}, J=9.9,6.5 \mathrm{~Hz}$, $1 \mathrm{H}), 6.47(\mathrm{~s}, 2 \mathrm{H}) ;{ }^{13} \mathrm{C}$ NMR $\left(75 \mathrm{MHz}\right.$, DMSO- $\left.d_{6}\right) \delta 185.4,161.4,158.9,158.5,154.3(\mathrm{dd}$, $J=251.2,2.2 \mathrm{~Hz}$ ), 150.9, 147.5 (dd, $J=246.0,3.2 \mathrm{~Hz}), 145.9$ (dd, $J=12.8,10.2 \mathrm{~Hz}$ ), 133.5, 130.8 (2C), 129.3, 129.1, 129.0, 127.9 (dd, $J=18.9,4.5 \mathrm{~Hz}$ ), 122.3, 120.6, 117.2, 116.6 (dd, $J=22.2,3.0 \mathrm{~Hz}), 109.3,109.1$ (d, $J=28.0 \mathrm{~Hz}) ;{ }^{19} \mathrm{~F} \mathrm{NMR}(282 \mathrm{MHz}$, DMSO- $\left.d_{6}\right) \delta-110.5(\mathrm{~d}, J=16.4 \mathrm{~Hz}, 1 \mathrm{~F}),-136.4(\mathrm{~d} J=16.4 \mathrm{~Hz}, 1 \mathrm{~F})$; LRMS $\mathrm{m} / \mathrm{z}$ calcd for $\mathrm{C}_{21} \mathrm{H}_{13} \mathrm{ClF}_{2} \mathrm{~N}_{5} \mathrm{O}_{4} \mathrm{~S}_{2}(\mathrm{M}+\mathrm{H})^{+}$536.0, found 535. $9(\mathrm{M}+\mathrm{H})^{+}$. 


\subsection{Synthesis of Compound 9.}

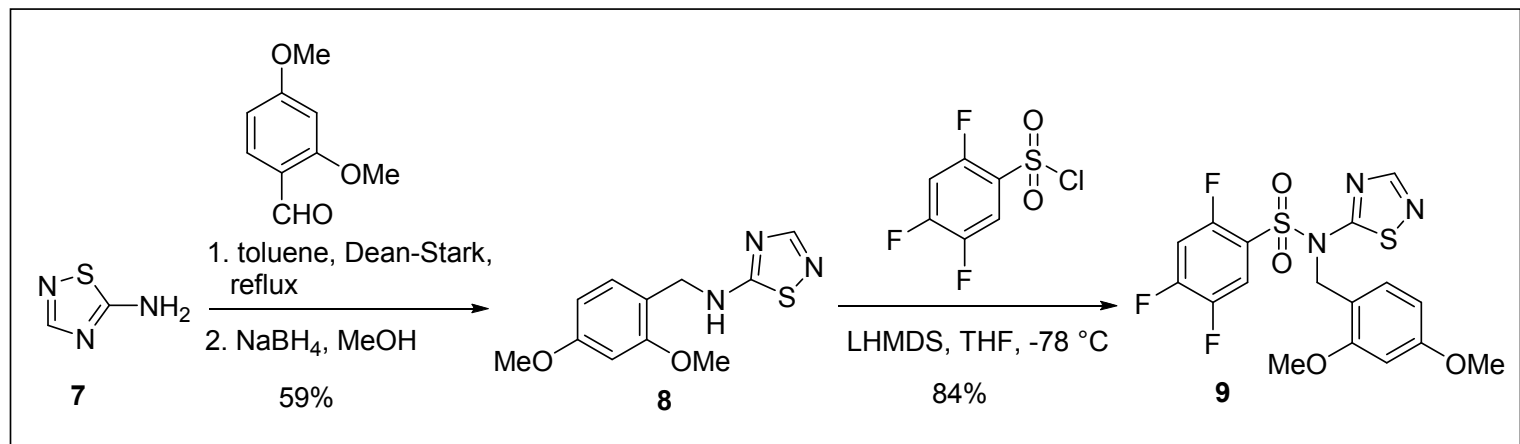

N-(2,4-Dimethoxybenzyl)-1,2,4-thiadiazol-5-amine (8). Step 1. To a solution of 1,2,4thiadiazol-5-amine $(7)(27.8 \mathrm{~g}, 274.6 \mathrm{mmol})$ in toluene $(830 \mathrm{~mL})$ was added 2,4dimethoxybenzaldehyde $(50.5 \mathrm{~g}, 303.8 \mathrm{mmol})$ and the reaction mixture was heated for $16 \mathrm{~h}$ under reflux and azeotropic removal of water using a Dean-Stark apparatus. After cooling to ambient temperature, the reaction mixture was concentrated in vacuo. The residue was triturated in boiling hexanes to provide $(E)-N$-(2,4-dimethoxybenzylidene)1,2,4-thiadiazol-5-amine as a yellow solid in $57 \%$ yield $(42.9 \mathrm{~g}) .{ }^{1} \mathrm{H}$ NMR $(300 \mathrm{MHz}$, $\left.\mathrm{CDCl}_{3}\right) \delta 9.32(\mathrm{~s}, 1 \mathrm{H}), 8.46(\mathrm{~s}, 1 \mathrm{H}), 8.20(\mathrm{~d}, J=8.8 \mathrm{~Hz}, 1 \mathrm{H}), 6.61(\mathrm{dd}, J=8.8,2.1 \mathrm{~Hz}$, $1 \mathrm{H}), 6.45(\mathrm{~d}, J=2.2 \mathrm{~Hz}, 1 \mathrm{H}), 3.91-3.90(\mathrm{~m}, 6 \mathrm{H})$. Step 2. To a mixture of the intermediate from step $1(42.9 \mathrm{~g}, 172.1 \mathrm{mmol})$ in $\mathrm{MeOH}(430 \mathrm{~mL})$ was slowly added $\mathrm{NaBH}_{4}(9.8 \mathrm{~g}, 258 \mathrm{mmol})$ at $0{ }^{\circ} \mathrm{C}$. The mixture was allowe $\mathrm{d}$ to warm to ambient temperature and stirred for $16 \mathrm{~h}$. After concentration of all volatiles, water $(200 \mathrm{~mL})$ was added to the residue, and the mixture was extracted with EtOAc $(3 \times 200 \mathrm{~mL})$. The combined organic phase was washed with water $(1 \times 200 \mathrm{~mL})$, brine $(1 \times 200 \mathrm{~mL})$, and dried over anhydrous $\mathrm{MgSO}_{4}$. Concentration in vacuo and trituration of the residue with a small volume of diethyl ether afforded 8 as an off-white solid in $53 \%$ yield $(23.0 \mathrm{~g}) .{ }^{1} \mathrm{H}$ NMR $\left(300 \mathrm{MHz}, \mathrm{CDCl}_{3}\right) \delta 7.82(\mathrm{~s}, 1 \mathrm{H}), 7.19(\mathrm{~d}, J=8.1 \mathrm{~Hz}, 1 \mathrm{H}), 6.81$ (br s, 1H), 6.47$6.42(\mathrm{~m}, 2 \mathrm{H}), 4.35(\mathrm{~d}, J=5.8 \mathrm{~Hz}, 2 \mathrm{H}), 3.82-3.80(\mathrm{~m}, 6 \mathrm{H})$.

$\mathrm{N}$-(2,4-Dimethoxybenzyl)-2,4,5-trifluoro-N-(1,2,4-thiadiazol-5-yl)benzenesulfonamide (9). To a mixture of $8(5.04 \mathrm{~g}, 20.1 \mathrm{mmol})$ in THF $(67 \mathrm{~mL})$ was added LHMDS (20 mL of a $1 \mathrm{M}$ solution in THF, $20 \mathrm{mmol}$ ) at $-78 \stackrel{\circ}{\circ} \mathrm{C}$. The reaction mixture was stirred at $-78 \stackrel{\circ}{\circ} \mathrm{C}$ for $30 \mathrm{~min}$, warmed to ambient temperature and stirred for additional $5 \mathrm{~min}$. The mixture was cooled to $-78 \stackrel{\circ}{\circ}$, and 2,4,5-trifluorobenzene-1-sulfonyl chloride $(2.7 \mathrm{~mL}$, $19.4 \mathrm{mmol}$ ) was slowly added to it. The reaction mixture was allowed to warm to ambient temperature, stirred for $3 \mathrm{~h}$, and quenched by addition of saturated $\mathrm{NH}_{4} \mathrm{Cl}$ solution $(100 \mathrm{~mL})$. The mixture was extracted with EtOAc $(3 \times 200 \mathrm{~mL})$. The combined organic phase was washed with brine $(100 \mathrm{~mL})$, dried over anhydrous $\mathrm{Na}_{2} \mathrm{SO}_{4}$, and concentrated in vacuo. Trituration with methanol provided the title compound as an offwhite solid in $75 \%$ yield $(6.48 \mathrm{~g}) .{ }^{1} \mathrm{H}$ NMR $\left(300 \mathrm{MHz} \mathrm{CDCl}_{3}\right) \delta 8.21(\mathrm{~s}, 1 \mathrm{H}), 7.64-7.57$ 
(m, 1H), $7.19(\mathrm{~d}, J=8.4 \mathrm{~Hz}, 1 \mathrm{H}), 6.97-6.89(\mathrm{~m}, 1 \mathrm{H}), 6.36(\mathrm{dd}, J=8.4,2.4 \mathrm{~Hz}, 1 \mathrm{H}), 6.22$ (d, $J=2.3 \mathrm{~Hz}, 1 \mathrm{H}), 5.34(\mathrm{~s}, 2 \mathrm{H}), 3.75(\mathrm{~s}, 3 \mathrm{H}), 3.69(\mathrm{~s}, 3 \mathrm{H}) ;{ }^{19} \mathrm{~F} \mathrm{NMR}\left(282 \mathrm{MHz}, \mathrm{CDCl}_{3}\right) \delta$ -107.5 (dd, $J=15.2,10.5 \mathrm{~Hz}, 1 \mathrm{~F}),-122.4$ (dd, $J=22.5,10.5 \mathrm{~Hz}, 1 \mathrm{~F}),-139.7$ (dd, $J=$ 22.5, $15.1 \mathrm{~Hz}, 1 \mathrm{~F})$.

\subsection{Synthesis of Compound 10.}

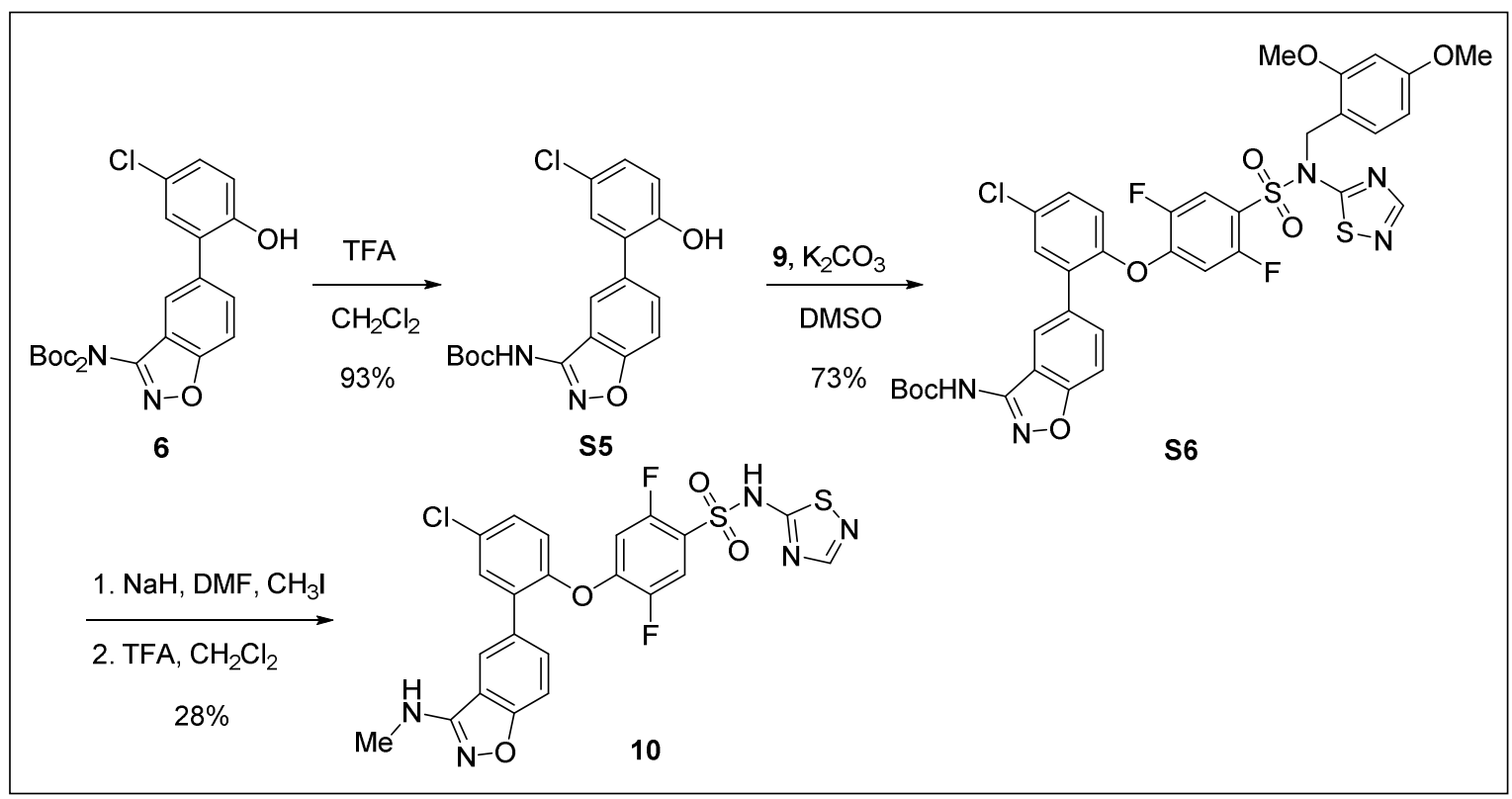

tert-Butyl (5-(5-chloro-2-hydroxyphenyl)benzo[d]isoxazol-3-yl)carbamate (S5). To a cold $(0 \stackrel{\circ}{\circ})$ mixture of $6(1.29 \mathrm{~g}, 2.8 \mathrm{mmol})$ in $\mathrm{CH}_{2} \mathrm{Cl}_{2}(10 \mathrm{~mL})$ was added TFA $(0.56 \mathrm{~mL}$, $5.6 \mathrm{mmol}$ ), and the reaction mixture was allowed to warm to ambient temperature and stirred to $2 \mathrm{~h}$. Saturated $\mathrm{NaHCO}_{3}$ solution $(20 \mathrm{~mL})$ was added and the mixture was diluted with $\mathrm{CH}_{2} \mathrm{Cl}_{2}(100 \mathrm{~mL})$. The organic phase was washed with brine $(10 \mathrm{~mL})$ and dried over anhydrous $\mathrm{Na}_{2} \mathrm{SO}_{4}$. Concentration in vacuo provided a residue which was purified by column chromatography, (0-50\% EtOAc in hexanes) to afford S5 as a colorless solid in $93 \%$ yield $(0.94 \mathrm{~g})$. ${ }^{1} \mathrm{H}$ NMR $\left(300 \mathrm{MHz}\right.$, DMSO- $\left.d_{6}\right) \delta 10.49(\mathrm{~s}, 1 \mathrm{H})$, $9.98(\mathrm{~s}, 1 \mathrm{H}), 8.19(\mathrm{~d}, J=1.4 \mathrm{~Hz}, 1 \mathrm{H}), 7.82(\mathrm{dd}, J=8.8,1.6 \mathrm{~Hz}, 1 \mathrm{H}), 7.66(\mathrm{~d}, J=8.8 \mathrm{~Hz}$, $1 \mathrm{H}), 7.32(\mathrm{~d}, J=2.6 \mathrm{~Hz}, 1 \mathrm{H}), 7.24(\mathrm{dd}, J=8.6,2.6 \mathrm{~Hz}, 1 \mathrm{H}), 6.99(\mathrm{~d}, J=8.6 \mathrm{~Hz}, 1 \mathrm{H})$, $1.50(\mathrm{~s}, 9 \mathrm{H})$.

tert-Butyl (5-(5-chloro-2-(4-(N-(2,4-dimethoxybenzyl)-N-(1,2,4-thiadiazol-5-yl)sulfamoyl)-2,5-difluorophenoxy)phenyl)benzo[d]isoxazol-3-yl)carbamate (S6). Following the procedure as described for $\mathbf{S 3}$, making non-critical variations to replace $\mathbf{S 2}$ with $\mathbf{S 5}$, S6 was obtained as a colorless solid in $73 \%$ yield $(1.49 \mathrm{~g}) .{ }^{1} \mathrm{H}$ NMR $\left(300 \mathrm{MHz}, \mathrm{CDCl}_{3}\right) \delta$ $8.28(\mathrm{~s}, 1 \mathrm{H}), 8.19-8.13(\mathrm{~m}, 1 \mathrm{H}), 7.64-7.60(\mathrm{~m}, 1 \mathrm{H}), 7.47-7.41(\mathrm{~m}, 5 \mathrm{H}), 7.14(\mathrm{~d}, J=8.2$ $\mathrm{Hz}, 1 \mathrm{H}), 6.97$ (dd, $J=8.6,1.3 \mathrm{~Hz}, 1 \mathrm{H}), 6.38$ (ddd, $J=10.1,6.2,1.2 \mathrm{~Hz}, 1 \mathrm{H}), 6.31(\mathrm{~d}, J=$ $8.4 \mathrm{~Hz}, 1 \mathrm{H}), 6.10(\mathrm{~s}, 1 \mathrm{H}), 5.25(\mathrm{~s}, 2 \mathrm{H}), 3.73(\mathrm{~s}, 3 \mathrm{H}), 3.59(\mathrm{~s}, 3 \mathrm{H}), 1.51(\mathrm{~s}, 9 \mathrm{H}) ;{ }^{19} \mathrm{~F} \mathrm{NMR}$ 
(282 MHz, $\left.\mathrm{CDCl}_{3}\right) \delta-107.4(\mathrm{~d}, J=15.0 \mathrm{~Hz}, 1 \mathrm{~F}),-134.98(\mathrm{~d}, J=15.1 \mathrm{~Hz}, 1 \mathrm{~F})$; LRMS $\mathrm{m} / \mathrm{z}$ calcd for $\mathrm{C}_{35} \mathrm{H}_{31} \mathrm{ClF}_{2} \mathrm{~N}_{5} \mathrm{O}_{8} \mathrm{~S}_{2}(\mathrm{M}+\mathrm{H})^{+}$786.1, found $785.6(\mathrm{M}+\mathrm{H})^{+}$.

4-(4-Chloro-2-(3-(methylamino)benzo[d]isoxazol-5-yl)phenoxy)-2,5-difluoro-N-(1,2,4thiadiazol-5-yl)benzenesulfonamide (10). Step 1. To a solution of S6 (1.09 g, 1.39 $\mathrm{mmol})$ in DMF $(3 \mathrm{~mL})$ was added $\mathrm{NaH}(0.061 \mathrm{~g}$ of a $60 \%$ dispersion in mineral oil, 1.53 $\mathrm{mmol}$ ) and the reaction mixture was stirred for 10 minutes at ambient temperature. Mel $(87 \mu \mathrm{L}, 1.39 \mathrm{mmol})$ was added and the reaction mixture for stirred for 30 minutes at ambient temperature. The reaction mixture was diluted with EtOAc $(100 \mathrm{~mL})$ and saturated aqueous $\mathrm{NH}_{4} \mathrm{Cl}$ solution $(10 \mathrm{~mL}$ ) was added. The organic phase was washed with water $(2 \times 5 \mathrm{~mL})$ and brine $(10 \mathrm{~mL})$ dried over anhydrous $\mathrm{Na}_{2} \mathrm{SO}_{4}$, and concentrated in vacuo. The residue was purified by column chromatography $(0-50 \%$ EtOAc in hexanes) to afford tert-butyl (5-(5-chloro-2-(4-( $N$-(2,4-dimethoxybenzyl)- $N$ (1,2,4-thiadiazol-5-yl)sulfamoyl)-2,5-difluorophenoxy)-phenyl)-benzo[d]isoxazol-3-

$\mathrm{yl}$ )(methyl)carbamate as a colorless foam in $37 \%$ yield $(0.41 \mathrm{~g})$. Step 2 . The foam was dissolved in $\mathrm{CH}_{2} \mathrm{Cl}_{2}(10 \mathrm{~mL})$ and TFA $(5 \mathrm{~mL})$ was added to it. The reaction mixture was stirred for $4 \mathrm{~h}$ at ambient temperature and then concentrated in vacuo. The residue was suspended in methanol $(20 \mathrm{~mL})$, the suspension filtered, and the filtrate concentrated in vacuo. Purification purified by column chromatography (20-100\% EtOAc in hexanes) provided 10 as a white solid in $75 \%$ yield $(0.21 \mathrm{~g}) .{ }^{1} \mathrm{H} \mathrm{NMR}\left(300 \mathrm{MHz}\right.$, DMSO- $\left.d_{6}\right) \delta 8.52$ $(\mathrm{s}, 1 \mathrm{H}), 7.95(\mathrm{~d}, J=1.1 \mathrm{~Hz}, 1 \mathrm{H}), 7.72(\mathrm{dd}, J=9.9,6.5 \mathrm{~Hz}, 1 \mathrm{H}), 7.65(\mathrm{dd}, J=8.7,1.6 \mathrm{~Hz}$, $1 \mathrm{H}), 7.61(\mathrm{~d}, J=2.6 \mathrm{~Hz}, 1 \mathrm{H}), 7.52-7.46(\mathrm{~m}, 2 \mathrm{H}), 7.28(\mathrm{~d}, J=8.7 \mathrm{~Hz}, 1 \mathrm{H}), 7.14(\mathrm{dd}, J=$ $10.4,6.5 \mathrm{~Hz}, 1 \mathrm{H}), 7.04-6.97(\mathrm{~m}, 1 \mathrm{H}), 2.86(\mathrm{~s}, 3 \mathrm{H})$, (sulfonamide $\mathrm{NH}$ not observed); ${ }^{13} \mathrm{C}$ NMR (300 MHz, DMSO- $\left.d_{6}\right) \delta 178.7,161.5,159.0,154.7$ (dd, $\left.J=252.8,1.7 \mathrm{~Hz}\right), 150.2$, 148.2 (dd, $J=12.4,10.6 \mathrm{~Hz}$ ), 147.7, 147.6 (dd, $J=246.8,2.2 \mathrm{~Hz}$ ), 133.9, 131.0, 130.8, 129.7, 129.2, 129.1, 123.9 (dd, $J=17.7,5.2 \mathrm{~Hz}$ ), 121.9, 121.6, 116.7, 116.5 (dd, $J=$ 23.1, $1.6 \mathrm{~Hz}$ ), 109.4, $108.7(\mathrm{~d}, J=27.4 \mathrm{~Hz}), 29.2 ;{ }^{19} \mathrm{~F} \mathrm{NMR}\left(282 \mathrm{MHz}\right.$, DMSO- $\left.d_{6}\right) \delta-$ $110.3(\mathrm{~d}, J=15.8 \mathrm{~Hz}, 1 \mathrm{~F}),-135.3(\mathrm{~d}, J=15.8 \mathrm{~Hz}, 1 \mathrm{~F})$; LRMS $\mathrm{m} / \mathrm{z}$ calcd for $\mathrm{C}_{22} \mathrm{H}_{15} \mathrm{ClF}_{2} \mathrm{~N}_{5} \mathrm{O}_{4} \mathrm{~S}_{2}(\mathrm{M}+\mathrm{H})^{+}$550.0, found 549.6. 


\subsection{Synthesis of Compound 11.}

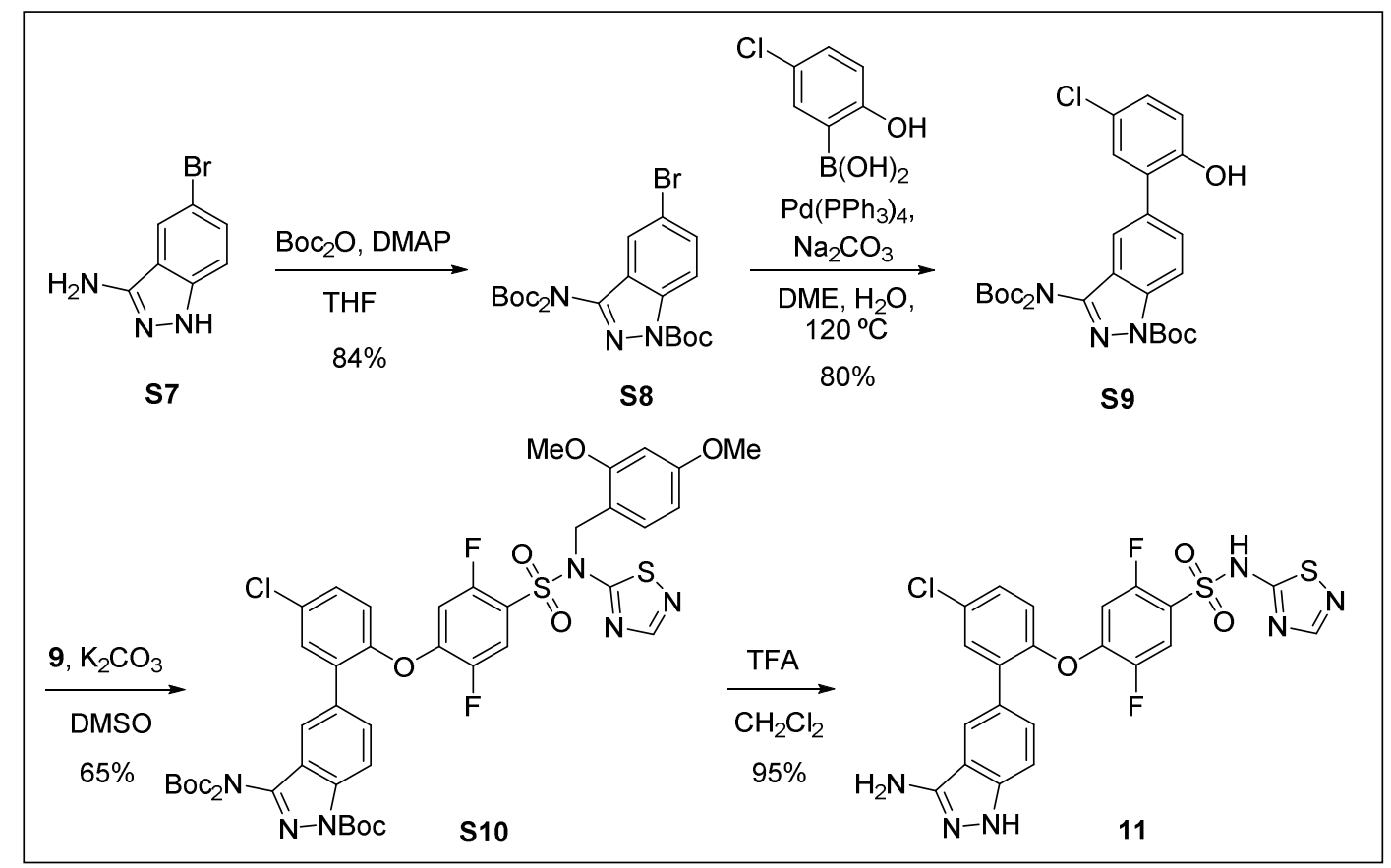

tert-Butyl 3-[bis(tert-butoxycarbonyl)amino]-5-bromo-1H-indazole-1-carboxylate (S8). To a mixture of 5-bromo-1 $\mathrm{H}$-indazol-3-amine (S7) $(1.5 \mathrm{~g}, 7.1 \mathrm{mmol})$ in THF was added di-tert-butyl dicarbonate $(4.8 \mathrm{~g}, 22.1 \mathrm{mmol})$ and 4-(N,N-dimethylamino)pyridine $(0.17 \mathrm{~g}, 1.4 \mathrm{mmol})$ and the reaction mixture was stirred for $16 \mathrm{~h}$ at ambient temperature. After concentration in vacuo, the residue was purified by column chromatography (0$20 \%$ EtOAc in hexanes) to afford S8 as a white solid in $84 \%$ yield $(3.06 \mathrm{~g})$. ${ }^{1} \mathrm{H}$ NMR $\left(300 \mathrm{MHz}, \mathrm{CDCl}_{3}\right) \delta 8.06(\mathrm{~d}, J=8.8 \mathrm{~Hz}, 1 \mathrm{H}), 7.72-7.68(\mathrm{~m}, 1 \mathrm{H}), 7.67-7.60(\mathrm{~m}, 1 \mathrm{H})$, $1.72(\mathrm{~s}, 9 \mathrm{H}), 1.44(\mathrm{~s}, 18 \mathrm{H})$; LRMS $\mathrm{m} / \mathrm{z}$ calcd for $\mathrm{C}_{22} \mathrm{H}_{31} \mathrm{BrN}_{3} \mathrm{O}_{6}(\mathrm{M}+\mathrm{H})^{+} 512.1$, found $511.9(\mathrm{M}+\mathrm{H})^{+}$.

tert-Butyl 3-[bis(tert-butoxycarbonyl)amino]-5-(5-chloro-2-hydroxyphenyl)-1Hindazole-1-carboxylate (S9). Following the procedure as described for $\mathbf{S 2}$ and making non-critical variations to replace 6-chloropyridin-2-amine (S1) with S8, S9 was obtained as a yellowish solid in $80 \%$ yield $(2.57 \mathrm{~g}) .{ }^{1} \mathrm{H}$ NMR $\left(300 \mathrm{MHz}, \mathrm{CDCl}_{3}\right) \delta 8.21(\mathrm{~d}, J=7.8$ $\mathrm{Hz}, 1 \mathrm{H}), 7.62-7.59(\mathrm{~m}, 2 \mathrm{H}), 7.46(\mathrm{~s}, 1 \mathrm{H}), 6.90-6.86(\mathrm{~m}, 2 \mathrm{H}), 5.33(\mathrm{br} \mathrm{s}, 1 \mathrm{H}), 1.72(\mathrm{~s}, 9 \mathrm{H})$, $1.42(\mathrm{~s}, 18 \mathrm{H})$; LRMS $\mathrm{m} / z$ calcd for $\mathrm{C}_{28} \mathrm{H}_{35} \mathrm{ClN}_{3} \mathrm{O}_{7}(\mathrm{M}+\mathrm{H})^{+} 560.2$, found $560.0(\mathrm{M}+\mathrm{H})^{+}$.

tert-Butyl 3-[bis(tert-butoxycarbonyl)amino]-5-(5-chloro-2-\{4-[(2,4-dimethoxybenzyl)(1,2,4-thiadiazol-5-yl)sulfamoyl]-2,5-difluorophenoxy\}phenyl)-1H-indazole-1-carboxylate (S10). To a mixture of $9(0.93 \mathrm{~g}, 2.1 \mathrm{mmol})$ and potassium carbonate $(0.35 \mathrm{~g}, 2.51$ $\mathrm{mmol})$ in DMSO $(10 \mathrm{~mL})$ was added $\mathbf{S 9}(1.1 \mathrm{~g}, 2.1 \mathrm{mmol})$ and the mixture was stirred at ambient temperature for $5 \mathrm{~h}$. After dilution with EtOAc $(150 \mathrm{~mL})$, the organic phase was washed with water $(2 \times 20 \mathrm{~mL})$, brine $(15 \mathrm{~mL})$, and dried over $\mathrm{Na}_{2} \mathrm{SO}_{4}$. Concentration in 
vacuo provided a residue which was purified by column chromatography (0-50\% EtOAc in hexanes) to afford $\mathbf{S 1 0}$ as a colorless solid in $65 \%$ yield $(1.3 \mathrm{~g}) .{ }^{1} \mathrm{H}$ NMR $(300 \mathrm{MHz}$, DMSO- $\left.d_{6}\right) \delta 8.15-8.11(\mathrm{~m}, 2 \mathrm{H}), 7.63-7.55(\mathrm{~m}, 2 \mathrm{H}), 7.49-7.38(\mathrm{~m}, 3 \mathrm{H}), 7.14-7.10(\mathrm{~m}$, $1 \mathrm{H}), 7.02-6.99(\mathrm{~m}, 1 \mathrm{H}), 6.32-6.19(\mathrm{~m}, 3 \mathrm{H}), 5.23-5.22(\mathrm{~m}, 2 \mathrm{H}), 3.74(\mathrm{~s}, 3 \mathrm{H}), 3.64(\mathrm{~s}$, $3 \mathrm{H}), 1.54(\mathrm{~s}, 9 \mathrm{H}), 1.38(\mathrm{~s}, 18 \mathrm{H})$; LRMS $\mathrm{m} / z$ calcd for $\mathrm{C}_{45} \mathrm{H}_{48} \mathrm{ClF}_{2} \mathrm{~N}_{6} \mathrm{O}_{11} \mathrm{~S}_{2}(\mathrm{M}+\mathrm{H})^{+}$985.2, found 985.1 .

4-(2-(3-Amino-1H-indazol-5-yl)-4-chlorophenoxy)-2,5-difluoro-N-(1,2,4-thiadiazol-5yl)benzenesulfonamide (11). To a mixture of $\mathbf{S} 10$ (1.3 g, $1.32 \mathrm{mmol})$ in $\mathrm{CH}_{2} \mathrm{Cl}_{2}(20 \mathrm{~mL})$ was added TFA $(10 \mathrm{~mL})$ and the reaction mixture was stirred for 3 at ambient temperature. After concentration in vacuo, the residue was triturated in methanol (20 $\mathrm{mL}$ ) and filtered. The filtrate was concentrated in vacuo and the residue was triturated in $\mathrm{MeOH}(20 \mathrm{~mL})$. The solid was filtered off to provide the 2,2,2-trifluoroacetic acid salt of 11 as an off-white solid in $95 \%$ yield $(0.82 \mathrm{~g})$. ${ }^{1} \mathrm{H}$ NMR $\left(300 \mathrm{MHz}\right.$, DMSO-d $d_{6} \delta$ 10.61-8.62 (br s, $5 \mathrm{H}), 8.52(\mathrm{~s}, 1 \mathrm{H}), 8.00(\mathrm{~d}, J=0.8 \mathrm{~Hz}, 1 \mathrm{H}), 7.72(\mathrm{dd}, J=9.9,6.4 \mathrm{~Hz}$, $1 \mathrm{H}), 7.59(\mathrm{~d}, J=2.6 \mathrm{~Hz}, 1 \mathrm{H}), 7.55(\mathrm{dd}, J=8.8,1.6 \mathrm{~Hz}, 1 \mathrm{H}), 7.48(\mathrm{dd}, J=8.7,2.6 \mathrm{~Hz}$, $1 \mathrm{H}), 7.36(\mathrm{~d}, J=8.7 \mathrm{~Hz}, 1 \mathrm{H}), 7.28(\mathrm{~d}, J=8.7 \mathrm{~Hz}, 1 \mathrm{H}), 7.09(\mathrm{dd}, J=10.4,6.5 \mathrm{~Hz}, 1 \mathrm{H})$; ${ }^{13} \mathrm{C}$ NMR $\left(75 \mathrm{MHz}\right.$, DMSO- $\left.d_{6}\right) \delta 178.8,154.8(\mathrm{dd}, J=252.6,2.1 \mathrm{~Hz}), 158.6(\mathrm{q}, J=35.3$ $\mathrm{Hz}, \mathrm{CF}_{3} \mathrm{COOH}$ ), 150.1, 147.8, 147.6 (dd, $J=247.4,2.8 \mathrm{~Hz}$ ), 148.4 (dd, $J=12.4,10.6$ $\mathrm{Hz}), 146.9,141.1,134.7,130.8,130.0,129.8,128.9,126.5,123.7$ (dd, $J=17.7,5.2 \mathrm{~Hz}$ ), 121.9, 121.7, $116.5(\mathrm{~d}, J=23.3 \mathrm{~Hz}), 116.1\left(\mathrm{br} q, J=291.5 \mathrm{~Hz}, \mathrm{CF}_{3} \mathrm{COOH}\right), 113.0$, 110.4, $108.4(\mathrm{~d}, J=27.5 \mathrm{~Hz}) ;{ }^{19} \mathrm{~F}$ NMR $\left(282 \mathrm{MHz}\right.$, DMSO- $\left.d_{6}\right) \delta-74.5(\mathrm{~s}, 3 \mathrm{~F}),-110.4(\mathrm{~d}$, $J=15.8 \mathrm{~Hz}, 1 \mathrm{~F}),-135.6(\mathrm{~d}, J=15.8 \mathrm{~Hz}, 1 \mathrm{~F})$; LRMS $\mathrm{m} / \mathrm{z}$ calcd for $\mathrm{C}_{21} \mathrm{H}_{14} \mathrm{ClF}_{2} \mathrm{~N}_{6} \mathrm{O}_{3} \mathrm{~S}_{2}$ $(\mathrm{M}+\mathrm{H})^{+} 535.0$, found 534.6 .

\subsection{Synthesis of Compound 12.}

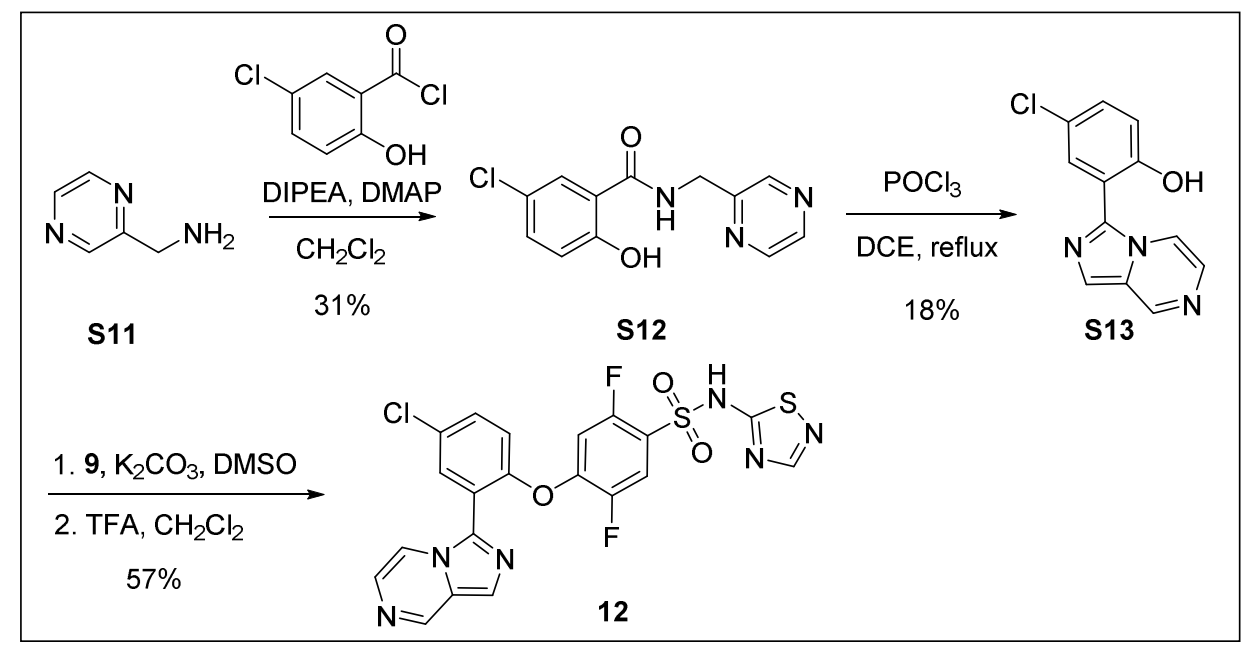

5-Chloro-2-hydroxy-N-(pyrazin-2-ylmethyl)benzamide (S12). To a suspension of 5chlorosalicylic acid $(0.96 \mathrm{~g}, 5.6 \mathrm{mmol})$ in $\mathrm{CH}_{2} \mathrm{Cl}_{2}(13 \mathrm{~mL})$ was added thionyl chloride (2 
$\mathrm{mL}, 28 \mathrm{mmol}$ ) and DMF ( 3 drops). The reaction mixture was heated at reflux for $1 \mathrm{~h}$, at which point a clear solution was obtained. The mixture was allowed to cool to ambient temperature and was concentrated in vacuo. The residue was dissolved in $\mathrm{CH}_{2} \mathrm{Cl}_{2}(10 \mathrm{~mL})$, and pyrazin-2-ylmethanamine (S11) $(0.80 \mathrm{~g}, 4.6 \mathrm{mmol}), \mathrm{N}, \mathrm{N}-$ diisopropylethylamine $(1.6 \mathrm{~mL}, 9.3 \mathrm{mmol})$, and 4-(N,N-dimethylamino)pyridine $(0.056 \mathrm{~m}$, $0.5 \mathrm{mmol}$ ) were added. The reaction mixture was stirred at ambient temperature for 16 h, diluted with $\mathrm{CH}_{2} \mathrm{Cl}_{2}(70 \mathrm{~mL})$ and washed with $1 \mathrm{~N}$ hydrochloric acid $(2 \times 7 \mathrm{~mL})$, water $(2 \times 7 \mathrm{~mL})$ and brine $(10 \mathrm{~mL})$. The organic phase was dried over anhydrous $\mathrm{Na}_{2} \mathrm{SO}_{4}$ and concentrated in vacuo. The residue was purified by column chromatography (10$60 \%$ EtOAc in hexanes) to afford $\mathbf{S 1 2}$ as a yellow solid in $31 \%$ yield $(0.379 \mathrm{~g}) .{ }^{1} \mathrm{H}$ NMR $\left(300 \mathrm{MHz}, \mathrm{CDCl}_{3}\right) \delta 12.10(\mathrm{~s}, 1 \mathrm{H}), 8.67(\mathrm{~s}, 1 \mathrm{H}), 8.57(\mathrm{~s}, 2 \mathrm{H}), 7.57(\mathrm{br} \mathrm{s}, 1 \mathrm{H}), 7.46(\mathrm{~d}, J=$ $2.1 \mathrm{~Hz}, 1 \mathrm{H}), 7.34(\mathrm{dd}, J=8.9,1.8 \mathrm{~Hz}, 1 \mathrm{H}), 6.93(\mathrm{~d}, J=8.9 \mathrm{~Hz}, 1 \mathrm{H}), 4.78(\mathrm{~d}, J=4.8 \mathrm{~Hz}$, $2 \mathrm{H}$ ); LRMS $\mathrm{m} / \mathrm{z}$ calcd for $\mathrm{C}_{12} \mathrm{H}_{11} \mathrm{CIN}_{3} \mathrm{O}_{2}(\mathrm{M}+\mathrm{H})^{+} 264.1$, found 264.0 .

4-Chloro-2-(imidazo[1,5-a]pyrazin-3-yl)phenol (S13). A suspension of $\mathbf{S 1 2}(0.38 \mathrm{~g}$, $1.4 \mathrm{mmol})$ in a mixture of 1,2-dichloroethane $(6 \mathrm{~mL})$ and phosphoryl chloride $(6 \mathrm{~mL})$ was heated at reflux for $2 \mathrm{~h}$, allowed to cool to ambient temperature and concentrated in vacuo. The residue was suspended in water $(10 \mathrm{~mL})$, and the $\mathrm{pH}$ was adjusted to 6-7 with $1 \mathrm{~N}$ aqueous sodium hydroxide. The aqueous phase was extracted with EtOAc ( 3 $\times 30 \mathrm{~mL})$ followed by $\mathrm{CH}_{2} \mathrm{Cl}_{2}(3 \times 40 \mathrm{~mL})$. The combined organic extracts were dried over anhydrous $\mathrm{Na}_{2} \mathrm{SO}_{4}$, and concentrated in vacuo. The residue was purified by column chromatography $\left(0-10 \%\right.$ methanol in $\left.\mathrm{CH}_{2} \mathrm{Cl}_{2}\right)$ to afford $\mathbf{S 1 3}$ as a pale yellow solid in $18 \%$ yield $(0.064 \mathrm{~g}) .{ }^{1} \mathrm{H}$ NMR $\left(300 \mathrm{MHz}, \mathrm{DMSO}-d_{6}\right) \delta 9.13(\mathrm{~s}, 1 \mathrm{H}), 8.34(\mathrm{br} \mathrm{s}$, $1 \mathrm{H}), 7.99(\mathrm{~s}, 1 \mathrm{H}), 7.83(\mathrm{~d}, J=4.0 \mathrm{~Hz}, 1 \mathrm{H}), 7.57(\mathrm{~d}, J=4.6 \mathrm{~Hz}, 1 \mathrm{H}), 7.50(\mathrm{~d}, J=1.9 \mathrm{~Hz}$, $1 \mathrm{H}), 7.42(\mathrm{~d}, J=8.3 \mathrm{~Hz}, 1 \mathrm{H}), 7.10(\mathrm{~d}, J=8.4 \mathrm{~Hz}, 1 \mathrm{H})$; LRMS $\mathrm{m} / \mathrm{z}$ calcd for $\mathrm{C}_{12} \mathrm{H}_{9} \mathrm{CIN}_{3} \mathrm{O}$ $(\mathrm{M}+\mathrm{H})^{+}$246.0, found 246.1.

4-(4-Chloro-2-(imidazo[1,5-a]pyrazin-3-yl)phenoxy)-2,5-difluoro-N-(1,2,4-thiadiazol5-yl)benzenesulfonamide (12). Following the procedure as described for 3 and making non-critical variations to replace phenol 6 with S13, 12 was obtained as a yellow solid containing trace amounts of trifluoroacetic acid in $57 \%$ yield over 2 steps $(0.075 \mathrm{~g}) .{ }^{1} \mathrm{H}$ $\operatorname{NMR}\left(300 \mathrm{MHz}, \mathrm{DMSO}-\mathrm{d}_{6}\right) \delta 9.14(\mathrm{~s}, 1 \mathrm{H}), 8.52(\mathrm{~s}, 1 \mathrm{H}), 8.10(\mathrm{~d}, J=4.6 \mathrm{~Hz}, 1 \mathrm{H}), 8.02(\mathrm{~s}$, $1 \mathrm{H}), 7.80(\mathrm{~s}, 1 \mathrm{H}), 7.71-7.56(\mathrm{~m}, 3 \mathrm{H}), 7.35(\mathrm{~d}, J=8.9 \mathrm{~Hz}, 1 \mathrm{H}), 7.29$ (dd, $J=10.3,6.2$ $\mathrm{Hz}, 1 \mathrm{H})\left(\mathrm{NH}\right.$ not observed); ${ }^{13} \mathrm{C}$ NMR $\left(75 \mathrm{MHz}\right.$, DMSO- $\left.d_{6}\right) \delta 178.9,154.6$ (dd, $J=252.4$, $2.1 \mathrm{~Hz}$ ), 151.7, 147.8, 147.7 (dd, $J=247.9,3.1 \mathrm{~Hz}$ ), 147.0 (dd, $J=12.7,10.7 \mathrm{~Hz}$ ), 145.7, 134.1, 131.8 (2C), 129.3, 127.7, 126.8, 126.1, 124.7 (dd, $J=17.8,5.3 \mathrm{~Hz}$ ), $121.6,120.9,116.6(\mathrm{~d}, J=22.8 \mathrm{~Hz}), 115.8,109.5(\mathrm{~d}, J=27.5 \mathrm{~Hz}) ;{ }^{19} \mathrm{~F}$ NMR $(282 \mathrm{MHz}$, DMSO- $\left.d_{6}\right) \delta-74.6\left(\mathrm{~s}, 1 \mathrm{~F}, 0.3 \cdot \mathrm{CF}_{3} \mathrm{COOH}\right),-110.4(\mathrm{~d}, J=16.0 \mathrm{~Hz}, 1 \mathrm{~F}),-134.7(\mathrm{~d}, J=$ $16.0 \mathrm{~Hz}, 1 \mathrm{~F})$; LRMS $\mathrm{m} / \mathrm{z}$ calcd for $\mathrm{C}_{20} \mathrm{H}_{12} \mathrm{ClF}_{2} \mathrm{~N}_{6} \mathrm{O}_{3} \mathrm{~S}_{2}(\mathrm{M}+\mathrm{H})^{+} 521.0$, found 520.7 $(\mathrm{M}+\mathrm{H})^{+}$. 


\subsection{Synthesis of Compound 13.}

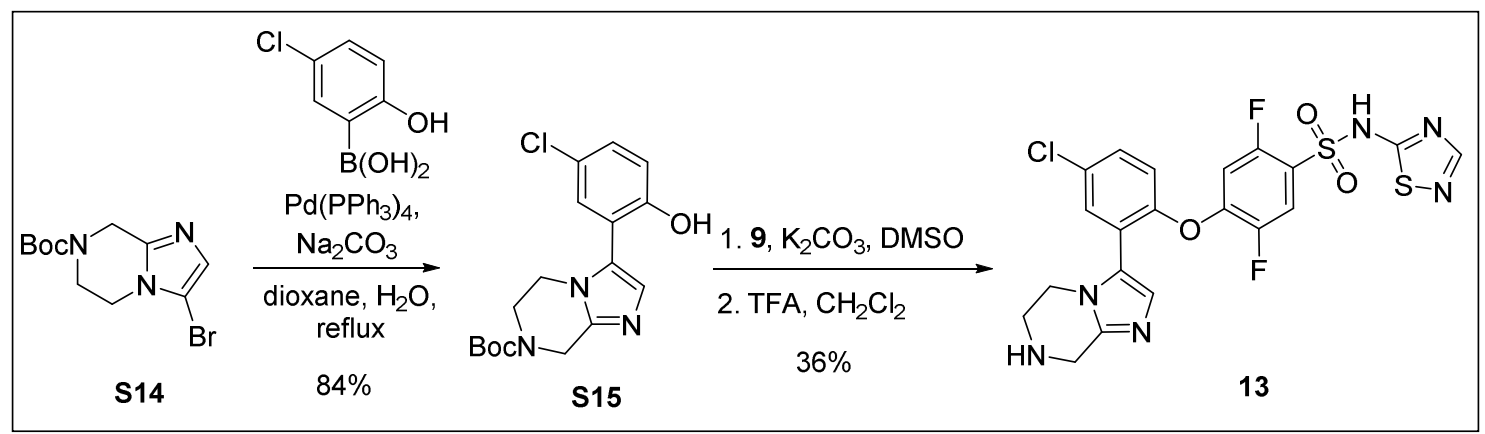

tert-Butyl 3-(5-chloro-2-hydroxyphenyl)-5,6-dihydroimidazo[1,2-a]pyrazine-7(8H)carboxylate (S15). Following the procedure as described for $\mathbf{S} 2$ and making non-critical variations to replace 6-chloropyridin-2-amine (S1) with tert-butyl 3-bromo-5,6dihydroimidazo[1,2-a]pyrazine-7(8H)-carboxylate $(\mathbf{S 1 4}), \mathbf{S 1 5}$ was obtained as a colorless solid in $84 \%$ yield $(0.126 \mathrm{~g}) .{ }^{1} \mathrm{H}$ NMR $\left(300 \mathrm{MHz}, \mathrm{CDCl}_{3}\right) \delta 10.16(\mathrm{~s}, 1 \mathrm{H}), 7.27$ (dd, $J=8.6,2.6 \mathrm{~Hz}, 1 \mathrm{H}), 7.21(\mathrm{~d}, J=2.3 \mathrm{~Hz}, 1 \mathrm{H}), 6.98-6.92(\mathrm{~m}, 2 \mathrm{H}), 4.58(\mathrm{br} \mathrm{s}, 2 \mathrm{H})$, 3.87-3.79 (m, 2H), 3.74-3.67 (m, 2H), $1.44(\mathrm{~s}, 9 \mathrm{H})$; LRMS $\mathrm{m} / \mathrm{z}$ calcd for $\mathrm{C}_{17} \mathrm{H}_{21} \mathrm{CIN}_{3} \mathrm{O}_{3}$ $(\mathrm{M}+\mathrm{H})^{+} 350.1$, found 349.5 .

4-(4-Chloro-2-(5,6,7,8-tetrahydroimidazo[1,2-a]pyrazin-3-yl)phenoxy)-2,5-difluoro-N(1,2,4-thiadiazol-5-yl)benzenesulfonamide (13). Following the procedure as described for the synthesis of $\mathbf{3}$ and making non-critical variations using $\mathbf{S 1 5}$ to replace phenol $\mathbf{6}$, the trifluoroacetic acid salt of $\mathbf{1 3}$ was obtained as a colorless solid in $36 \%$ yield over 2 steps $(0.080 \mathrm{~g}) .{ }^{1} \mathrm{H}$ NMR $\left(300 \mathrm{MHz}\right.$, DMSO- $\left.d_{6}\right) \delta 8.45(\mathrm{~s}, 1 \mathrm{H}), 7.84-7.75(\mathrm{~m}, 1 \mathrm{H}), 7.60-$ $7.52(\mathrm{~m}, 2 \mathrm{H}), 7.35-7.21(\mathrm{~m}, 3 \mathrm{H}), 4.45(\mathrm{~s}, 2 \mathrm{H}), 4.19-4.09(\mathrm{~m}, 2 \mathrm{H}), 3.82-3.50(\mathrm{~m}, 3 \mathrm{H})$ (NH and $\mathrm{CF}_{3} \mathrm{COOH}$ not observed); ${ }^{13} \mathrm{C}$ NMR $\left(75 \mathrm{MHz}\right.$, DMSO- $\left.d_{6}\right) \delta 180.2,155.2(\mathrm{~d}, \mathrm{~J}=$ $253.9 \mathrm{~Hz}$ ), 159.1 (q, $J=33.1,32.8 \mathrm{~Hz}, \mathrm{CF}_{3} \mathrm{COOH}$ ), 152.1, 149.7, 148.5 (dd, $J=247.6$, $3.0 \mathrm{~Hz}$ ), $147.2(\mathrm{dd}, J=12.6,10.6 \mathrm{~Hz}), 139.1,132.0,131.4,129.4,127.0,126.8,125.9$ (dd, $J=17.9,5.1 \mathrm{~Hz}$ ), 121.2, 120.6, $117.3(\mathrm{~d}, J=22.6 \mathrm{~Hz}), 117.0$ (br q, $J=298.5 \mathrm{~Hz}$, $\mathrm{CF}_{3} \mathrm{COOH}$ ), 110.3 (d, $J=27.2 \mathrm{~Hz}$ ), 56.0 (br), 55.9 (br), 30.1; ${ }^{19} \mathrm{~F}$ NMR (282 MHz, DMSO- $\left.d_{6}\right) \delta-74.2\left(\mathrm{~s}, 3 \mathrm{~F}, \mathrm{CF}_{3} \mathrm{COOH}\right),-110.2(\mathrm{~d}, J=16.0 \mathrm{~Hz}, 1 \mathrm{~F}),-134.4(\mathrm{~d}, J=16.0$ $\mathrm{Hz}, 1 \mathrm{~F})$; LRMS $\mathrm{m} / \mathrm{z}$ calcd for $\mathrm{C}_{20} \mathrm{H}_{16} \mathrm{ClF}_{2} \mathrm{~N}_{6} \mathrm{O}_{3} \mathrm{~S}_{2}(\mathrm{M}+\mathrm{H})^{+}$525.0, found 524.7. 


\subsection{Synthesis of Compound 14.}

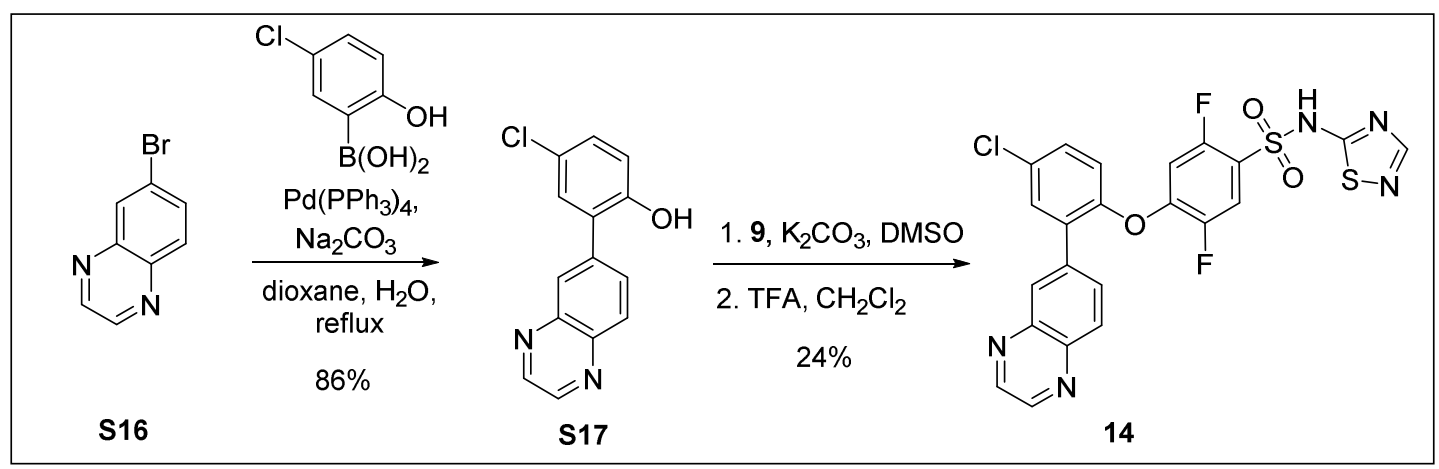

4-Chloro-2-(quinoxalin-6-yl)phenol (S17). Following the procedure as described for S2 and making non-critical variations to replace 6-chloropyridin-2-amine (S1) with 6bromoquinoxaline (S16), $\mathbf{S} 17$ was obtained as a beige solid in $86 \%$ yield $(4.2 \mathrm{~g}) .{ }^{1} \mathrm{H}$ NMR $\left(300 \mathrm{MHz}\right.$, DMSO- $\left.d_{6}\right) \delta 10.18(\mathrm{~s}, 1 \mathrm{H}), 8.98-8.94(\mathrm{~m}, 2 \mathrm{H}), 8.25(\mathrm{~d}, J=1.1 \mathrm{~Hz}, 1 \mathrm{H})$, $8.12(\mathrm{~d}, J=8.7 \mathrm{~Hz}, 1 \mathrm{H}), 8.07$ (dd, $J=8.8,1.6 \mathrm{~Hz}, 1 \mathrm{H}), 7.50(\mathrm{~d}, J=2.6 \mathrm{~Hz}, 1 \mathrm{H}), 7.30$ (dd, $J=8.7,2.6 \mathrm{~Hz}, 1 \mathrm{H}), 7.04(\mathrm{~d}, J=8.7 \mathrm{~Hz}, 1 \mathrm{H})$; LRMS $m / z$ calcd for $\mathrm{C}_{14} \mathrm{H}_{8} \mathrm{CIN}_{2} \mathrm{O}(\mathrm{M}-\mathrm{H})^{-}$ 255.0 , found 255.1 .

4-(4-Chloro-2-(quinoxalin-6-yl)phenoxy)-2,5-difluoro-N-(1,2,4-thiadiazol-5-

$y$ l)benzenesulfonamide (14). Following the procedure as described for the synthesis of $\mathbf{3}$ and making non-critical variations using $\mathbf{S 1 7}$ to replace phenol 6, 14 was obtained as a colorless solid in $24 \%$ yield over 2 steps $(0.15 \mathrm{~g})$. ${ }^{1} \mathrm{H}$ NMR $\left(300 \mathrm{MHz}\right.$, DMSO- $\left.d_{6}\right) \delta$ $8.95(\mathrm{~s}, 2 \mathrm{H}), 8.54(\mathrm{~s}, 1 \mathrm{H}), 8.22(\mathrm{~d}, J=1.6 \mathrm{~Hz}, 1 \mathrm{H}), 8.12(\mathrm{~d}, J=8.7 \mathrm{~Hz}, 1 \mathrm{H}), 7.99(\mathrm{dd}, J=$ 8.7, $1.8 \mathrm{~Hz}, 1 \mathrm{H}), 7.79(\mathrm{~d}, J=2.5 \mathrm{~Hz}, 1 \mathrm{H}), 7.71(\mathrm{dd}, J=9.9,6.4 \mathrm{~Hz}, 1 \mathrm{H}), 7.57(\mathrm{dd}, J=$ 8.8, $2.5 \mathrm{~Hz}, 1 \mathrm{H}), 7.34(\mathrm{~d}, J=8.8 \mathrm{~Hz}, 1 \mathrm{H}), 7.25(\mathrm{dd}, J=10.4,6.5 \mathrm{~Hz}, 1 \mathrm{H})$, (NH not observed); ${ }^{13} \mathrm{C}$ NMR $\left(75 \mathrm{MHz}\right.$, DMSO- $\left.d_{6}\right) \delta 178.7,154.7$ (dd, $\left.J=252.5,2.4 \mathrm{~Hz}\right), 150.3$, 148.2 (dd, $J=12.4,10.6 \mathrm{~Hz}$ ), 147.6, 147.5 (dd, $J=247.3,2.9 \mathrm{~Hz}), 146.3,146.2,141.8$, 141.6, 136.8, 133.1, 131.2, 131.0, 130.1, 129.9, 129.2, 129.1, 123.9 (dd, $J=17.7,5.3$ $\mathrm{Hz}$ ), 121.7, 116.5 (d, $J=22.9 \mathrm{~Hz}), 108.8$ (d, $J=27.4 \mathrm{~Hz}) ;{ }^{19} \mathrm{~F}$ NMR (282 MHz, DMSO$\left.d_{6}\right) \delta-110.2(\mathrm{~d}, J=15.9 \mathrm{~Hz}, 1 \mathrm{~F}),-135.6(\mathrm{~d}, J=15.9 \mathrm{~Hz}, 1 \mathrm{~F})$; HRMS $\mathrm{m} / \mathrm{z}$ calcd for $\mathrm{C}_{22} \mathrm{H}_{13} \mathrm{ClF}_{2} \mathrm{~N}_{5} \mathrm{O}_{3} \mathrm{~S}_{2}(\mathrm{M}+\mathrm{H})^{+}$532.0111, found 532.0115. 


\subsection{Synthesis of Compound 15.}

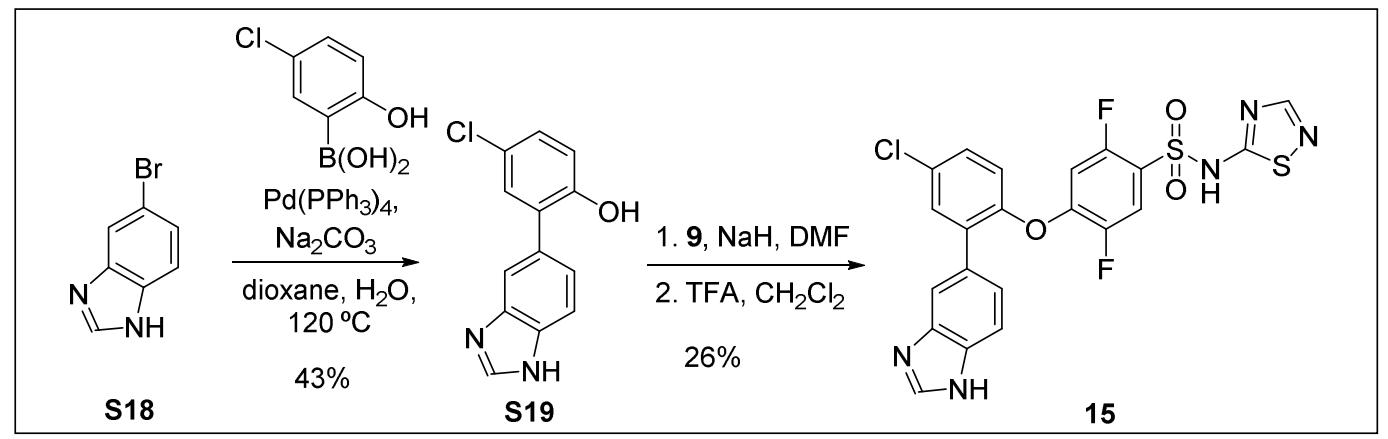

2-(1H-Benzo[d]imidazol-5-yl)-4-chlorophenol (S18). Following the procedure as described for the synthesis of $\mathbf{S 2}$ and making non-critical variations to replace 6chloropyridin-2-amine (S1) with 6-bromo-1 $\mathrm{H}$-benzo[d]imidazole hydrochloride salt (S18), S19 was obtained as a beige solid in $43 \%$ yield $(0.110 \mathrm{~g})$. ${ }^{1} \mathrm{H}$ NMR $(300 \mathrm{MHz}$, DMSO$\left.d_{6}\right) \delta 12.48(\mathrm{~s}, 1 \mathrm{H}), 9.80(\mathrm{~s}, 1 \mathrm{H}), 8.24(\mathrm{~s}, 1 \mathrm{H}), 7.74(\mathrm{~s}, 1 \mathrm{H}), 7.60(\mathrm{~d}, J=8.3 \mathrm{~Hz}, 1 \mathrm{H}), 7.36$ (dd, $J=8.4,1.1 \mathrm{~Hz}, 1 \mathrm{H}$ ), 7.30 (d, $J=2.5 \mathrm{~Hz}, 1 \mathrm{H}), 7.18$ (dd, $J=8.6,2.6 \mathrm{~Hz}, 1 \mathrm{H}), 6.96$ (d, $J=8.6 \mathrm{~Hz}, 1 \mathrm{H})$; LRMS $\mathrm{m} / z$ calcd for $\mathrm{C}_{13} \mathrm{H}_{10} \mathrm{CIN}_{2} \mathrm{O}(\mathrm{M}+\mathrm{H})^{+}$245.0, found 245.1.

4-(2-(1H-Benzo[d]imidazol-5-yl)-4-chlorophenoxy)-2,5-difluoro-N-(1,2,4-thiadiazol-5$y l)$ benzenesulfonamide (15). Following the procedure as described for the synthesis of 3 and making non-critical variations using $\mathbf{S 1 9}$ to replace phenol 6 , the trifluoroacetic acid salt of 15 was obtained as a colorless solid in $24 \%$ yield over 2 steps $(0.15 \mathrm{~g}) .{ }^{1} \mathrm{H}$ NMR $\left(300 \mathrm{MHz}\right.$, DMSO- $\left.d_{6}\right) \delta 9.11(\mathrm{~s}, 1 \mathrm{H}), 8.37(\mathrm{~s}, 1 \mathrm{H}), 7.84(\mathrm{~s}, 1 \mathrm{H}), 7.77(\mathrm{~d}, J=8.5 \mathrm{~Hz}$, $1 \mathrm{H}), 7.64(\mathrm{dd}, J=10.2,6.5 \mathrm{~Hz}, 1 \mathrm{H}), 7.62(\mathrm{~d}, J=2.6 \mathrm{~Hz}, 1 \mathrm{H}), 7.54(\mathrm{~d}, J=8.3 \mathrm{~Hz}, 1 \mathrm{H})$, 7.49 (dd, $J=8.7,2.5 \mathrm{~Hz}, 1 \mathrm{H}), 7.27(\mathrm{~d}, J=8.7 \mathrm{~Hz}, 1 \mathrm{H}$ ), 7.11 (dd, $J=10.4,6.5 \mathrm{~Hz}, 1 \mathrm{H}$ ), (2 $\mathrm{NH}$ and $\mathrm{CF}_{3} \mathrm{COOH}$ not observed); ${ }^{13} \mathrm{C}$ NMR $\left(75 \mathrm{MHz}\right.$, DMSO- $\left.d_{6}\right) \delta 179.9,154.7$ (d, $J$ $=252.3 \mathrm{~Hz}$ ), 150.2, 149.8, 148.1 (dd, $J=12.3,10.6 \mathrm{~Hz}), 147.4(\mathrm{dd}, J=247.0,2.6 \mathrm{~Hz})$, $141.9,134.2,132.6,132.3,131.8,131.2,129.8,129.5,126.0,124.4$ (dd, $J=17.8,4.8$ $\mathrm{Hz}), 121.8,116.5(\mathrm{~d}, J=22.9 \mathrm{~Hz}), 115.0,114.7,108.4(\mathrm{~d}, J=27.4 \mathrm{~Hz})\left(\mathrm{CH}_{3} \mathrm{COOH}\right.$ peaks not observed); $\left.{ }^{19} \mathrm{~F} \mathrm{NMR} \mathrm{(282} \mathrm{MHz,} \mathrm{DMSO-} d_{6}\right) \delta$-76.6 (s, 3F), -113.0 (d, J = 15.8 $\mathrm{Hz}, 1 \mathrm{~F}),-139.0(\mathrm{~d}, J=15.9 \mathrm{~Hz}, 1 \mathrm{~F})$; LRMS $\mathrm{m} / \mathrm{z}$ calcd for $\mathrm{C}_{21} \mathrm{H}_{13} \mathrm{ClF}_{2} \mathrm{~N}_{5} \mathrm{O}_{3} \mathrm{~S}_{2}(\mathrm{M}+\mathrm{H})^{+}$ 520.0 , found 519.7 . 


\subsection{Synthesis of Compound 16.}

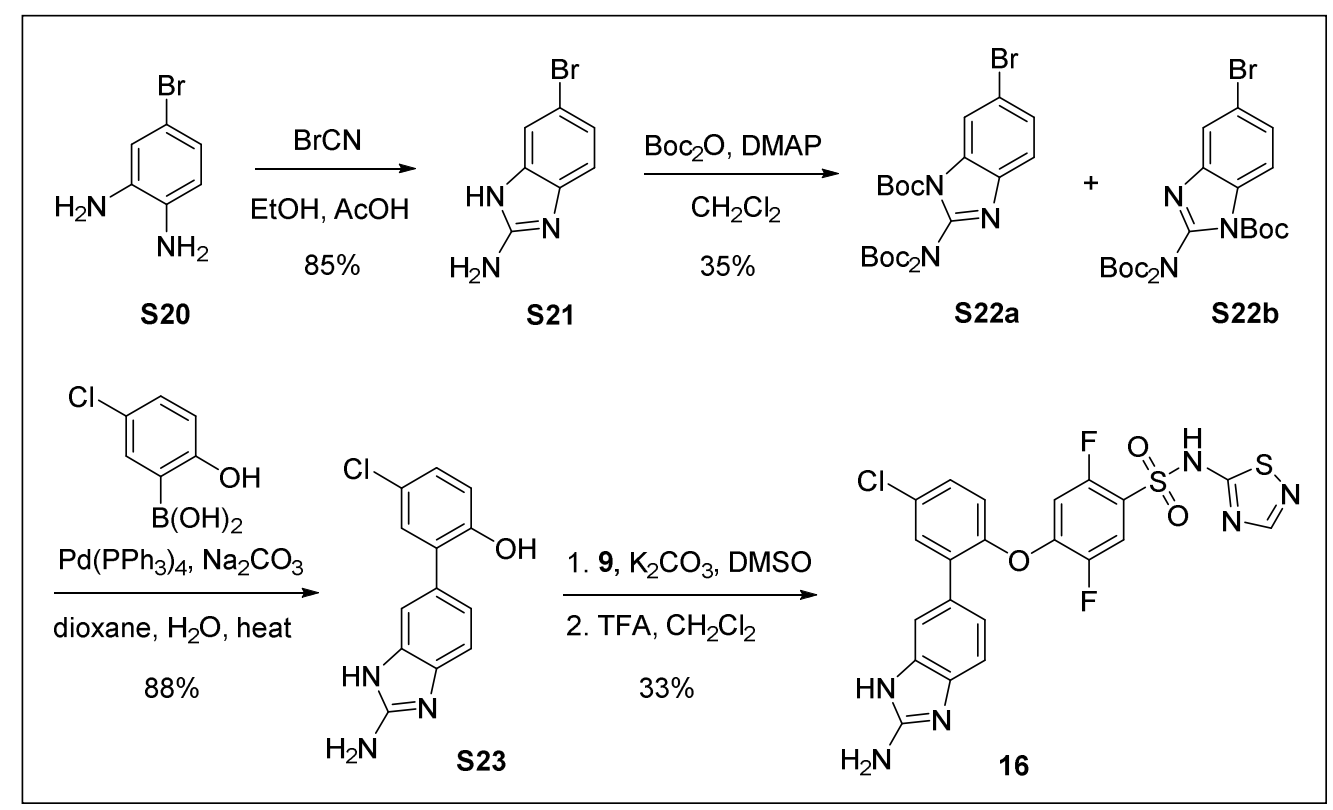

5-Bromo-1H-benzo[d]imidazol-2-amine hydrobromide (S21). To a solution of 4bromo-1,2-diaminobenzene (S20) (3.0 g, $16 \mathrm{mmol})$ in a mixture of ethanol and acetic acid $(1: 1 \mathrm{v} / \mathrm{v}, 180 \mathrm{~mL})$ was added cyanogen bromide $(2.56 \mathrm{~g}, 24.0 \mathrm{mmol})$ and the reaction mixture was stirred at ambient temperature for $16 \mathrm{~h}$. Concentration in vacuo and trituration of the residue in EtOAc $(200 \mathrm{~mL})$ provided $\mathbf{S 2 1}$ as a tannish solid in $85 \%$ yield $(3.98 \mathrm{~g}) .{ }^{1} \mathrm{H}$ NMR $\left(300 \mathrm{MHz}\right.$, DMSO- $\left.d_{6}\right) \delta 12.49(\mathrm{br} \mathrm{s}, 2 \mathrm{H}), 8.61(\mathrm{~s}, 2 \mathrm{H}), 7.50(\mathrm{~s}$, $1 \mathrm{H}), 7.38-7.23(\mathrm{~m}, 2 \mathrm{H})$; LRMS $\mathrm{m} / z$ calcd for $\mathrm{C}_{7} \mathrm{H}_{7} \mathrm{BrN}_{3}(\mathrm{M}+\mathrm{H})^{+} 212.0$, found 211.9 .

tert-Butyl

2-[bis(tert-butoxycarbonyl)amino]-5-bromo-1H-benzimidazole-1carboxylate and tert-butyl 2-[bis(tert-butoxycarbonyl)amino]-6-bromo-1 H-benzimidazole1-carboxylate (S22a and S22b). To a solution of $\mathbf{S 2 1}\left(2.21 \mathrm{~g}, 7.54 \mathrm{mmol}\right.$ ) in $\mathrm{CH}_{2} \mathrm{Cl}_{2}$ $(100 \mathrm{~mL})$ was added $\mathrm{Boc}_{2} \mathrm{O}(4.94 \mathrm{~g}, 22.6 \mathrm{mmol})$ and DMAP $(0.921 \mathrm{~g}, 7.54 \mathrm{mmol})$ and the reaction mixture was stirred for $16 \mathrm{~h}$ at ambient temperature. Concentration in vacuo and purification of the residue by column chromatography (gradient of $10-20 \%$ EtOAc in hexanes) afforded a $1: 1$ mixture of $\mathbf{S 2 2 a}$ and $\mathbf{S 2 2} \mathbf{b}$ in $35 \%$ yield $(1.37 \mathrm{~g})$. LRMS $m / z$ calcd for $\mathrm{C}_{22} \mathrm{H}_{31} \mathrm{BrN}_{3} \mathrm{O}_{6}(\mathrm{M}+\mathrm{H})^{+} 512.1$, found 511.8 .

2-(2-Amino-1H-benzo[d]imidazol-5-yl)-4-chlorophenol (S23). Following the procedure as described for the synthesis of $\mathbf{S 2}$ and making non-critical variations to replace 6-chloropyridin-2-amine (S1) with a mixture of $\mathbf{S 2 2 a}$ and $\mathbf{S 2 2 b}, \mathbf{S 2 3}$ was obtained as a yellow solid in $88 \%$ yield $(0.61 \mathrm{~g})$. ${ }^{1} \mathrm{H}$ NMR $\left(300 \mathrm{MHz}\right.$, DMSO- $\left.d_{6}\right) \delta 9.81$ (br s, 1H), $7.58(\mathrm{br} \mathrm{s}, 2 \mathrm{H}), 7.42(\mathrm{~s}, 1 \mathrm{H}), 7.27-7.10(\mathrm{~m}, 5 \mathrm{H}), 6.92(\mathrm{~d}, J=8.6 \mathrm{~Hz}, 1 \mathrm{H})$; LRMS $\mathrm{m} / \mathrm{z}$ calcd for $\mathrm{C}_{13} \mathrm{H}_{11} \mathrm{CIN}_{3} \mathrm{O}(\mathrm{M}+\mathrm{H})^{+} 260.1$, found 260.0 . 
4-(2-(2-Amino-1H-benzo[d]imidazol-5-yl)-4-chlorophenoxy)-2,5-difluoro-N-(1,2,4thiadiazol-5-yl)benzenesulfonamide (16). Following the procedure as described for the synthesis of $\mathbf{3}$ and making non-critical variations using $\mathbf{S 2 3}$ to replace phenol $\mathbf{6}$ followed by preparative HPLC purification (Gemini NX, C18, $5 \mu \mathrm{m}, 30 \times 150 \mathrm{~mm}, 20-60 \% \mathrm{CH}_{3} \mathrm{CN}$ in water containing $\left.0.1 \% \mathrm{NH}_{4} \mathrm{OH}\right) \mathbf{1 6}$ was obtained as an off-white solid in $33 \%$ yield over 2 steps $(0.57 \mathrm{~g}) .{ }^{1} \mathrm{H}$ NMR $\left(300 \mathrm{MHz}\right.$, DMSO- $\left.d_{6}\right) \delta 8.36(\mathrm{~s}, 2 \mathrm{H}), 7.92(\mathrm{~s}, 1 \mathrm{H}), 7.59-$ $7.52(\mathrm{~m}, 2 \mathrm{H}), 7.48-7.42(\mathrm{~m}, 2 \mathrm{H}), 7.33(\mathrm{~d}, J=8.2 \mathrm{~Hz}, 1 \mathrm{H}), 7.28(\mathrm{dd}, J=8.3,1.3 \mathrm{~Hz}, 1 \mathrm{H})$, $7.21\left(\mathrm{~d}, J=8.7 \mathrm{~Hz}, 1 \mathrm{H}\right.$ ), 7.00 (dd, $J=10.0,6.5 \mathrm{~Hz}, 1 \mathrm{H}$ ), (two $\mathrm{NH}$ not observed); ${ }^{13} \mathrm{C}$ NMR $\left(75 \mathrm{MHz}, \mathrm{DMSO}-d_{6}\right) \delta 185.1,158.6,154.3(\mathrm{dd}, J=251.7,1.7 \mathrm{~Hz}), 151.1,150.4$, 147.1 (dd, $J=245.8,3.1 \mathrm{~Hz}$ ), 146.6 (dd, $J=12.6,10.2 \mathrm{~Hz}$ ), 134.2, 130.8, 130.0, 130.0, 129.9, 129.3, 129.1, 127.0 (dd, $J=19.0,4.3 \mathrm{~Hz}$ ), 123.8, 121.5, 111.6, 116.5 (dd, $J=$ 22.2, $2.7 \mathrm{~Hz}$ ), $111.3,108.3\left(\mathrm{~d}, J=27.8 \mathrm{~Hz}\right.$ ); ${ }^{19} \mathrm{~F} \mathrm{NMR}\left(282 \mathrm{MHz}\right.$, DMSO- $\left.d_{6}\right) \delta$-110.4 (d, $J=16.9 \mathrm{~Hz}),-137.2(\mathrm{~d}, J=16.9 \mathrm{~Hz})$; HRMS $\mathrm{m} / z$ calcd for $\mathrm{C}_{21} \mathrm{H}_{14} \mathrm{ClF}_{2} \mathrm{~N}_{6} \mathrm{O}_{3} \mathrm{~S}_{2}(\mathrm{M}+\mathrm{H})^{+}$ 535.0220 , found 535.0227 .

\subsection{Synthesis of Compound 17.}

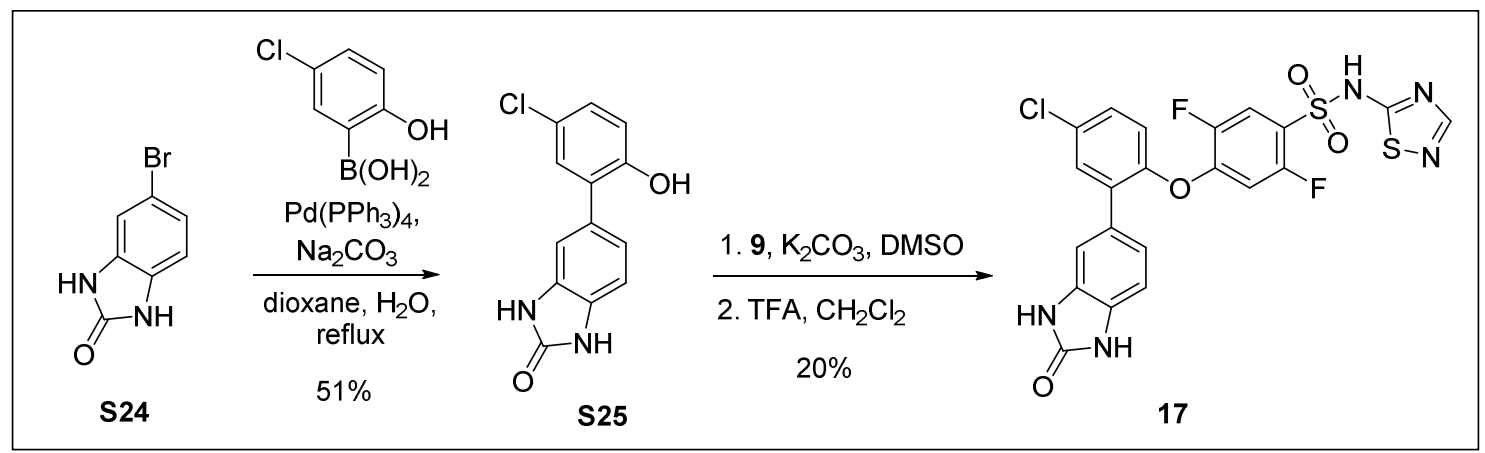

5-(5-Chloro-2-hydroxyphenyl)-1H-benzo[d]imidazol-2(3H)-one (S25). Following the procedure as described for the synthesis of $\mathbf{S 2}$ and making non-critical variations to replace 6-chloropyridin-2-amine (S1) with 5-bromo-1,3-dihydro-2H-benzo[d]imidazol-2one (S24) and purification by trituration in $\mathrm{CH}_{2} \mathrm{Cl}_{2}$, $\mathbf{S 2 5}$ was obtained as a tan solid in $51 \%$ yield $(0.198 \mathrm{~g}){ }^{1} \mathrm{H}$ NMR $\left(300 \mathrm{MHz}\right.$, DMSO- $\left.d_{6}\right) \delta 10.62(\mathrm{~s}, 1 \mathrm{H}), 10.60(\mathrm{~s}, 1 \mathrm{H}), 9.73$ $(\mathrm{s}, 1 \mathrm{H}), 7.19(\mathrm{~d}, J=2.6 \mathrm{~Hz}, 1 \mathrm{H}), 7.15-7.08(\mathrm{~m}, 2 \mathrm{H}), 7.05(\mathrm{dd}, J=8.1,1.3 \mathrm{~Hz}, 1 \mathrm{H})$, 6.94-6.86 (m, 2H); LRMS $\mathrm{m} / z$ calcd for $\mathrm{C}_{13} \mathrm{H}_{10} \mathrm{CIN}_{2} \mathrm{O}_{2}(\mathrm{M}+\mathrm{H})^{+} 261.0$, found 260.9 .

4-(4-Chloro-2-(2-oxo-2,3-dihydro-1H-benzo[d]imidazol-5-yl)phenoxy)-2,5-difluoro- $\mathrm{N}$ $(1,2,4-$ thiadiazol-5-yl)benzenesulfonamide (17). Following the procedure as described for the synthesis of $\mathbf{3}$ and making non-critical variations using $\mathbf{S 2 5}$ to replace phenol $\mathbf{6}$ and purification by column chromatography $\left(0-20 \%\right.$ methanol in $\left.\mathrm{CH}_{2} \mathrm{Cl}_{2}\right), 17$ was obtained as a colorless solid in $20 \%$ yield over 2 steps $(0.081 \mathrm{~g}) .{ }^{1} \mathrm{H}$ NMR $(300 \mathrm{MHz}$, DMSO- $\left.d_{6}\right) \delta 10.67(\mathrm{~s}, 1 \mathrm{H}), 10.64(\mathrm{~s}, 1 \mathrm{H}), 8.49(\mathrm{~s}, 1 \mathrm{H}), 7.69(\mathrm{dd}, J=9.9,6.4 \mathrm{~Hz}, 1 \mathrm{H})$, $7.50(\mathrm{~d}, J=2.5 \mathrm{~Hz}, 1 \mathrm{H}), 7.40$ (dd, $J=8.7,2.6 \mathrm{~Hz}, 1 \mathrm{H}), 7.22(\mathrm{~d}, J=8.7 \mathrm{~Hz}, 1 \mathrm{H}), 7.05-$ 
$6.98(\mathrm{~m}, 3 \mathrm{H}), 6.90(\mathrm{~d}, J=7.9 \mathrm{~Hz}, 1 \mathrm{H})$, (sulfonamide $\mathrm{NH}$ not observed); ${ }^{13} \mathrm{C}$ NMR $(75$ $\left.\mathrm{MHz}, \mathrm{DMSO}-d_{6}\right) \delta 178.6,155.3,154.8(\mathrm{dd}, J=252.5,2.0 \mathrm{~Hz}), 149.8,148.7$ (dd, $J=$ 12.3, $10.5 \mathrm{~Hz}$ ), 147.6, 147.4 (dd, $J=246.9,2.8 \mathrm{~Hz}), 135.3,130.9,129.8,129.7(2 \mathrm{C})$, 128.6, 127.3, 123.3 (dd, $J=17.7,5.2 \mathrm{~Hz}$ ), 122.1, 121.4, 116.4 (d, $J=22.9 \mathrm{~Hz}$ ), 108.7 , $107.9(\mathrm{~d}, J=27.4 \mathrm{~Hz}), 108.4 ;{ }^{19} \mathrm{~F}$ NMR $\left(282 \mathrm{MHz}\right.$, DMSO- $\left.d_{6}\right) \delta-110.3(\mathrm{~d}, J=15.7 \mathrm{~Hz}$, $1 \mathrm{~F}),-136.1(\mathrm{~d}, J=15.8 \mathrm{~Hz}, 1 \mathrm{~F})$; LRMS $\mathrm{m} / z$ calcd for $\mathrm{C}_{21} \mathrm{H}_{11} \mathrm{ClF}_{2} \mathrm{~N}_{5} \mathrm{O}_{4} \mathrm{~S}_{2}(\mathrm{M}-\mathrm{H})^{-}$534.0, found 533.8 .

\subsection{Synthesis of Compound 18.}

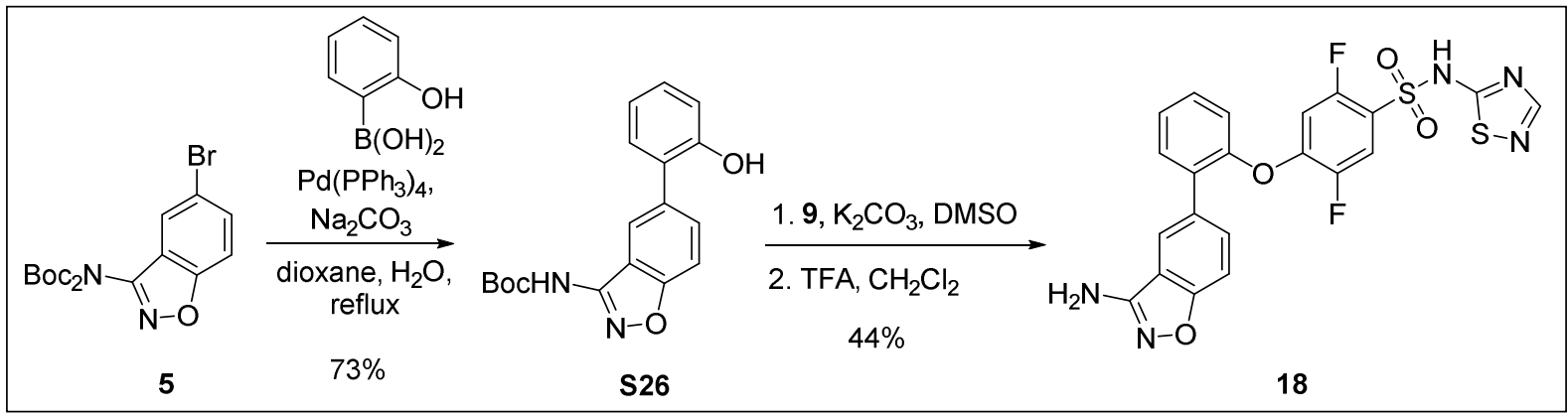

tert-Butyl (5-(2-hydroxyphenyl)benzo[d]isoxazol-3-yl)carbamate (S26). Following the procedure as described for the synthesis of 9 and making non-critical variations to replace (5-chloro-2-hydroxyphenyl)boronic acid with phenylboronic acid, S26 was obtained as a pale yellow solid in $73 \%$ yield $(0.36 \mathrm{~g})$. ${ }^{1} \mathrm{H}$ NMR $\left(300 \mathrm{MHz}\right.$, DMSO- $\left.d_{6}\right) \delta$ $10.50(\mathrm{~s}, 1 \mathrm{H}), 9.64(\mathrm{~s}, 1 \mathrm{H}), 8.16-8.15(\mathrm{~m}, 1 \mathrm{H}), 7.79(\mathrm{dd}, J=8.8,1.7 \mathrm{~Hz}, 1 \mathrm{H}), 7.65(\mathrm{~d}, J$ $=8.8 \mathrm{~Hz}, 1 \mathrm{H}), 7.28(\mathrm{dd}, J=7.6,1.6 \mathrm{~Hz}, 1 \mathrm{H}), 7.23-7.16(\mathrm{~m}, 1 \mathrm{H}), 6.97(\mathrm{~d}, J=8.1 \mathrm{~Hz}$, $1 \mathrm{H}), 6.91(\mathrm{t}, J=7.4 \mathrm{~Hz}, 1 \mathrm{H}), 1.50(\mathrm{~s}, 9 \mathrm{H})$; LRMS $\mathrm{m} / \mathrm{z}$ calcd for $\mathrm{C}_{18} \mathrm{H}_{17} \mathrm{~N}_{2} \mathrm{O}_{4}(\mathrm{M}-\mathrm{H})^{-}$325.1, found 325.1 .

4-(2-(3-Aminobenzo[d]isoxazol-5-yl)phenoxy)-2,5-difluoro-N-(1,2,4-thiadiazol-5$y$ l)benzenesulfonamide (18). Following the procedure as described for the synthesis of 3 and making non-critical variations using S26 to replace phenol 6, 18 was obtained as a colorless solid in $44 \%$ yield $(0.185 \mathrm{~g})$. ${ }^{1} \mathrm{H}$ NMR $\left(300 \mathrm{MHz}\right.$, DMSO- $\left.d_{6}\right) \delta 8.52(\mathrm{~s}, 1 \mathrm{H})$, $7.95(\mathrm{~d}, J=1.17 \mathrm{~Hz}, 1 \mathrm{H}), 7.71$ (dd, $J=10.0,6.5 \mathrm{~Hz}, 1 \mathrm{H}), 7.62(\mathrm{dd}, J=8.7,1.7 \mathrm{~Hz}, 1 \mathrm{H})$, $7.55(\mathrm{dd}, J=7.3,1.9 \mathrm{~Hz}, 1 \mathrm{H}), 7.51-7.36(\mathrm{~m}, 3 \mathrm{H}), 7.24(\mathrm{dd}, J=7.8,1.1 \mathrm{~Hz}, 1 \mathrm{H}), 6.98$ (dd, $J=10.4,6.4 \mathrm{~Hz}, 1 \mathrm{H}$ ), 6.45 (br s, $2 \mathrm{H}$ ) (sulfonamide $\mathrm{NH}$ not observed); ${ }^{13} \mathrm{C}$ NMR $(75$ MHz, DMSO- $\left.d_{6}\right) \delta 178.6,161.2,158.5,154.7(\mathrm{dd}, J=252.3,2.3 \mathrm{~Hz}$ ), 151.2, 148.7 (dd, $J=12.4,10.5 \mathrm{~Hz}$ ), 147.7 (dd, $J=247.3,2.9 \mathrm{~Hz}$ ), 147.6, 132.3, 131.7, 130.8, 130.4, 129.6, 126.0, 123.4 (dd, $J=17.6,5.2 \mathrm{~Hz}$ ), 122.0, 119.8, 117.1, 116.5 (dd, $J=22.9,1.6$ $\mathrm{Hz}$ ), 109.2, 108.2 (d, $J=27.3 \mathrm{~Hz}$ ); ${ }^{19} \mathrm{~F} \mathrm{NMR}\left(282 \mathrm{MHz}\right.$, DMSO- $\left.d_{6}\right) \delta-110.5(\mathrm{~d}, J=15.7$ $\mathrm{Hz}, 1 \mathrm{~F}),-135.5(\mathrm{~d}, J=15.8 \mathrm{~Hz}, 1 \mathrm{~F})$; LRMS $\mathrm{m} / \mathrm{z}$ calcd for $\mathrm{C}_{21} \mathrm{H}_{14} \mathrm{~F}_{2} \mathrm{~N}_{5} \mathrm{O}_{4} \mathrm{~S}_{2}(\mathrm{M}+\mathrm{H})^{+}$502.0, found 501.6 . 


\subsection{Synthesis of Compound 19.}

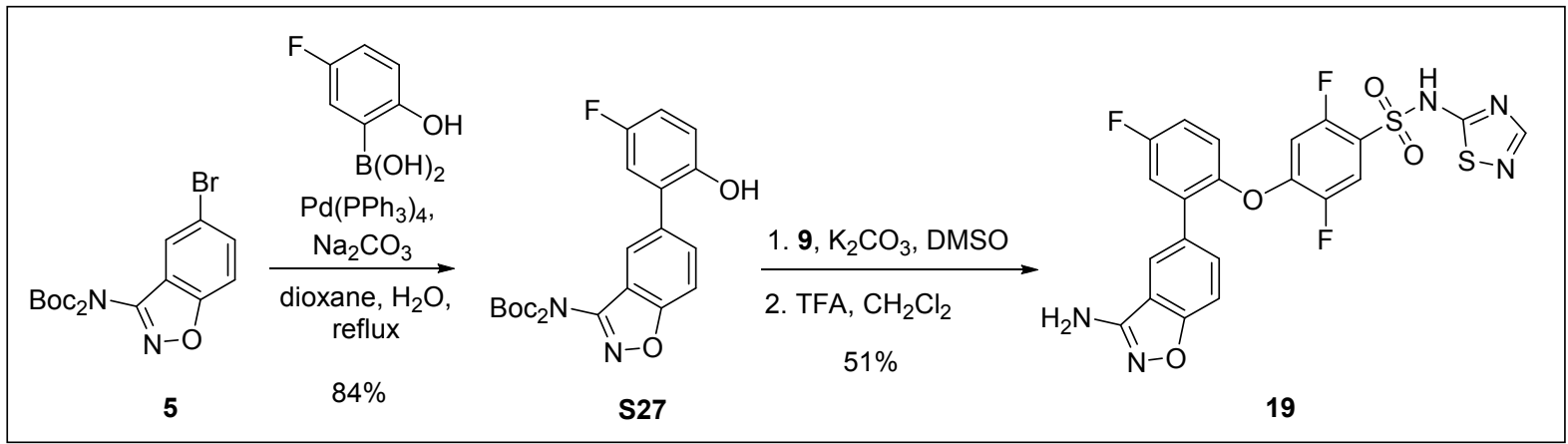

di-tert-Butyl (5-(5-fluoro-2-hydroxyphenyl)-1,2-benzoxazol-3-yl)imidodicarbonate (S27). Following the procedure as described for the synthesis of 6 and making noncritical variations to replace (5-chloro-2-hydroxyphenyl)boronic acid with (fluoro-2hydroxyphenyl)boronic acid, compound $\mathbf{S 2 7}$ was obtained as a colorless solid in $84 \%$ yield $(10.8 \mathrm{~g}) .{ }^{1} \mathrm{H}$ NMR $\left(300 \mathrm{MHz}, \mathrm{DMSO}-d_{6}\right) \delta 9.74(\mathrm{~s}, 1 \mathrm{H}), 7.94-7.86(\mathrm{~m}, 2 \mathrm{H}), 7.81(\mathrm{~d}$, $J=8.9 \mathrm{~Hz}, 1 \mathrm{H}), 7.16(\mathrm{dd}, J=9.7,3.1 \mathrm{~Hz}, 1 \mathrm{H}), 7.00(\mathrm{dd}, J=8.2,3.1 \mathrm{~Hz}, 1 \mathrm{H}), 6.96-6.90$ $(\mathrm{m}, 1 \mathrm{H}), 1.34(\mathrm{~s}, 18 \mathrm{H})$; LRMS $\mathrm{m} / z$ calcd for $\mathrm{C}_{23} \mathrm{H}_{24} \mathrm{FN}_{2} \mathrm{O}_{6}(\mathrm{M}-\mathrm{H})^{-} 443.2$, found 443.1 .

4-(2-(3-Aminobenzo[d]isoxazol-5-yl)-4-fluorophenoxy)-2,5-difluoro-N-(1,2,4thiadiazol-5-yl)benzenesulfonamide (19). Following the procedure as described for the synthesis of $\mathbf{3}$ and making non-critical variations using $\mathbf{S 2 7}$ to replace phenol $\mathbf{6}$, compound 19 was obtained as an off-white solid in $51 \%$ yield over 2 steps $(0.188 \mathrm{~g}) .{ }^{1} \mathrm{H}$ NMR $\left(300 \mathrm{MHz}, \mathrm{DMSO}-d_{6}\right) \delta 8.47(\mathrm{~s}, 1 \mathrm{H}), 7.95-7.94(\mathrm{~m}, 1 \mathrm{H}), 7.65(\mathrm{dd}, J=10.0,6.5$ $\mathrm{Hz}, 1 \mathrm{H}), 7.59$ (dd, $J=8.7,1.8 \mathrm{~Hz}, 1 \mathrm{H}), 7.43(\mathrm{~d}, J=8.7 \mathrm{~Hz}, 1 \mathrm{H}), 7.43-7.37(\mathrm{~m}, 1 \mathrm{H})$, 7.34-7.24 (m, 2H), 6.94 (dd, $J=10.5,6.5 \mathrm{~Hz}, 1 \mathrm{H}$ ), 6.43 (br s, 2H), (sulfonamide NH not observed); ${ }^{13} \mathrm{C}$ NMR $\left(75 \mathrm{MHz}\right.$, DMSO- $\left.d_{6}\right) \delta 178.8,161.4,159.4(\mathrm{~d}, J=242.7 \mathrm{~Hz}), 158.5$, 154.7 (dd, $J=252.3,2.3 \mathrm{~Hz}$ ), 148.9 (dd, $J=12.0,10.7 \mathrm{~Hz}$ ), 147.9, 147.3 (dd, $J=248.5$, $2.7 \mathrm{~Hz}$ ), $147.2(\mathrm{~d}, J=2.4 \mathrm{~Hz}), 134.5(\mathrm{~d}, J=8.5 \mathrm{~Hz}), 130.7,129.4(\mathrm{~d}, J=1.1 \mathrm{~Hz}), 123.4$ (dd, $J=17.8,5.2 \mathrm{~Hz}), 122.5,122.3,118.0(\mathrm{~d}, J=23.9 \mathrm{~Hz}), 117.2,116.7-115.9(\mathrm{~m}, 2 \mathrm{C})$, 109.3, $107.7(\mathrm{~d}, J=27.4 \mathrm{~Hz}) ;{ }^{19} \mathrm{~F}$ NMR $\left(282 \mathrm{MHz}\right.$, DMSO- $\left.d_{6}\right) \delta-110.4(\mathrm{~d}, J=15.7 \mathrm{~Hz}$, $1 F),-116.6(\mathrm{~s}, 1 \mathrm{~F}),-136.0(\mathrm{~d}, J=15.8 \mathrm{~Hz}, 1 \mathrm{~F})$; HRMS $\mathrm{m} / \mathrm{z}$ calcd for $\mathrm{C}_{21} \mathrm{H}_{13} \mathrm{~F}_{3} \mathrm{~N}_{5} \mathrm{O}_{4} \mathrm{~S}_{2}$ $(\mathrm{M}+\mathrm{H})^{+} 520.0356$, found 520.0363 . 


\subsection{Synthesis of Compound 20.}

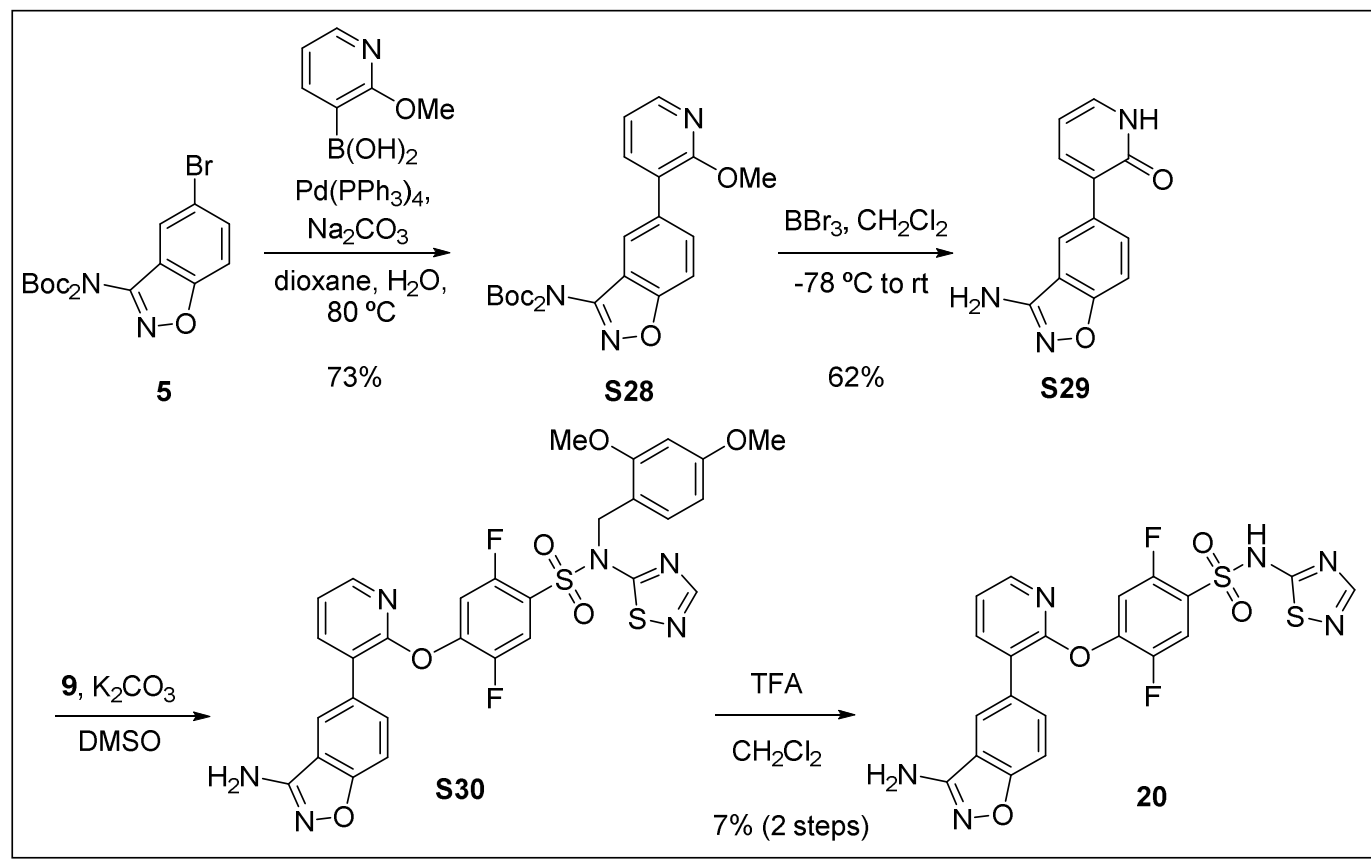

di-tert-Butyl [5-(2-methoxypyridin-3-yl)-1,2-benzoxazol-3-yl]imidodicarbonate (S28). Following the procedure as described for the synthesis of 6 and making non-critical variations to replace (5-chloro-2-hydroxyphenyl)boronic acid with (2-methoxypyridin-3yl)boronic acid, S28 was obtained as a tan solid in $71 \%$ yield $(0.47 \mathrm{~g}) .{ }^{1} \mathrm{H}$ NMR (300 $\left.\mathrm{MHz} \mathrm{CDCl}_{3}\right) \delta 8.15(\mathrm{dd}, J=5.0,1.7 \mathrm{~Hz}, 1 \mathrm{H}), 7.74-7.68(\mathrm{~m}, 2 \mathrm{H}), 7.62-7.55(\mathrm{~m}, 2 \mathrm{H}), 6.97$ (dd, $J=7.3,5.0 \mathrm{~Hz}, 1 \mathrm{H}$ ), $3.92(\mathrm{~s}, 3 \mathrm{H}), 1.37(\mathrm{~s}, 18 \mathrm{H})$; LRMS $\mathrm{m} / \mathrm{z}$ calcd for $\mathrm{C}_{23} \mathrm{H}_{28} \mathrm{~N}_{3} \mathrm{O}_{6}$ $(\mathrm{M}+\mathrm{H})^{+}$442.2, found 442.1 .

3-(3-Aminobenzo[d]isoxazol-5-yl)pyridin-2(1H)-one (S29). To a mixture of $\mathbf{S 2 8}$ $(0.235 \mathrm{~g}, 0.53 \mathrm{mmol})$ in acetic acid $(3 \mathrm{~mL})$ was added $48 \%$ hydrobromic acid $(1 \mathrm{~mL})$, the reaction mixture stirred at ambient temperature $16 \mathrm{~h}$, and subsequently heated to $75{ }^{\circ} \mathrm{C}$ for $6 \mathrm{~h}$. After cooling to ambient temperature, the reaction mixture was concentrated in vacuo. The residue was partitioned between water $(100 \mathrm{~mL})$ and EtOAc $(50 \mathrm{~mL})$, and the aqueous phase was extracted with EtOAc $(2 \times 50 \mathrm{~mL})$. The combined organic phase was washed with brine $(25 \mathrm{~mL})$, dried over anhydrous $\mathrm{MgSO}_{4}$, and concentrated in vacuo to afford $\mathbf{S} 29$ as a brownish solid in $62 \%$ yield $(0.075 \mathrm{~g})$. ${ }^{1} \mathrm{H}$ NMR $(300 \mathrm{MHz}$, DMSO-d $\left.d_{6}\right) \delta 11.87(\mathrm{br} \mathrm{s}, 1 \mathrm{H}), 8.18(\mathrm{~d}, J=1.2 \mathrm{~Hz}, 1 \mathrm{H}), 7.84(\mathrm{dd}, J=8.7,1.8 \mathrm{~Hz}, 1 \mathrm{H})$, $7.64(\mathrm{dd}, J=6.9,2.1 \mathrm{~Hz}, 1 \mathrm{H}), 7.46-7.38(\mathrm{~m}, 2 \mathrm{H}), 6.43(\mathrm{br} \mathrm{s}, 2 \mathrm{H}), 6.32$ (dd, $J=6.7,6.7$ $\mathrm{Hz}, 1 \mathrm{H}) ;{ }^{13} \mathrm{C}$ NMR $\left(75 \mathrm{MHz}\right.$, DMSO- $\left.d_{6}\right) \delta 161.2,161.1,158.6,138.6,134.5,130.9$, 130.3, 129.6, 121.3, 116.7, 108.6, 105.4; LRMS $\mathrm{m} / z$ calcd for $\mathrm{C}_{12} \mathrm{H}_{10} \mathrm{~N}_{3} \mathrm{O}_{2}(\mathrm{M}+\mathrm{H})^{+}$ 228.1, found 228.0 . 
4-((3-(3-Aminobenzo[d]isoxazol-5-yl)pyridin-2-yl)oxy)-N-(2,4-dimethoxybenzyl)-2,5difluoro- $N$-(1,2,4-thiadiazol-5-yl)benzenesulfonamide (S30). To a mixture of S29 (0.075 $\mathrm{g}, 0.33 \mathrm{mmol})$ and potassium carbonate $(0.065 \mathrm{~g}, 0.50 \mathrm{mmol})$ in anhydrous DMSO (2 $\mathrm{mL}$ ) was added $9(0.147 \mathrm{~g}, 0.33 \mathrm{mmol})$ and the reaction mixture was stirred at ambient temperature for $16 \mathrm{~h}$. After dilution with EtOAc $(80 \mathrm{~mL})$, the mixture was washed with water $(2 \times 10 \mathrm{~mL})$, brine $(10 \mathrm{~mL})$, and dried over anhydrous $\mathrm{MgSO}_{4}$. Concentration in vacuo provided a residue which was purified by column chromatography $(20-70 \%$ EtOAc in hexanes) to afford $\mathbf{S 3 0}$ as first eluting compound and 4-(3-(3aminobenzo[d]isoxazol-5-yl)-2-oxopyridin-1(2H)-yl)- $N$-(2,4-dimethoxybenzyl)-2,5-

difluoro- $N$-(1,2,4-thiadiazol-5-yl)benzenesulfonamide as second eluting compound. Data for S30: ${ }^{1} \mathrm{H}$ NMR $\left(300 \mathrm{MHz}\right.$, DMSO- $\left.d_{6}\right) \delta 8.21(\mathrm{~s}, 1 \mathrm{H}), 8.12(\mathrm{dd}, J=4.9,1.8 \mathrm{~Hz}$, $1 \mathrm{H}), 7.87-7.82(\mathrm{~m}, 2 \mathrm{H}), 7.72(\mathrm{dd}, J=8.7,1.6 \mathrm{~Hz}, 1 \mathrm{H}), 7.53(\mathrm{~d}, J=8.7 \mathrm{~Hz}, 1 \mathrm{H}), 7.42$ (dd, $J=9.4,6.2 \mathrm{~Hz}, 1 \mathrm{H}), 7.25-7.20(\mathrm{~m}, 2 \mathrm{H}), 6.99$ (dd, $J=9.8,5.8 \mathrm{~Hz}, 1 \mathrm{H}), 6.38(\mathrm{dd}, J=$ 8.5, $2.3 \mathrm{~Hz}, 1 \mathrm{H}), 6.20(\mathrm{~d}, J=2.3 \mathrm{~Hz}, 1 \mathrm{H}), 5.36(\mathrm{~s}, 2 \mathrm{H}), 4.68(\mathrm{~s}, 2 \mathrm{H}), 3.73(\mathrm{~s}, 3 \mathrm{H}), 3.64$ (s, 3H); ${ }^{19} \mathrm{~F}$ NMR $(282 \mathrm{MHz}$, DMSO-d 6 ) $\delta-108.70(\mathrm{~d}, J=15.3 \mathrm{~Hz}, 1 \mathrm{~F}),-129.26(\mathrm{~d}, J=$ $15.3 \mathrm{~Hz}, 1 \mathrm{~F})$; LRMS $\mathrm{m} / \mathrm{z}$ calcd for $\mathrm{C}_{29} \mathrm{H}_{23} \mathrm{~F}_{2} \mathrm{~N}_{6} \mathrm{O}_{6} \mathrm{~S}_{2}(\mathrm{M}+\mathrm{H})^{+}$653.1, found 652.7. Data for 4-(3-(3-aminobenzo[d] isoxazol-5-yl)-2-oxopyridin-1(2H)-yl)- $N$-(2,4-dimethoxybenzyl)-

2,5-difluoro- $N$-(1,2,4-thiadiazol-5-yl)benzenesulfonamide: ${ }^{1} \mathrm{H}$ NMR $\left(300 \mathrm{MHz}\right.$, DMSO- $\left.d_{6}\right)$ $\delta 8.22(\mathrm{~s}, 1 \mathrm{H}), 8.02-7.98(\mathrm{~m}, 1 \mathrm{H}), 7.72(\mathrm{dd}, J=8.8,1.7 \mathrm{~Hz}, 1 \mathrm{H}), 7.64-7.52(\mathrm{~m}, 2 \mathrm{H})$, $7.40(\mathrm{~d}, J=8.8 \mathrm{~Hz}, 1 \mathrm{H}), 7.29-7.15(\mathrm{~m}, 3 \mathrm{H}), 6.44(\mathrm{dd}, J=7.1,7.1 \mathrm{~Hz}, 1 \mathrm{H}), 6.36(\mathrm{dd}, J=$ 8.5, $2.3 \mathrm{~Hz}, 1 \mathrm{H}), 6.21(\mathrm{~d}, J=2.3 \mathrm{~Hz}, 1 \mathrm{H}), 5.37(\mathrm{~s}, 2 \mathrm{H}), 4.60(\mathrm{~s}, 2 \mathrm{H}), 3.73(\mathrm{~s}, 3 \mathrm{H}), 3.67$ (s, 3H); ${ }^{19} \mathrm{~F}$ NMR $(282 \mathrm{MHz}$, DMSO-d 6 ) $\delta-109.48(\mathrm{~d}, J=16.8 \mathrm{~Hz}, 1 \mathrm{~F}),-121.85$ (d, $J=$ $16.9 \mathrm{~Hz}, 1 \mathrm{~F})$; LRMS $\mathrm{m} / \mathrm{z}$ calcd for $\mathrm{C}_{29} \mathrm{H}_{23} \mathrm{~F}_{2} \mathrm{~N}_{6} \mathrm{O}_{6} \mathrm{~S}_{2}(\mathrm{M}+\mathrm{H})^{+} 653.1$, found 652.7 .

4-((3-(3-Aminobenzo[d]isoxazol-5-yl)pyridin-2-yl)oxy)-2,5-difluoro-N-(1,2,4thiadiazol-5-yl)benzenesulfonamide (20). To a solution of $\mathbf{S} 30$ in $\mathrm{CH}_{2} \mathrm{Cl}_{2}(10 \mathrm{~mL})$ was added TFA (1 mL). The mixture was stirred at ambient temperature for $5 \mathrm{~min}$ and then concentrated in vacuo. The residue was triturated in methanol $(15 \mathrm{~mL})$, filtered, and the filtrate concentrated to afford $\mathbf{2 0}$ as a colorless solid in 7\% yield over 2 steps from $\mathbf{S 2 9}$ $(0.011 \mathrm{~g}) .{ }^{1} \mathrm{H}$ NMR $\left(300 \mathrm{MHz}, \mathrm{DMSO}-d_{6}\right) \delta 8.44(\mathrm{~s}, 1 \mathrm{H}), 8.16-8.11(\mathrm{~m}, 2 \mathrm{H}), 8.02(\mathrm{dd}, J$ $=7.5,1.8 \mathrm{~Hz}, 1 \mathrm{H}), 7.83(\mathrm{dd}, J=8.7,1.8 \mathrm{~Hz}, 1 \mathrm{H}), 7.78(\mathrm{dd}, J=9.6,6.4 \mathrm{~Hz}, 1 \mathrm{H}), 7.66$ (dd, $J=10.1,6.1 \mathrm{~Hz}, 1 \mathrm{H}), 7.57(\mathrm{~d}, J=8.7 \mathrm{~Hz}, 1 \mathrm{H}), 7.36(\mathrm{dd}, J=7.5,4.9 \mathrm{~Hz}, 1 \mathrm{H}), 6.52$ (br s, $2 \mathrm{H}$ ), (sulfonamide $\mathrm{NH}$ not observed); HRMS $m / z$ calcd for $\mathrm{C}_{20} \mathrm{H}_{13} \mathrm{~F}_{2} \mathrm{~N}_{6} \mathrm{O}_{4} \mathrm{~S}_{2}(\mathrm{M}+\mathrm{H})^{+}$ 503.0402 , found 503.0409 . 


\subsection{Synthesis of Compound 21.}

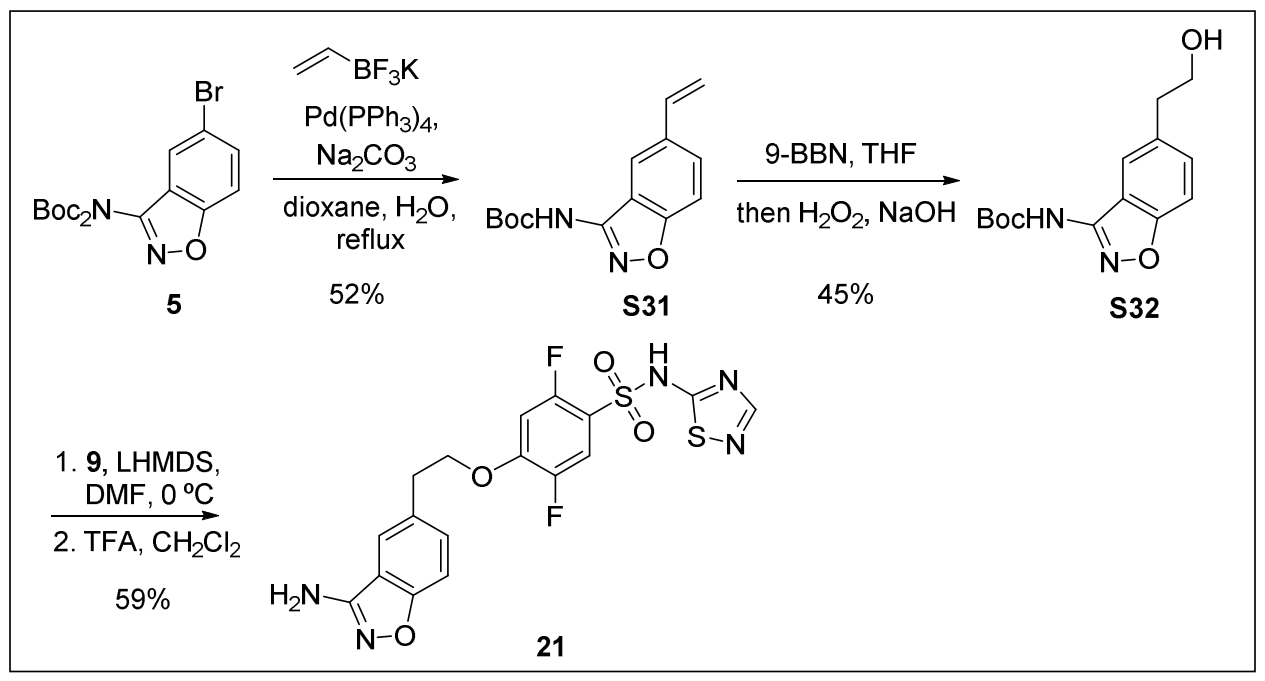

tert-Butyl (5-vinylbenzo[d]isoxazol-3-yl)carbamate (S31). To a mixture of di-tert-butyl (5-bromo-1,2-benzoxazol-3-yl)imidodicarbonate (8) $(0.827 \mathrm{~g}, 2.0 \mathrm{mmol})$, potassium vinyltrifluoroborate $(0.402 \mathrm{~g}, 3.0 \mathrm{mmol})$, and tetrakis(triphenylphosphine)palladium(0) $(0.232 \mathrm{~g}, 0.2 \mathrm{mmol})$ in dioxane $(12 \mathrm{~mL})$ was added $2 \mathrm{M}$ sodium carbonate $(3.0 \mathrm{~mL}, 6.0$ $\mathrm{mmol})$. The reaction mixture was degassed by passing argon through it and then heated to $120^{\circ} \mathrm{C}$ for $16 \mathrm{~h}$. After cooling to ambient temperature, the mixture was diluted with EtOAc $(50 \mathrm{~mL})$ and filtered over $\mathrm{Na}_{2} \mathrm{SO}_{4}$. Concentration of the filtrate in vacuo provided a residue which was purified by column chromatography $(0-20 \%$ EtOAc in hexanes) to afford $\mathbf{S} 31$ as a yellowish oil in $52 \%$ yield $(0.27 \mathrm{~g})$. ${ }^{1} \mathrm{H}$ NMR $(300 \mathrm{MHz}$, $\left.\mathrm{CDCl}_{3}\right) \delta 8.07(\mathrm{~s}, 1 \mathrm{H}), 7.65(\mathrm{dd}, J=8.8,1.6 \mathrm{~Hz}, 1 \mathrm{H}), 7.46-7.36(\mathrm{~m}, 2 \mathrm{H}), 6.81(\mathrm{dd}, J=$ $17.5,10.9 \mathrm{~Hz}, 1 \mathrm{H}), 5.74(\mathrm{~d}, J=17.6 \mathrm{~Hz}, 1 \mathrm{H}), 5.26(\mathrm{~d}, J=10.9 \mathrm{~Hz}, 1 \mathrm{H}), 1.55(\mathrm{~s}, 9 \mathrm{H})$.

tert-Butyl (5-(2-hydroxyethyl)benzo[d]isoxazol-3-yl)carbamate (S32). To a cold (0 $\left.{ }^{\circ} \mathrm{C}\right)$ mixture of $\mathrm{S} 31(0.270 \mathrm{~g}, 1.04 \mathrm{mmol})$ in anhydrous THF $(5 \mathrm{~mL})$ was added 9borabicyclo[3.3.1]nonane (10.4 $\mathrm{mL}$ of a $0.5 \mathrm{M}$ solution in THF, $5.2 \mathrm{mmol})$. The reaction mixture was allowed to warm to ambient temperature and stirred for $16 \mathrm{~h}$. The mixture was then diluted with methanol $(10 \mathrm{~mL})$, cooled to $0 \stackrel{\circ}{\circ} \mathrm{C}$, and $1 \mathrm{M}$ sodium hydroxide $(6.2$ $\mathrm{mmol})$ followed by $32 \%$ hydrogen peroxide $(0.59 \mathrm{~mL}, 6.2 \mathrm{mmol})$ was added. The reaction mixture was stirred for $2 \mathrm{~h}$ at $0 \stackrel{\circ}{\circ} \mathrm{C}$. The mixture was extracted with $\mathrm{CH}_{2} \mathrm{Cl}_{2}(3 \mathrm{x}$ $15 \mathrm{~mL})$, and the combined organic phase was washed with brine $(5 \mathrm{~mL})$, dried over anhydrous $\mathrm{Na}_{2} \mathrm{SO}_{4}$, and concentrated in vacuo. Purification of the residue by column chromatography (0-20\% EtOAc in hexanes) afforded $\mathbf{S 3 2}$ as a colorless solid in $45 \%$ yield $(0.13 \mathrm{~g})$. ${ }^{1} \mathrm{H} \mathrm{NMR}\left(300 \mathrm{MHz}, \mathrm{CDCl}_{3}+\mathrm{CD}_{3} \mathrm{OD}\right) \delta 7.74(\mathrm{~s}, 1 \mathrm{H}), 7.33-7.32(\mathrm{~m}, 2 \mathrm{H})$, $3.76(\mathrm{t}, J=6.7,6.7 \mathrm{~Hz}, 2 \mathrm{H}), 2.87(\mathrm{t}, J=6.6,6.6 \mathrm{~Hz}, 2 \mathrm{H}), 1.47(\mathrm{~s}, 9 \mathrm{H})(\mathrm{NH}$ and $\mathrm{OH}$ not observed); LRMS $\mathrm{m} / \mathrm{z}$ calcd for $\mathrm{C}_{14} \mathrm{H}_{18} \mathrm{~N}_{2} \mathrm{NaO}_{4}(\mathrm{M}+\mathrm{Na})^{+} 301.1$, found 301.0 . 
4-(2-(3-Aminobenzo[d]isoxazol-5-yl)ethoxy)-2,5-difluoro-N-(1,2,4-thiadiazol-5-yl)benzenesulfonamide (21). Step 1. To a cold $(0 \stackrel{\circ}{\circ} \mathrm{C})$ mixture of $\mathbf{S} 32(0.120 \mathrm{~g}, 0.43$ $\mathrm{mmol}$ ) in anhydrous DMF ( $3 \mathrm{~mL})$ was added a $1.0 \mathrm{M}$ solution of LHMDS in THF (1.3 mL, $1.3 \mathrm{mmol})$. The reaction mixture was stirred for $1 \mathrm{~h}$ at $0 \stackrel{\circ}{\circ} \mathrm{C}$ and then allowed to warm to ambient temperature. To it was then added sulfonamide $9(0.211 \mathrm{~g}, 0.47 \mathrm{mmol})$ in one portion. The reaction mixture was stirred for $1 \mathrm{~h}$ at ambient temperature and then quenched by addition of saturated $\mathrm{NH}_{4} \mathrm{Cl}$ solution $(5 \mathrm{~mL})$. The mixture was extracted with EtOAc $(3 \times 20 \mathrm{~mL})$, and the organic phase was washed with water $(2 \times 5 \mathrm{~mL})$, brine $(2 \times 5 \mathrm{~mL})$, and dried over anhydrous $\mathrm{Na}_{2} \mathrm{SO}_{4}$. After concentration in vacuo, the obtained residue was purified by column chromatography (10-100\% EtOAc in hexanes) to afford tert-butyl (5-(2-(4-(N-(2,4-dimethoxybenzyl)- $N$-(1,2,4-thiadiazol-5-yl)sulfamoyl)2,5-difluorophenoxy)ethyl)benzo[d] isoxazol-3-yl)carbamate as an off-white solid in 84\% yield $(0.256 \mathrm{~g})$. LRMS $\mathrm{m} / z$ calcd for $\mathrm{C}_{31} \mathrm{H}_{32} \mathrm{~F}_{2} \mathrm{~N}_{5} \mathrm{O}_{8} \mathrm{~S}_{2}(\mathrm{M}+\mathrm{H})^{+} 704.2$, found 703.9. Step 2. To a mixture of the product from step 1 in $\mathrm{CH}_{2} \mathrm{Cl}_{2}(4 \mathrm{~mL})$ was added TFA $(0.4 \mathrm{~mL})$ and the reaction mixture was stirred at ambient temperature for $2 \mathrm{~h}$. Concentration in vacuo provided a residue which was purified by column chromatography $(0-20 \% \mathrm{MeOH}$ in $\mathrm{CH}_{2} \mathrm{Cl}_{2}$ ) followed by lyophilization from water to afford 21 as an off-white solid in $70 \%$ yield $(0.115 \mathrm{~g})$. ${ }^{1} \mathrm{H}$ NMR $\left(300 \mathrm{MHz}\right.$, DMSO- $\left.d_{6}\right) \delta 8.35(\mathrm{~s}, 1 \mathrm{H}), 7.68(\mathrm{~d}, J=0.9 \mathrm{~Hz}, 1 \mathrm{H})$, $7.54(\mathrm{dd}, J=10.5,6.7 \mathrm{~Hz}, 1 \mathrm{H}), 7.45(\mathrm{dd}, J=8.6,1.7 \mathrm{~Hz}, 1 \mathrm{H}), 7.38-7.30(\mathrm{~m}, 2 \mathrm{H}), 6.31$ (br s, 2H), 4.33 (t, $J=6.8 \mathrm{~Hz}, 2 \mathrm{H}$ ), $3.12(\mathrm{t}, J=6.7 \mathrm{~Hz}, 2 \mathrm{H}$ ), (sulfonamide $\mathrm{NH}$ not oberved); ${ }^{13} \mathrm{C}$ NMR $\left(75 \mathrm{MHz}\right.$, DMSO- $\left.d_{6}\right) \delta 179.7,160.9,158.3,155.2$ (dd, $J=250.3,2.2$ $\mathrm{Hz}), 150.7(\mathrm{dd}, J=11.9,10.9 \mathrm{~Hz}), 149.8,146.5(\mathrm{dd}, J=244.2,2.7 \mathrm{~Hz}), 131.3,131.0$, 121.5, 120.7 (dd, $J=17.9,5.2 \mathrm{~Hz}$ ), 116.9, 115.2 (dd, $J=22.9,2.4 \mathrm{~Hz}), 109.2,104.3$ (d, $J=27.7 \mathrm{~Hz}), 70.3,34.0 .{ }^{19} \mathrm{~F} \mathrm{NMR}\left(282 \mathrm{MHz}\right.$, DMSO- $\left.d_{6}\right) \delta-110.6(\mathrm{~d}, J=15.2 \mathrm{~Hz}, 1 \mathrm{~F}),-$ $138.4(\mathrm{~d}, J=15.3 \mathrm{~Hz}, 1 \mathrm{~F})$; HRMS $\mathrm{m} / z$ calcd for $\mathrm{C}_{17} \mathrm{H}_{14} \mathrm{~F}_{2} \mathrm{~N}_{5} \mathrm{O}_{4} \mathrm{~S}_{2}(\mathrm{M}+\mathrm{H})^{+}$454.0450, found 454.0457.

\subsection{Synthesis of Compound 22.}

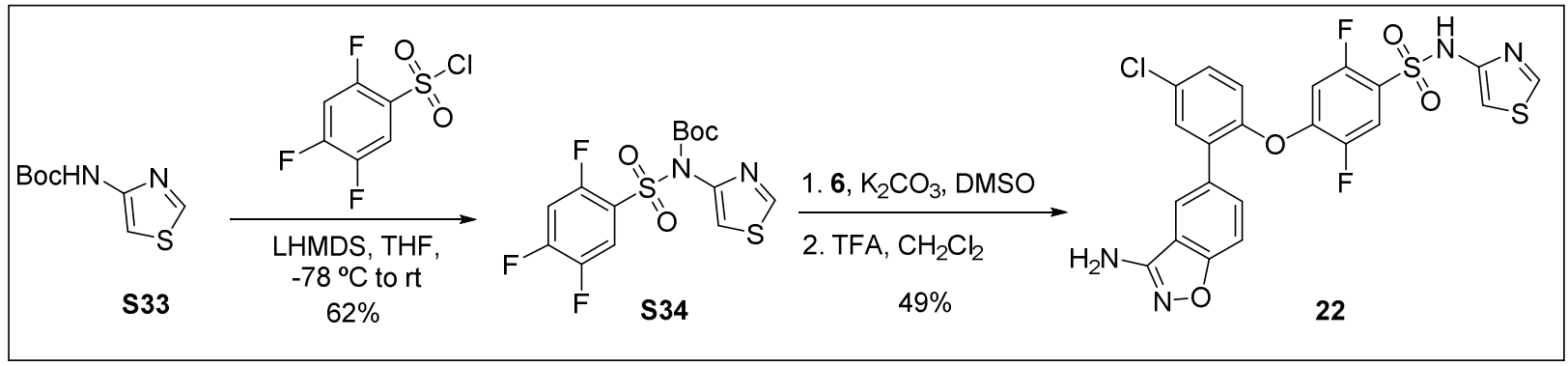

tert-Butyl thiazol-4-yl((2,4,5-trifluorophenyl)sulfonyl)carbamate (S34). A cold (at -78 ${ }^{\circ}$ C) solution of tert-butyl thiazol-4-ylcarbamate (S33) $(3.46 \mathrm{~g}, 17.3 \mathrm{mmol})$ in anhydrous THF $(150 \mathrm{~mL})$ was treated with a $1.0 \mathrm{M}$ solution of LHMDS in THF $(20.8 \mathrm{~mL}, 20.8$ $\mathrm{mmol})$. The resulting mixture was stirred at $-78{ }^{\circ} \mathrm{C}$ for $0.5 \mathrm{~h}$, allowed to warm to ambient 
temperature and stirred for a further $0.5 \mathrm{~h}$. The reaction mixture was cooled to $-78 \stackrel{\circ}{\circ} \mathrm{C}$, and a solution of 2,4,5-trifluorobenzene-1-sulfonyl chloride $(3.99 \mathrm{~g}, 17.3 \mathrm{mmol})$ in anhydrous THF $(30 \mathrm{~mL})$ was added to it. The resulting mixture was stirred at $-78{ }^{\circ} \mathrm{C}$ for $4 \mathrm{~h}$, allowed to warm to ambient temperature and stirred for $16 \mathrm{~h}$. The reaction mixture was diluted with EtOAc $(300 \mathrm{~mL})$, washed with saturated aqueous $\mathrm{NH}_{4} \mathrm{Cl}$ solution $(2 \mathrm{x}$ $150 \mathrm{~mL})$, brine $(2 \times 150 \mathrm{~mL})$, and dried over anhydrous $\mathrm{Na}_{2} \mathrm{SO}_{4}$. Concentration in vacuo provided a residue which was purified by column chromatography (EtOAc in hexanes) to afford S34 as a beige solid in $62 \%$ yield $(4.23 \mathrm{~g}) .{ }^{1} \mathrm{H}$ NMR $(300 \mathrm{MHz}$, $\left.\mathrm{CDCl}_{3}\right) \delta 8.79-8.75(\mathrm{~m}, 1 \mathrm{H}), 8.06-7.96(\mathrm{~m}, 1 \mathrm{H}), 7.53-7.48(\mathrm{~m}, 1 \mathrm{H}), 7.15-7.04(\mathrm{~m}, 1 \mathrm{H})$, $1.34(\mathrm{~s}, 9 \mathrm{H})$; LRMS $\mathrm{m} / z$ calcd for $\mathrm{C}_{14} \mathrm{H}_{14} \mathrm{~F}_{3} \mathrm{~N}_{2} \mathrm{O}_{4} \mathrm{~S}_{2}(\mathrm{M}+\mathrm{H})^{+} 395.0$, found 394.7 .

4-(2-(3-Aminobenzo[d]isoxazol-5-yl)-4-chlorophenoxy)-2,5-difluoro-N-(thiazol-4-

$y$ l)benzenesulfonamide (22). Following the procedure as described for the synthesis of $\mathbf{3}$ and making non-critical variations using S34 to replace sulfonamide $\mathbf{9}$, compound 22 was obtained as a colorless solid in $49 \%$ yield over 2 steps $(0.35 \mathrm{~g}) .{ }^{1} \mathrm{H}$ NMR (300 $\left.\mathrm{MHz}, \mathrm{DMSO}-\mathrm{d}_{6}\right) \delta 11.36(\mathrm{br} \mathrm{s}, 1 \mathrm{H}), 8.82(\mathrm{~d}, J=1.9 \mathrm{~Hz}, 1 \mathrm{H}), 7.94(\mathrm{~d}, J=1.3 \mathrm{~Hz}, 1 \mathrm{H})$, 7.67 (dd, $J=10.1,6.4 \mathrm{~Hz}, 1 \mathrm{H}$ ), 7.61-7.55 (m, 2H), 7.48 (dd, $J=8.5,2.5 \mathrm{~Hz}, 1 \mathrm{H}$ ), 7.41 $(\mathrm{d}, J=8.8 \mathrm{~Hz}, 1 \mathrm{H}), 7.26(\mathrm{~d}, J=8.8 \mathrm{~Hz}, 1 \mathrm{H}), 7.05(\mathrm{dd}, J=10.7,6.4 \mathrm{~Hz}, 1 \mathrm{H}), 6.98(\mathrm{~d}, J=$ $2.0 \mathrm{~Hz}, 1 \mathrm{H}), 6.44(\mathrm{~s}, 2 \mathrm{H}) ;{ }^{13} \mathrm{C}$ NMR $\left(75 \mathrm{MHz}\right.$, DMSO- $\left.d_{6}\right) \delta 161.3,158.5,154.6$ (dd, $J=$ 253.7, $2.4 \mathrm{~Hz}$ ), 153.2, 149.9, 148.7 (dd, $J=12.4,10.6 \mathrm{~Hz}$ ), 147.3 (dd, $J=247.2,2.9$ $\mathrm{Hz}), 146.5,134.1,131.0,130.6,129.8,129.2,128.9,122.2,122.2-122.0(\mathrm{~m}), 121.9$, $117.9(\mathrm{~d}, J=22.7 \mathrm{~Hz}), 117.1,109.2,108.2(\mathrm{~d}, J=27.2 \mathrm{~Hz}), 104.3$; HRMS $\mathrm{m} / \mathrm{z}$ calcd for $\mathrm{C}_{22} \mathrm{H}_{14} \mathrm{ClF}_{2} \mathrm{~N}_{4} \mathrm{O}_{4} \mathrm{~S}_{2}(\mathrm{M}+\mathrm{H})^{+} 535.0108$, found 535.0115 .

\subsection{Synthesis of Compound 23.}

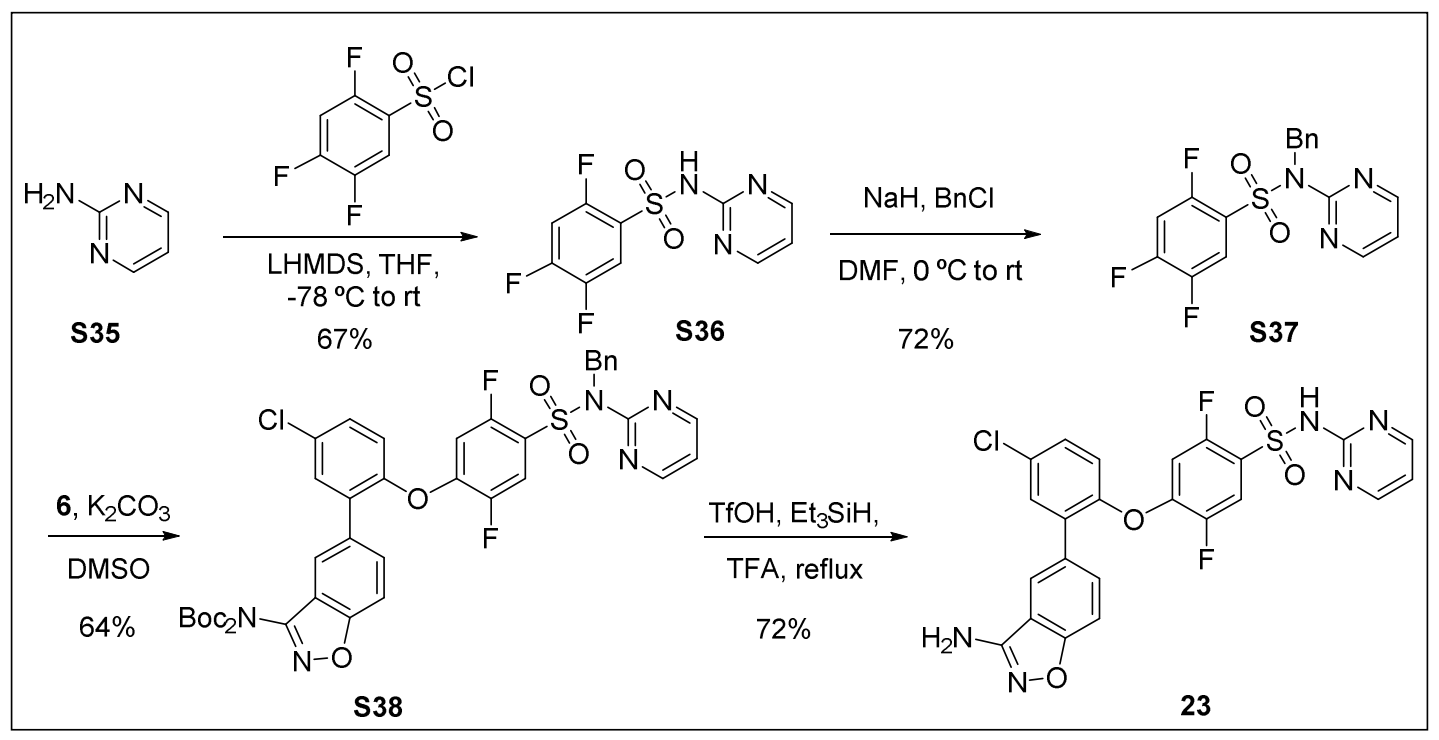


2,4,5-Trifluoro- $N$-(pyrimidin-2-yl)benzenesulfonamide (S36). To a cold $\left(0^{0} \mathrm{C}\right)$ solution of 2-aminopyrimidine (S35) $(10.1 \mathrm{~g}, 10.5 \mathrm{mmol})$ in anhydrous THF (150 mL) was added a $1.0 \mathrm{M}$ solution of LHMDS in THF $(15 \mathrm{~mL}, 15 \mathrm{mmol})$ and the reaction mixture was stirred for $0.5 \mathrm{~h}$. The reaction mixture was cooled to $-78{ }^{\circ} \mathrm{C}$, and a solution of 2,4,5-trifluorobenzene-1-sulfonyl chloride $(10.1 \mathrm{mmol})$ in anhydrous THF $(100 \mathrm{~mL})$ was added to it. The reaction mixture was allowed to warm to ambient temperature and stirred for $16 \mathrm{~h}$. The mixture was diluted with EtOAc $(150 \mathrm{~mL})$, washed with $\mathrm{NH}_{4} \mathrm{Cl}$ solution $(3 \times 50 \mathrm{~mL})$, brine $(3 \times 50 \mathrm{~mL})$, and dried over $\mathrm{Na}_{2} \mathrm{SO}_{4}$. After concentration in vacuo, the residue was triturated with $\mathrm{Et}_{2} \mathrm{O}$ to afford $\mathbf{S} 36$ as pale yellow solid in $67 \%$ yield $(19.5 \mathrm{~g}) .{ }^{1} \mathrm{H}$ NMR $\left(300 \mathrm{MHz}\right.$, DMSO- $\left.d_{6}\right) \delta 12.88(\mathrm{br} \mathrm{s}, 1 \mathrm{H}), 8.51(\mathrm{~d}, J=5.0 \mathrm{~Hz}$, 2H), 8.00 (ddd, $J=9.6,8.9,6.6 \mathrm{~Hz}, 1 \mathrm{H}$ ), 7.76 (ddd, $J=10.2,10.2,6.3 \mathrm{~Hz}, 1 \mathrm{H}$ ), 7.03 (t, $J=5.0 \mathrm{~Hz}, 1 \mathrm{H}) ;{ }^{19} \mathrm{~F} \mathrm{NMR}\left(282 \mathrm{MHz}\right.$, DMSO- $\left.d_{6}\right) \delta-111.1(\mathrm{dd}, J=15.7,8.6 \mathrm{~Hz}, 1 \mathrm{~F}),-$ 126.3-126.6 (m, 1F), -141.2 (dd, $J=22.4,15.8 \mathrm{~Hz}, 1 \mathrm{~F})$; LRMS $\mathrm{m} / \mathrm{z}$ calcd for $\mathrm{C}_{10} \mathrm{H}_{7} \mathrm{~F}_{3} \mathrm{~N}_{3} \mathrm{O}_{2} \mathrm{~S}(\mathrm{M}+\mathrm{H})^{+} 290.0$, found 290.1 .

$N$-Benzyl-2,4,5-trifluoro-N-(pyrimidin-2-yl)benzenesulfonamide (S37). To a cold (0 $\left.{ }^{\circ} \mathrm{C}\right)$ solution of $\mathbf{S} 36(1.00 \mathrm{~g}, 3.46 \mathrm{mmol})$ in anhydrous DMF $(10 \mathrm{~mL})$ was added $\mathrm{NaH}$ $(0.20 \mathrm{~g}, 5.19 \mathrm{mmol}, 60 \%$ dispersion in oil), the reaction mixture was stirred for $0.5 \mathrm{~h}$, and benzyl chloride $(0.65 \mathrm{~g}, 5.1 \mathrm{mmol})$ was added to it. The reaction mixture was allowed to warm to ambient temperature, and stirred for $16 \mathrm{~h}$. The mixture was diluted with EtOAc $(100 \mathrm{~mL})$, washed with brine $(3 \times 25 \mathrm{~mL})$, and dried over anhydrous $\mathrm{Na}_{2} \mathrm{SO}_{4}$. After concentration in vacuo, the residue was triturated with $\mathrm{Et}_{2} \mathrm{O}$ to afford the S37 as beige solid in $72 \%$ yield $(0.95 \mathrm{~g})$. ${ }^{1} \mathrm{H}$ NMR $\left(300 \mathrm{MHz}\right.$, DMSO- $\left.d_{6}\right) \delta 8.53-8.51$ $(\mathrm{m}, 2 \mathrm{H}), 8.18-8.09(\mathrm{~m}, 1 \mathrm{H}), 7.89-7.81(\mathrm{~m}, 1 \mathrm{H}), 7.41-7.28(\mathrm{~m} \mathrm{4H}), 7.26-7.18(\mathrm{~m}, 1 \mathrm{H})$, 7.14-7.11 (m, $1 \mathrm{H}), 5.37(\mathrm{~s}, 2 \mathrm{H})$; LRMS $\mathrm{m} / z$ calcd for $\mathrm{C}_{17} \mathrm{H}_{13} \mathrm{~F}_{3} \mathrm{~N}_{3} \mathrm{O}_{2} \mathrm{~S}(\mathrm{M}+\mathrm{H})^{+} 380.1$, found 380.0 .

di-tert-Butyl (5-(2-(4-(N-benzyl-N-(pyrimidin-2-yl)sulfamoyl)-2,5-difluorophenoxy)-5chlorophenyl)benzo[d]isoxazol-3-yl)imidodicarbonate (S38). To a mixture of phenol 6 (1.99 g, $4.32 \mathrm{mmol}$ ) and sulfonamide $\mathbf{S} 37$ (1.90 g, $5.01 \mathrm{mmol})$ in anhydrous DMSO (15 $\mathrm{mL}$ ) was added potassium carbonate $(1.20 \mathrm{~g}, 8.68 \mathrm{mmol})$ and the reaction mixture was stirred at ambient temperature for $5 \mathrm{~h}$. Saturated $\mathrm{NaHCO}_{3}$ solution $(50 \mathrm{~mL})$ was added to it, and the mixture was extracted with $\mathrm{Et}_{2} \mathrm{O}(2 \times 200 \mathrm{~mL})$. The combined organic phase was dried over $\mathrm{MgSO}_{4}$, and concentrated in vacuo. Purification of the residue by column chromatography $(0-30 \%$ EtOAc in hexanes) to afford $\mathbf{S 3 8}$ as a colorless, amorphous solid in $64 \%$ yield $(2.27 \mathrm{~g})$. ${ }^{1} \mathrm{H}$ NMR $\left(300 \mathrm{MHz}, \mathrm{CDCl}_{3}\right) \delta 8.31-8.29(\mathrm{~m}, 2 \mathrm{H})$, $7.84(\mathrm{dd}, J=6.4,9.8 \mathrm{~Hz}, 1 \mathrm{H}), 7.67-7.63(\mathrm{~m}, 2 \mathrm{H}), 7.52-7.49(\mathrm{~m}, 1 \mathrm{H}), 7.46-7.42(\mathrm{~m}, 3 \mathrm{H})$, 7.40-7.36 (m, 1H), 7.31-7.29 (m, 1H), 7.26-7.22 (m, 2H), $7.05(\mathrm{~d}, J=8.6 \mathrm{~Hz}, 1 \mathrm{H})$, 6.88-6.85 (m, 1H), $6.38(\mathrm{dd}, J=6.2,10.2 \mathrm{~Hz}, 1 \mathrm{H}), 5.39(\mathrm{~s}, 2 \mathrm{H}), 1.38(\mathrm{~s}, 18 \mathrm{H})$; LRMS $\mathrm{m} / \mathrm{z}$ calcd for $\mathrm{C}_{40} \mathrm{H}_{37} \mathrm{ClF}_{2} \mathrm{~N}_{5} \mathrm{O}_{8} \mathrm{~S}(\mathrm{M}+\mathrm{H})^{+} 820.2$, found 819.7 . 
4-(2-(3-Aminobenzo[d]isoxazol-5-yl)-4-chlorophenoxy)-2,5-difluoro-N-(pyrimidin-2$y$ l)benzenesulfonamide (23). To a solution of $\mathbf{S 3 8}(2.03 \mathrm{~g}, 2.47 \mathrm{mmol})$ in TFA (50 mL) was added triethylsilane $(2.0 \mathrm{~mL}, 13 \mathrm{mmol})$ and trifluoromethanesulfonic acid $(0.5 \mathrm{~mL})$ and the reaction mixture was heated at reflux for $5 \mathrm{~h}$. After cooling to ambient temperature and concentrating the mixture in vacuo, the obtained residue was triturated in $\mathrm{Et}_{2} \mathrm{O}(40 \mathrm{~mL})$ to afford 23 as an off-white solid in $72 \%$ yield $(0.95 \mathrm{~g}) .{ }^{1} \mathrm{H}$ NMR (300 $\left.\mathrm{MHz}, \mathrm{DMSO}-d_{6}\right) \delta 8.38(\mathrm{~d}, J=5.1 \mathrm{~Hz}, 2 \mathrm{H}), 7.92(\mathrm{~m}, 1 \mathrm{H}), 7.75(\mathrm{dd}, J=10.2,6.5 \mathrm{~Hz}, 1 \mathrm{H})$, 7.60-7.56 (m, 2H), $7.48(\mathrm{dd}, J=8.7,2.7 \mathrm{~Hz}, 1 \mathrm{H}), 7.38(\mathrm{~d}, J=8.7 \mathrm{~Hz}, 1 \mathrm{H}), 7.27(\mathrm{~d}, J=$ $8.7 \mathrm{~Hz}, 1 \mathrm{H}), 7.00-6.93(\mathrm{~m}, 2 \mathrm{H}), 6.47-6.36(\mathrm{~m}, 2 \mathrm{H})$, (sulfonamide $\mathrm{NH}$ not observed); ${ }^{19} \mathrm{~F}$ NMR (282 MHz, DMSO- $\left.d_{6}\right) \delta-112.4(\mathrm{~d}, J=16.4 \mathrm{~Hz}, 1 \mathrm{~F}),-137.9(\mathrm{~d}, J=16.4 \mathrm{~Hz}, 1 \mathrm{~F})$; HRMS $\mathrm{m} / \mathrm{z}$ calcd for $\mathrm{C}_{23} \mathrm{H}_{15} \mathrm{ClF}_{2} \mathrm{~N}_{5} \mathrm{O}_{4} \mathrm{~S}(\mathrm{M}+\mathrm{H})^{+} 530.0496$, found 530.0502 .

\subsection{Synthesis of Compound 24.}

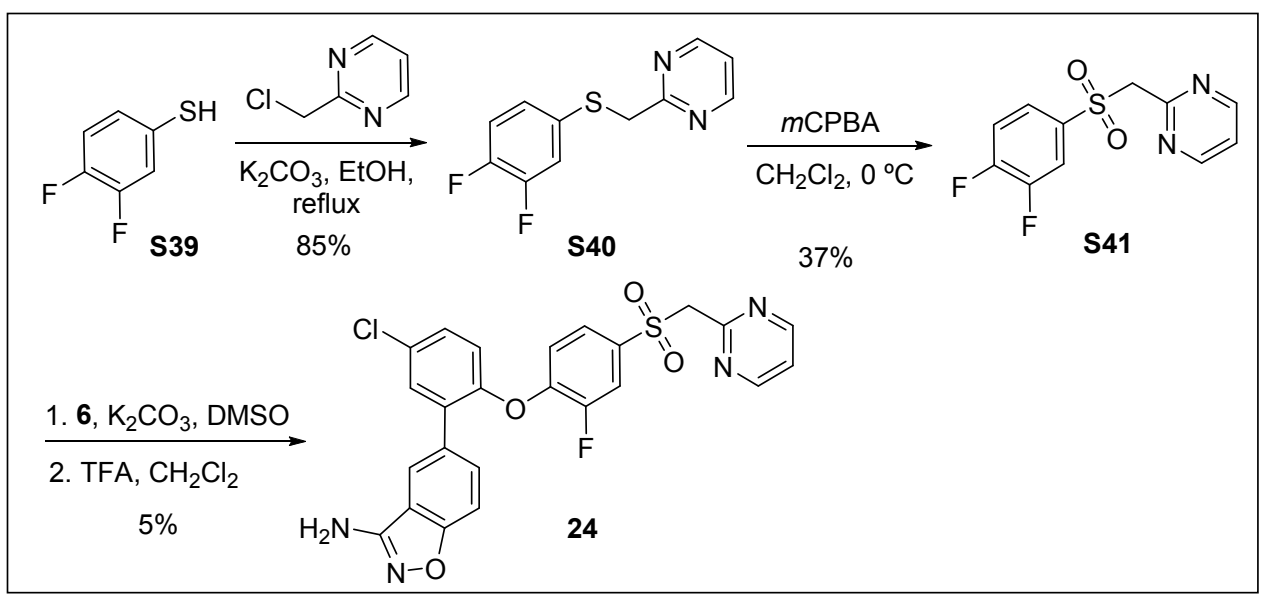

2-(((3,4-Difluorophenyl)thio)methyl)pyrimidine (S40). To a mixture of 2(chloromethyl)pyrimidine hydrochloride $(12.2 \mathrm{~g}, 73.9 \mathrm{mmol})$ and $\mathrm{K}_{2} \mathrm{CO}_{3}(27.9 \mathrm{~g}, 201.6$ $\mathrm{mmol}$ ) in anhydrous ethanol $(150 \mathrm{~mL})$ was added with 3,4-difluorobenzenethiol (S39) $(7.4 \mathrm{~mL}, 67.2 \mathrm{mmol})$ and the reaction mixture was heated under reflux for $18 \mathrm{~h}$. After cooling to ambient temperature, the solid was filtered off and the filtrate was concentrated in vacuo. The residue was dissolved in EtOAc $(250 \mathrm{~mL})$, washed with saturated ammonium chloride $(2 \times 75 \mathrm{~mL})$, brine $(75 \mathrm{~mL})$, dried over anhydrous sodium sulfate, and concentrated in vacuo. Purification by column chromatography $(0-75 \%$ EtOAc in hexanes) provided $\mathbf{S} 40$ as a colorless oil in $85 \%$ yield $(13.6 \mathrm{~g}) .{ }^{1} \mathrm{H}$ NMR $(300$ $\left.\mathrm{MHz}, \mathrm{CDCl}_{3}\right) \delta 8.66(\mathrm{~d}, J=5.1 \mathrm{~Hz}, 2 \mathrm{H}), 7.26-7.18(\mathrm{~m}, 1 \mathrm{H}), 7.15(\mathrm{dd}, J=5.0 \mathrm{~Hz}, 1 \mathrm{H})$, 7.11-7.05 (m, 1H), 7.05-9.95 (m, 1H), $4.29(\mathrm{~s}, 2 \mathrm{H})$; LRMS $\mathrm{m} / z$ calcd for $\mathrm{C}_{11} \mathrm{H}_{9} \mathrm{~F}_{2} \mathrm{~N}_{2} \mathrm{~S}$ $(\mathrm{M}+\mathrm{H})^{+}$239.0, found 239.0 .

2-(((3,4-Difluorophenyl)sulfonyl)methyl)pyrimidine (S41). To a cold $\left(0{ }^{\circ} \mathrm{C}\right)$ solution of S40 (11.6 g, $48.7 \mathrm{mmol})$ in $\mathrm{CH}_{2} \mathrm{Cl}_{2}(250 \mathrm{~mL})$ was added $77 \%$ m-chloroperoxybenzoic acid $(16.4 \mathrm{~g}, 73.1 \mathrm{mmol})$. The resulting mixture was stirred for $18 \mathrm{~h}$ and then 
concentrated in vacuo. The residue was diluted with ethyl acetate $(250 \mathrm{~mL})$, washed with $1 \mathrm{M}$ sodium hydroxide $(3 \times 100 \mathrm{~mL})$, brine $(3 \times 75 \mathrm{~mL})$, dried over anhydrous sodium sulfate, and concentrated in vacuo. The residue was purified by flash chromatography (15-100\% EtOAc in hexanes) to afford $\mathbf{S 4 1}$ as a colorless solid in $37 \%$ yield $(4.9 \mathrm{~g})$. ${ }^{1} \mathrm{H}$ NMR $\left(300 \mathrm{MHz}, \mathrm{CDCl}_{3}\right) \delta 8.66(\mathrm{~d}, J=5.1 \mathrm{~Hz}, 2 \mathrm{H}), 7.60-4.86(\mathrm{~m}, 2 \mathrm{H})$, 7.31-7.21 (m, 2H), $4.72(\mathrm{~s}, 2 \mathrm{H})$; LRMS $\mathrm{m} / \mathrm{z}$ calcd for $\mathrm{C}_{11} \mathrm{H}_{9} \mathrm{~F}_{2} \mathrm{~N}_{2} \mathrm{O}_{2} \mathrm{~S}(\mathrm{M}+\mathrm{H})^{+}$271.0, found 271.0 .

5-(5-Chloro-2-(2-fluoro-4-((pyrimidin-2-ylmethyl)sulfonyl)phenoxy)phenyl)benzo[d]isoxazol-3-amine (24). A mixture of $\mathbf{S 4 1}(0.18 \mathrm{~g}, 0.65 \mathrm{mmol}), 6(0.30 \mathrm{~g}, 0.65 \mathrm{mmol})$ and potassium carbonate $(0.27 \mathrm{~g}, 1.95 \mathrm{mmol})$ in anhydrous dimethylformamide $(4.0 \mathrm{~mL})$ was heated to $80{ }^{\circ} \mathrm{C}$ for $3 \mathrm{~h}$. The reaction mixture was diluted with ethyl acetate (50 $\mathrm{mL})$, washed with saturated ammonium chloride $(2 \times 30 \mathrm{~mL})$, dried over anhydrous sodium sulfate, and concentrated in vacuo. The residue was dissolved in $\mathrm{CH}_{2} \mathrm{Cl}_{2}(5 \mathrm{~mL})$ and TFA $(5 \mathrm{~mL})$ was added to it. The resulting mixture was stirred at ambient temperature for $2 \mathrm{~h}$ and then concentrated in vacuo. The residue was purified by preparative HPLC (Waters XBridge, C18, $5 \mu \mathrm{m}, 30 \times 50 \mathrm{~mm}, 15-95 \% \mathrm{CH}_{3} \mathrm{CN}$ in water containing $0.1 \%$ TFA) to provide 24 as a colorless solid in $5 \%$ yield $(0.017 \mathrm{~g})$. ${ }^{1} \mathrm{H}$ NMR $\left(300 \mathrm{MHz}, \mathrm{DMSO}-\mathrm{d}_{6}\right) \delta 8.58(\mathrm{~d}, J=4.8 \mathrm{~Hz}, 2 \mathrm{H}), 7.98-7.96(\mathrm{~m}, 1 \mathrm{H}), 7.71-7.60(\mathrm{~m}, 3 \mathrm{H})$, $7.53(\mathrm{dd}, J=8.6,2.5 \mathrm{~Hz}, 1 \mathrm{H}), 7.46(\mathrm{~d}, J=8.9 \mathrm{~Hz}, 1 \mathrm{H}), 7.39-7.30(\mathrm{~m}, 2 \mathrm{H}), 7.22(\mathrm{~d}, J=$ $8.8 \mathrm{~Hz}, 1 \mathrm{H}), 7.00-6.93(\mathrm{~m}, 1 \mathrm{H}), 6.47(\mathrm{br} \mathrm{s}, 2 \mathrm{H}), 4.88(\mathrm{~s}, 2 \mathrm{H})$; LRMS $\mathrm{m} / \mathrm{z}$ calcd for $\mathrm{C}_{24} \mathrm{H}_{17} \mathrm{CIFN}_{4} \mathrm{O}_{4} \mathrm{~S}(\mathrm{M}+\mathrm{H})^{+} 511.1$, found 510.8 .

\subsection{HPLC Purity Check of Final Compounds}

Purity was determined by HPLC analysis on Agilent 1100, 1200, or 1260 systems (Agilent Technologies) using an Xbridge C-18 column $(5 \mu \mathrm{m}, 4.6 \times 50 \mathrm{~mm}$, Waters Corporation) with a gradient of $\mathrm{CH}_{3} \mathrm{CN}$ in water containing $0.1 \%$ TFA at a flow rate of $1.0 \mathrm{~mL} / \mathrm{min}$ at $25{ }^{\circ} \mathrm{C}: 5 \% \mathrm{CH}_{3} \mathrm{CN}$ for $1 \mathrm{~min}, 5 \%$ to $95 \% \mathrm{CH}_{3} \mathrm{CN}$ over $5 \mathrm{~min}, 95 \% \mathrm{CH}_{3} \mathrm{CN}$ for 3 min. Peaks were detected at a wavelength of 254 or $280 \mathrm{~nm}$ with an Agilent photodiode array detector. The retention times vary by about $0.1 \mathrm{~min}$ between the different HPLC systems (Agilent 1100, 1200, or 1260). 


\begin{tabular}{|l|l|c|}
\hline Compound & RT $(\mathbf{m i n})$ & Purity (\%) \\
\hline $\mathbf{2}$ & 4.59 & 98 \\
\hline $\mathbf{3}$ & 5.62 & 97 \\
\hline $\mathbf{1 0}$ & 5.95 & 95 \\
\hline $\mathbf{1 1}$ & 4.97 & 99 \\
\hline $\mathbf{1 2}$ & 4.85 & $>99$ \\
\hline $\mathbf{1 3}$ & 4.56 (broad) & 97 \\
\hline $\mathbf{1 4}$ & 5.92 & $>99$ \\
\hline $\mathbf{1 5}$ & 4.93 & $>99$ \\
\hline $\mathbf{1 6}$ & 4.94 & $>99$ \\
\hline $\mathbf{1 7}$ & 5.34 & 99 \\
\hline $\mathbf{1 8}$ & 5.30 & 98 \\
\hline $\mathbf{1 9}$ & 5.54 & 98 \\
\hline $\mathbf{2 0}$ & 5.17 & 96 \\
\hline $\mathbf{2 1}$ & 5.06 & 91 \\
\hline $\mathbf{2 2}$ & 5.90 & $>99$ \\
\hline $\mathbf{2 3}$ & 5.45 & 96 \\
\hline $\mathbf{2 4}$ & 5.49 & 97 \\
\hline
\end{tabular}

For selected compounds, purity check was also performed using a high $\mathrm{pH}$ method: Gemini NX C-18 column ( $3 \mu \mathrm{m}, 4.6 \times 150 \mathrm{~mm}$, Phenomenex) with a gradient of $\mathrm{CH}_{3} \mathrm{CN}$ in water containing $0.1 \% \mathrm{NH}_{4} \mathrm{OH}$ at a flow rate of $1.0 \mathrm{~mL} / \mathrm{min}$ at $25{ }^{\circ} \mathrm{C}: 10 \% \mathrm{CH}_{3} \mathrm{CN}$ for 2 min, $10 \%$ to $80 \% \mathrm{CH}_{3} \mathrm{CN}$ over $16 \mathrm{~min}, 95 \% \mathrm{CH}_{3} \mathrm{CN}$ for $4 \mathrm{~min}$.

\begin{tabular}{|l|l|l|}
\hline Compound & RT (min) & Purity (\%) \\
\hline $\mathbf{1 3}$ & 8.98 & 96 \\
\hline
\end{tabular}

Compounds that were used for advanced profiling and in vivo studies were checked for purity by a longer HPLC method using a Gemini NX C-18 column $(5 \mu \mathrm{m}, 4.6 \times 150 \mathrm{~mm}$, Phenomenex) with a gradient of $\mathrm{CH}_{3} \mathrm{CN}$ in water containing $0.1 \%$ TFA at a flow rate of $1.0 \mathrm{~mL} / \mathrm{min}$ at $25 \stackrel{\circ}{\circ} \mathrm{C}: 5 \% \mathrm{CH}_{3} \mathrm{CN}$ for $2 \mathrm{~min}, 5 \%$ to $95 \% \mathrm{CH}_{3} \mathrm{CN}$ over $40 \mathrm{~min}$.

\begin{tabular}{|l|l|l|}
\hline Compound & RT (min) & Purity (\%) \\
\hline 3a & 24.86 & 98 \\
\hline $\mathbf{1 6}$ & 23.04 & 99 \\
\hline
\end{tabular}

\section{Voltage-Clamp Whole Cell Recordings and Cell Lines}

Nav1.x cell lines: cDNA sequences encoding the full-length human sodium channel $\alpha-$ subunit were cloned into an expression vector and permanently transfected into human embryonic kidney cells (HEK) and grown in culture media containing $10 \% \mathrm{FBS}, 1 \%$ 
PSG, and $0.5 \mathrm{mg} / \mathrm{mL} \mathrm{G418}$ at $37{ }^{\circ} \mathrm{C}$ with $5 \% \mathrm{CO}_{2}$. The human sodium channel $\beta 1$ subunit was co-expressed in all these cell lines except $\mathrm{Nav}_{v} 1.8$ (which was co-expressed with the human sodium channel $\beta 3$ subunit). The neuronal CAD cell was used to assess endogenous mouse NaV1.7 currents. ${ }^{1}$ Macroscopic sodium currents were recorded in the whole-cell configuration using either the PatchXpress ${ }^{\circledR}$ (PX, Molecular Devices, Sunnyvale, CA) or QPatch HT (Sophion A/S, Copenhagen, Denmark) automated voltage clamp device.

For the majority of $\mathrm{Nav}_{v}$ cell line studies (except $\mathrm{Nav}_{1} 1.8$ ), the intracellular solution comprised $5 \mathrm{mM} \mathrm{NaCl}, 10 \mathrm{mM} \mathrm{CsCl}, 120 \mathrm{mM} \mathrm{CsF}, 0.1 \mathrm{mM} \mathrm{CaCl}, 2 \mathrm{mM} \mathrm{MgCl}_{2}, 10 \mathrm{mM}$ HEPES, $10 \mathrm{mM}$ EGTA (adjusted to $\mathrm{pH} 7.2$ with $\mathrm{CsOH}$ ), while the extracellular solution comprised $140 \mathrm{mM} \mathrm{NaCl}, 5 \mathrm{mM} \mathrm{KCl}, 2 \mathrm{mM} \mathrm{CaCl}, 1 \mathrm{mM} \mathrm{MgCl}, 10 \mathrm{mM}$ HEPES (adjusted to $\mathrm{pH} 7.4$ with $\mathrm{NaOH}$ ). Generally, the external sodium was reduced by equimolar replacement with choline.

For $\mathrm{Na}_{v} 1.8$ studies, a flipped $\mathrm{Na}^{+}$gradient was used where the intracellular solution comprised $115 \mathrm{mM} \mathrm{NaF}, 15 \mathrm{mM} \mathrm{CsCl}_{2}, 5 \mathrm{mM}$ CsF, $3 \mathrm{mM} \mathrm{Na}{ }_{2} \mathrm{ATP}, 0.3 \mathrm{mM} \mathrm{Na}_{2} \mathrm{GTP}$, $2 \mathrm{mM} \mathrm{MgCl} 2 \cdot \mathrm{H}_{2} \mathrm{O}, 0.1 \mathrm{mM} \mathrm{CaCl} 2,10 \mathrm{mM}$ EGTA, $10 \mathrm{mM}$ HEPES (pH 7.2 with $\mathrm{CsOH}$ ), while the extracellular solution comprised $5 \mathrm{mM} \mathrm{NaCl}, 125 \mathrm{mM}$ Choline chloride, $5 \mathrm{mM}$ $\mathrm{KCl}, 2 \mathrm{mM} \mathrm{CaCl}_{2}, 1 \mathrm{mM} \mathrm{MgCl}_{2}$ and $10 \mathrm{mM} \mathrm{HEPES}$ (adjusted to $\mathrm{pH} 7.4$ with $\mathrm{NaOH}$ ).

Osmolarity in the internal and external solutions was adjusted to $300 \mathrm{mOsm} / \mathrm{kg}$ and 310 $\mathrm{mOsm} / \mathrm{kg}$ with glucose, respectively. Currents were recorded at $40 \mathrm{kHz}$ sampling frequency, filtered at $5 \mathrm{~Hz}$, and analyzed either with DataXpress software (DX2, Molecular Devices, Sunnyvale, CA) or with QPatch Assay Software (Sophion A/S, Copenhagen, Denmark). Series resistance compensation was applied at $60-80 \%$.

The membrane potential was maintained at a holding voltage $\left(V_{\text {hold }}\right)$ where inactivation of the channel was complete. Specifically, for inactivated state block, general holding voltages were $-60 \mathrm{mV}$ (Nav1.7 and Nav1.5), $-35 \mathrm{mV}$ (Nav1.2, and Nav1.6), $-40 \mathrm{mV}$ (Nav1.1), $-50 \mathrm{mV}$ (Nav1.3), and $-20 \mathrm{mV}$ (Nav1.8). Once every second, the voltage was then stepped back to a very negative $\left(V_{\text {hold }}=-150 \mathrm{mV}\right)$ voltage for $20 \mathrm{~ms}$ and then a test pulse is applied to quantify the drug block. Compound inhibition was fitted to the hill equation $Y=C^{h} /\left(I C_{50}{ }^{h}+C^{h}\right)$ to estimate the half maximal inhibition concentration $\left(\mathrm{IC}_{50}\right.$ value); where $\mathrm{Y}$ is the normalized inhibition relative to the control, $\mathrm{C}$ the test compound concentration, $\mathrm{IC}_{50}$ the concentration of test compound to inhibit the currents $50 \%$, and $\mathrm{h}$ the Hill coefficient. 
Table 1-3 data by automated voltage clamp device:

\begin{tabular}{|c|c|c|c|c|}
\hline Cmpd & Voltage clamp device & $\mathrm{hNav1.7} \mathrm{IC}$ 50 $[\mathrm{nM}]$ & Voltage clamp device & $\mathrm{hNav1.5} \mathrm{IC}_{50}[\mathrm{nM}]$ \\
\hline 2 & PatchXpress $\AA^{a}$ & $17 \pm 6$ & PatchXpress $\AA^{a}$ & $>10,000$ \\
\hline 3 & PatchXpress $\AA^{a}$ & $0.4 \pm 0.2$ & PatchXpress $\AA^{a}$ & $1,380 \pm 668$ \\
\hline 10 & PatchXpress $\AA^{a}$ & $0.5 \pm 0.0$ & ${\text { PatchXpress } \AA^{a}}^{a}$ & $230 \pm 42$ \\
\hline 11 & ${\text { PatchXpress }{ }^{a}{ }^{a}}$ & $5.3 \pm 2.1$ & QPatch $\mathrm{HT}^{b}$ & $>10,000$ \\
\hline 12 & PatchXpress $\AA^{a}$ & $2,300 \pm 870$ & $\mathrm{~N} / \mathrm{A}$ & nd \\
\hline 13 & PatchXpress $\AA^{a}$ & $222 \pm 54$ & QPatch $\mathrm{HT}^{b}$ & $>10,000$ \\
\hline 14 & PatchXpress $\AA^{a}$ & $3.6 \pm 2.0$ & PatchXpress $\AA^{a}$ & $>10,000$ \\
\hline 15 & PatchXpress $\AA^{a}$ & $1.7 \pm 0.9$ & QPatch $\mathrm{HT}^{b}$ & $>10,000$ \\
\hline 16 & ${\text { PatchXpress } \AA^{a}}^{a}$ & $0.3 \pm 0.2$ & ${\text { PatchXpress } \AA^{a}}^{a}$ & $>10,000$ \\
\hline 17 & ${\text { PatchXpress }{ }^{a}{ }^{a}}$ & $1.7 \pm 0.5$ & PatchXpress $\AA^{a}$ & $>10,000$ \\
\hline 18 & PatchXpress $\AA^{a}$ & $3.0 \pm 0.8$ & $\mathrm{~N} / \mathrm{A}$ & nd \\
\hline 19 & ${\text { PatchXpress } \AA^{a}}^{a}$ & $1.7 \pm 0.4$ & $\mathrm{~N} / \mathrm{A}$ & nd \\
\hline 20 & PatchXpress $\AA^{a}$ & $51 \pm 11$ & $\mathrm{~N} / \mathrm{A}$ & nd \\
\hline 21 & PatchXpress $\AA^{a}$ & $241 \pm 122$ & $\mathrm{~N} / \mathrm{A}$ & nd \\
\hline 22 & PatchXpress $\AA^{a}$ & $8.7 \pm 3.6$ & $\mathrm{~N} / \mathrm{A}$ & nd \\
\hline 23 & PatchXpress $\AA^{a}$ & $4.4 \pm 0.9$ & $\mathrm{~N} / \mathrm{A}$ & nd \\
\hline 24 & QPatch $\mathrm{HT}^{b}$ & 5,200 & $\mathrm{~N} / \mathrm{A}$ & nd \\
\hline
\end{tabular}

${ }^{a} \mathrm{IC}_{50}$ values are reported as average values of two or more determinations $\pm \mathrm{SD}$, generated from a 5-point concentration response curve on an automated voltage-clamp platform; nd: not determined. ${ }^{b}$ IC50 generated from the fit of pooled data; average and SD do not apply in this case.

Table 4 and text data by automated voltage clamp device:

\begin{tabular}{|c|c|c|c|c|}
\hline \multirow[t]{2}{*}{ Nav1.x } & & Cmpd 3 & Cmpd 16 & Cmpd 14 \\
\hline & & $\mathrm{IC}_{50}[\mathrm{nM}]$ & $\mathrm{IC}_{50}[\mathrm{nM}]$ & $\mathrm{IC}_{50}[\mathrm{nM}]$ \\
\hline $\mathrm{hNa} \mathrm{N}_{\mathrm{V}} \mathrm{1.1}$ & PatchXpress $\AA^{a}$ & $3,080 \pm 1850$ & $6,380 \pm 3900$ & - \\
\hline $\mathrm{hNa} \mathrm{a}_{\mathrm{v}} 1.2$ & PatchXpress $\AA^{a}$ & $4.2 \pm 2.3$ & $0.2 \pm 0.0$ & - \\
\hline $\mathrm{hNa}$ 1.3 & PatchXpress $\AA^{a}$ & nd & $9,330 \pm 4590$ & - \\
\hline $\mathrm{hNa} \mathrm{v}_{\mathrm{v}} 1.4$ & QPatch $\mathrm{HT}^{b}$ & nd & $>10,000$ & - \\
\hline $\mathrm{hNa} \mathrm{a}_{\mathrm{V}} 1.5$ & PatchXpress $\AA^{a} /$ QPatch $\mathrm{HT}^{b}$ & $1,380 \pm 668 / 5,660$ & $>10,000$ & - \\
\hline $\mathrm{hNa} 1.6$ & PatchXpress $\AA^{a}$ & $11 \pm 4$ & $0.8 \pm 0.7$ & - \\
\hline $\mathrm{hNa} \mathrm{v}_{\mathrm{v}} 1.7$ & PatchXpress $\AA^{a}$ / QPatch $\mathrm{HT}^{b}$ & $0.4 \pm 0.2 / 0.2$ & $0.3 \pm 0.2 / 0.1$ & $3.6 \pm 2.0 / 2.2$ \\
\hline $\mathrm{hNa} \mathrm{v}_{\mathrm{V}} 1.7$ & Manual, $-150 \mathrm{mV}^{c}$ & - & $495 \pm 23$ & - \\
\hline $\mathrm{hNa} v 1.8$ & Manual $^{c}$ & nd & $3,850 \pm 930$ & - \\
\hline rNav1.7 & PatchXpress $\AA^{a}$ / QPatch $\mathrm{HT}^{b}$ & $26 \pm 10 /-$ & nd & -1740 \\
\hline $\mathrm{mNa} 1.7$ & PatchXpress $\AA^{a}$ & $0.2 \pm 0.1$ & nd & - \\
\hline
\end{tabular}

${ }^{a} \mathrm{IC}_{50}$ values are reported as average values of two or more determinations, generated from a 5-point concentration response curve on an automated voltage-clamp platform; nd: not determined. ${ }^{b}$ IC50 generated from the fit of pooled data; average and SD do not apply in this case. ${ }^{c}$ Determined by manual voltage-clamp. 


\section{In Vitro Predicated Hepatic Clearance Data with Hepatocytes}

The oxidative and conjugative metabolism of compounds were evaluated in cryopreserved hepatocytes from CD-1 mice $(n=10)$, Sprague-Dawley rats $(n=3)$, (Invitrogen Corporation, Carlsbad, CA), and humans ( $n=10$; Celsis, Baltimore, MD). The cells were seeded at a density of $0.5 \times 10^{6}$ cells $/ \mathrm{mL}$, reactions were initiated with the addition of compound to make the final substrate concentration of $1 \mu \mathrm{M}$. Samples were incubated at $37{ }^{\circ} \mathrm{C}$ in $5 \%$ carbon dioxide with s aturating humidity, and aliquots were sampled at $0,1,2$ and 3 hours. Reactions were quenched with acetonitrile containing internal standard at each timepoint. Samples were centrifuged at $2000 \mathrm{~g}$ for 10 minutes. Supernatant was diluted with water (1:2 ratio) and the percentage of compound remaining was determined by LC/MS/MS. Using the $\mathrm{t}=0$ peak area ratio values as $100 \%$, the in vitro $\mathrm{CL}_{\text {int }}$ and scaled hepatic $\mathrm{CL}$ were determined as described: ${ }^{2-4}$ Standard deviation not applicable.

$C L_{\text {hep }}=\frac{\mathrm{Q}_{\text {Liver }}{ }^{*} \mathrm{C}_{\text {int }}}{\mathrm{Q}_{\text {Liver }}+\mathrm{L}_{\mathrm{int}}}$, where $\mathrm{Q}_{\text {Liver }}$ is the liver blood flow.

\section{In Vitro MDCK Cell Permeability}

The MDCKI (Madin-Darby Canine Kidney) cell line was acquired from American Type Culture Collection (Manassas, VA). The cells were seeded at a density of $1.3 \times 10^{5}$ cells $/ \mathrm{mL}$ in Costar Transwell@ plates (12-well, polyester membrane, $0.4 \mu \mathrm{m}$ pore size, $1.0 \mathrm{~cm} 2$ growth area). Cells were cultured with Eagle's Minimum Essential Medium (Earle's BSS, $0.1 \%$ non essential amino acids, $1 \mathrm{mM}$ sodium pyruvate, $2 \mathrm{mM} \mathrm{L}$ glutamine, $1.5 \mathrm{~g} / \mathrm{L}$ sodium bicarbonate, $10 \% \mathrm{FBS}$ ) for 5 days at $37{ }^{\circ} \mathrm{C}$ with $5 \% \mathrm{CO}_{2}$ and $95 \%$ humidity. Compound was added to either the apical or basolateral side of the monolayer at an initial concentration of $10 \mu \mathrm{M}$, and incubated at $37{ }^{\circ} \mathrm{C}$ for 2 hours. Transepithelial electrical resistance (TEER) and lucifer yellow (LY) permeability were used to monitor monolayer integrity at the beginning and the end of the experiments, respectively. The apparent permeability $P_{a p p}$, in the apical to basolateral $(A-B)$ and basolateral to apical (B-A) directions, was calculated as:

$P_{\text {app }}=(d Q / d t) \cdot\left(1 / A \cdot C_{0}\right)$

Where: $\mathrm{dQ} / \mathrm{dt}=$ rate of compound appearance in the receiver compartment; $\mathrm{A}=$ Surface area of the insert; $C_{0}=$ Initial substrate concentration at $T_{0}$. Standard deviation not available.

\section{In Vitro Pgp (MDR1) and BCRP Transport Assays}

Madin-Darby canine kidney (MDCK) cells heterologously expressing either human Pgp or mouse Bcrp1 were used to determine if a compound was a substrate of these transporters. MDR1-MDCKI cells were licensed from the National Cancer Institute 
Bethesda, MD), whereas Bcrp1-MDCKII cells were obtained from the Netherlands Cancer Institutes (Amsterdam, The Netherlands). For transport studies, cells were seeded on 12-well Costar Transwell plates 4 days before use (polyester membrane, 0.4 $\mu \mathrm{m}$ pore size; Corning Life Sciences, Lowell, MA) at a seeding density of $1.3 \times 105$ cells $/ \mathrm{mL}$. Compounds were tested at $10 \mu \mathrm{M}$ in the MDR1 assay, and at $5 \mu \mathrm{M}$ in the Bcrp1 assay in the apical-to-basolateral (A-B) and basolateral-to-apical (B-A) directions. The compound was dissolved in transport buffer consisting of Hank's balanced salt solution and $10 \mathrm{mM}$ HEPES (Invitrogen Corporation, Grand Island, NY). Lucifer Yellow (Sigma-Aldrich) was used as the paracellular marker. The efflux ratio (ER) was calculated as ER $=\frac{P_{a p p, B-A}}{P_{a p p, A-B}} ;$ Standard deviation not available.

\section{Plasma Protein Binding Incubations}

Plasma protein binding in rat plasma was determined using 96-well equilibrium dialysis method (DIALYZER ${ }^{\mathrm{TM}}$ ). The percent of drug bound to protein was determined by measuring the amount of free drug that couldn pass through a semi-permeable membrane that retained plasma proteins. The test compound was prepared at a final $10 \mu \mathrm{M}(0.01 \% \mathrm{v} / \mathrm{v}$ with $\mathrm{DMSO})$ in rat plasma. $200 \mu \mathrm{L}$ of the $10 \mu \mathrm{M}$ test compound plasma was added to the plasma side of the equilibrium dialysis membrane and $200 \mu \mathrm{L}$ of phosphate buffer $(\mathrm{pH}$ 7.4) was added to the opposite side. The dialysis plate was sealed and incubated with rotation at $37{ }^{\circ} \mathrm{C}$ in a $5 \% \mathrm{CO}_{2}$ incubator for 20 hours, at which time equilibrium had been reached. $100 \mu \mathrm{L}$ of the plasma and buffer samples were removed from each side of the dialysis wells into a new 96-deep well plate. To eliminate matrix effect on HPLC-MS/MS quantiation, equal volume of blank plasma and blank buffer were added to the plasma and buffer samples, respecitvely. 500 $\mu \mathrm{L}$ acetonitrile with internal standard was then added to all samples. The plate was centrifuged at $4000 \mathrm{rpm}$ for 20 minutes at ${ }^{\circ} \mathrm{C}$. The amount of the parent analyte in the supernatants was then quantified in HPLC-MS/MS. All experiments were done in triplicate.

The percentage of bound drug was calculated using this equation:

$\%$ Protein Binding $=($ Plasma - Buffer $) /(\text { Plasma })^{*} 100 \%$

Note: Under othwerwise similar conditions, using a shorter equibliration time (4 h) and a RED (rapid equilibrium dialysis) device, higher PPB (99.9\%) was observed.

\section{Cytochrome P450 (CYP) inhibition Assays}

Test compounds were incubated with $0.2 \mathrm{mg} / \mathrm{mL}$ human liver microsomes (150 donor pool, BD Biosciences, San Jose, CA) together with NADPH cofactor and the specific probe substrate for each CYP tested: CYP1A2 (phenacetin), CYP2C9 (warfarin), 
CYP2C19 (mephenytoin), CYP2D6 (dextromethorphan), and CYP3A4 (testosterone and midazolam). The reactions were terminated after $30 \mathrm{~min}$ by addition of cold acetonitrile/formic acid (94:6 v/v) containing an internal standard. Inhibition was determined through conversion of the probes substrates by CYP's as determined by LC/MS/MS analysis. Five concentrations of each test compound were tested $(0.1,1,5$, and $10 \mu \mathrm{M}$, as well as a solvent control) to generate $I \mathrm{I}_{50}$ values. $I \mathrm{C}_{50}$ 's obtained from single experiments, SD not applicable.

\section{UV-metric pKa method}

The dissociation constant (pKa) of the test compound was determined by using Spectrophotometric titration method, a UV-metric pKa method. The analysis was performed using an automatic titration instrument, Sirius T3, manufactured by Sirius Analytical Ltd. The acid/base titration was performed in the titration cell with an in-situ UV probe to measure the UV absorbance profile of the compound at each pH point during the titration. $5 \mu \mathrm{L}$ of $10 \mathrm{mM}$ DMSO stock compound was dissolved by acid $(0.5 \mathrm{M}$ $\mathrm{HCl})$ and base $(0.5 \mathrm{M} \mathrm{KOH})$ to make $100 \mathrm{uM}$ concentration. The available titration $\mathrm{pH}$ range was 2 to 11 . The changes of UV absorbance with each $\mathrm{pH}$ were recorded as the compound undergoes ionization. A mathematical technique (Target Factor Analysis) was applied to this set of data to produce molar absorption profiles and to plot the proportion of each species varies with $\mathrm{pH}$ values. The $\mathrm{pKa}$ values were then determined by the combination of molar absorption profile, $\mathrm{pH}$ titration curve, and TFA best fit. The report pKa value was the average from three duplicate titrations. Standard deviation not available.

\section{Pharmacokinetic Studies in Rats}

All studies performed were approved by the Institutional Animal Care and Use Committee at Genentech, Inc. (South San Francisco, CA). Jugular and femoral vein canulated male Sprague-Dawley rats (Charles River Laboratories, Hollister, CA) were assigned to the IV group and only jugular vein canulaed rats were assigned to the PO group. At the initiation of the study, the rats weighed from 250 to $300 \mathrm{~g}$. Three rats were given a single IV dose in 10\% DMSO, 50\% polyethylene glycol 400 and $40 \%$ phosphate buffered saline as a solution via a femoral vein canulae. Three additional rats were given a single $\mathrm{PO}$ dose in $0.5 \%$ methylcellulose with $0.2 \%$ Tween 80 (MCT). Blood samples (approximately $0.2 \mathrm{~mL}$ per sample) were drawn from each animal via the jugular vein cannulae at $0.033,0.083,0.25,0.5,1,2,4,6$, and 8 hours post-dose. Plasma samples were collected and analyzed. 


\section{Formalin- and Aconitine-Induced Pain Model in Rats}

Compound 3 was dosed intraperitoneally (IP) in $0.9 \%$ saline 2 hours prior to the subcutaneous injection of formalin ( $50 \mu \mathrm{L} ; 2.5 \% \mathrm{v} / \mathrm{v}$ in saline) or aconitine (50 $\mu \mathrm{L} ; 39 \mu \mathrm{M}$ in saline) into the dorsal hindpaw to initiate the pain response. Rats were acclimatized to the test chamber for 30 minutes prior to formalin or aconitine injection. Following the injection, rats were immediately placed on the recording platform of the automated nociception analyzer (University of California San Diego, Department of Anesthesiology) where paw flinches were captured for 60 minutes using the associated data analysis software. Following data acquisition, animals were euthanized and blood was withdrawn by cardiac puncture. Plasma was then harvested and stored frozen at $-80^{\circ} \mathrm{C}$ until analyzed for the presence of test compound. The aconitine pain model was validated using the unselective sodium channel blockers mexiletine, carbamazepine, and lamotrigine.

\section{CFA-Induced Cold Allodynia Pain Model in Mice}

Mice were injected subcutaneously with $20 \mu \mathrm{L}$ of Complete Freund's Adjuvant (CFA) into the ventral left hindpaw. On Day 2 post-CFA, the mice were dosed IP $(10 \mathrm{ml} / \mathrm{kg})$ with test compound formulated in saline 1 hour before inducing cold allodynia with acetone. Acclimation to the test environment was provided for 30-45 minutes prior to the application of acetone (100 ul to the plantar surface of the ipsilateral hind paw). Commencing $15 \mathrm{sec}$ post acetone, the time spent flinching, licking and lifting the paw is scored for $120 \mathrm{sec}$. As detailed above for the formalin and aconitine assays, terminal plasma samples were harvested for subsequent analysis of test compound,

\section{Analysis of Plasma and Brain Samples}

Plasma samples (50uL) previously generated by centrifugation of blood samples collected at each time point and extracted by protein precipitation with $\mathrm{CH}_{3} \mathrm{CN}$ after addition of an appropriate internal standard, centrifuged for $20 \mathrm{~min}$ and the supernatants collected for analysis. Individual rat brains were homogenized and extracted in $4 \mathrm{~mL}$ of 1:1 water: $\mathrm{CH}_{3} \mathrm{CN}$ and centrifuged to collect the supernatant. A sample (50uL) of the supernatant was spiked with the appropriate internal standard and readied for analysis. All samples were analyzed by ultra-high pressure liquid chromatography (UHPLC) using gradient elution with $0.1 \%(\mathrm{v} / \mathrm{v})$ formic acid in water $(\mathrm{A})$ and $0.1 \%(\mathrm{v} / \mathrm{v})$ formic acid in acetonitrile (B) starting at $50 \% \mathrm{~B}$ and ending at $100 \% \mathrm{~B}$ in 2 minutes on a Acquity $\mathrm{C} 18$, $2.5 \times 50 \mathrm{~mm}, 1.7 \mathrm{um}$ column. Analytes were detected by tandem mass spectrometry (MS/MS) using Waters Premier XE mass spectrometer as detector. 


\section{References}

(1) Wang, H., Oxford, G. S. Voltage-dependent ion channels in CAD cells: A catecholaminergic neuronal line that exhibits inducible differentiation. J. Neurophysiol. 2000, 84, 2888-2895.

(2) Obach, R. S.; Baxter, J. G.; Liston, T. E.; Silber, B. M.; Jones, B. C.; Maclntyre, F.; Rance, D. J.; Wastall, P. The Prediction of Human Pharmacokinetic Parameters from Preclinical and In Vitro Metabolism Data. J. Pharmacol. Exp. Ther. 1997, 283, 46-58.

(3) Chiba, M.; Ishii, Y.; Sugiyama, Y. Prediction of Hepatic Clearance in Human From In Vitro Data for Successful Drug Development. AASP J. 2009, 11, 262-276.

(4) McGinnity, D. F.; Soars, M. G.; Urbanowicz, R. A.; Riley, R. J. Evaluation of Fresh and Cryopreseved Hepatocytes as In Vitro Drug Metabolism Tools for the Prediction of Metabolic Clearance. Drug. Metab. Dispos. 2004, 32, 1247-1253.

\section{NMR Spectra}

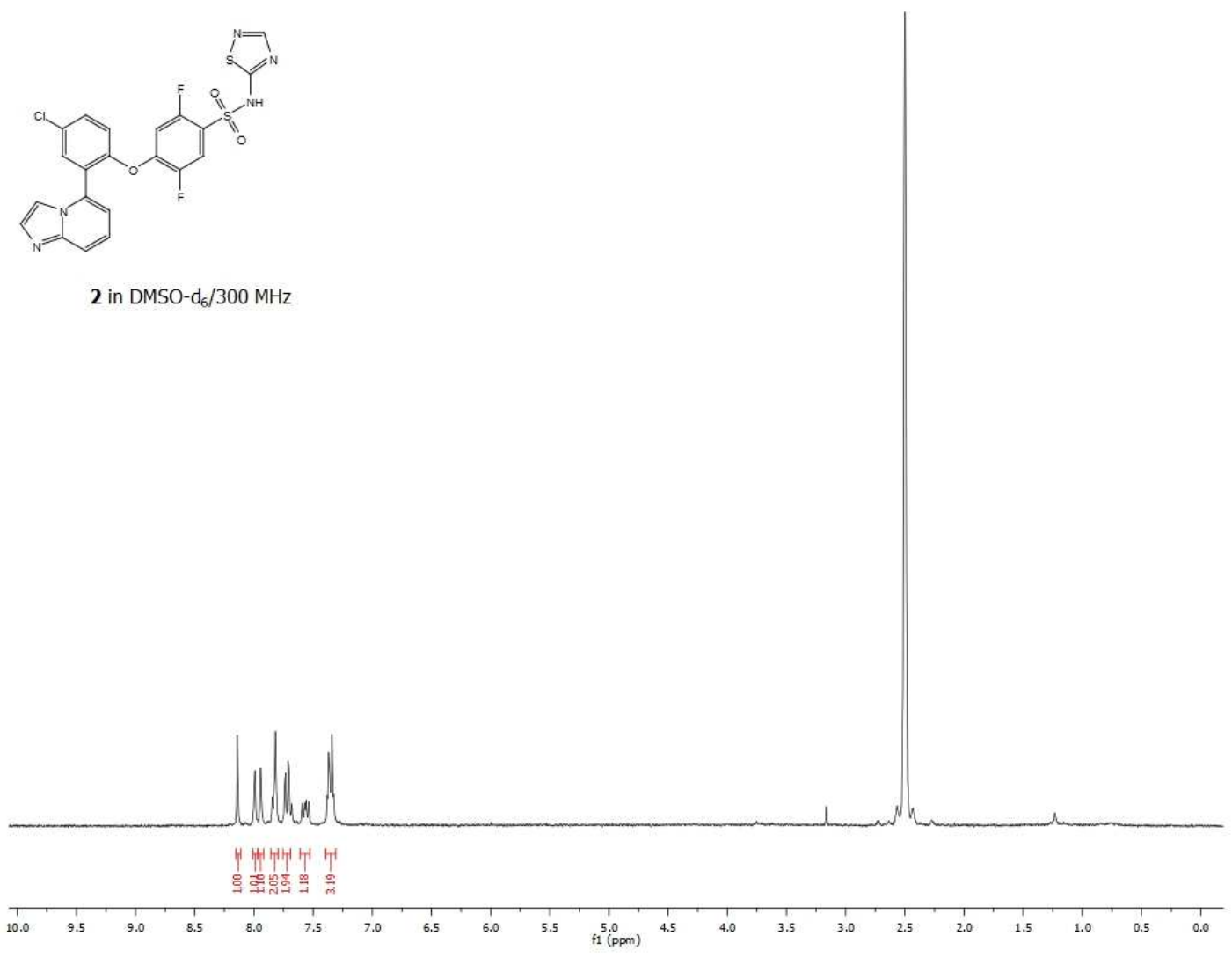




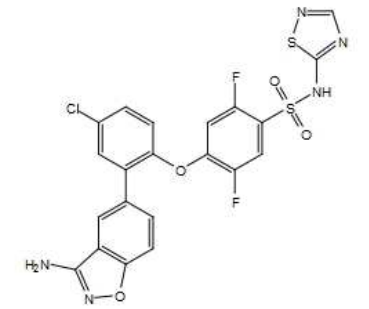

3 in DMSO- $\mathrm{d}_{6} / 300 \mathrm{MHz}$
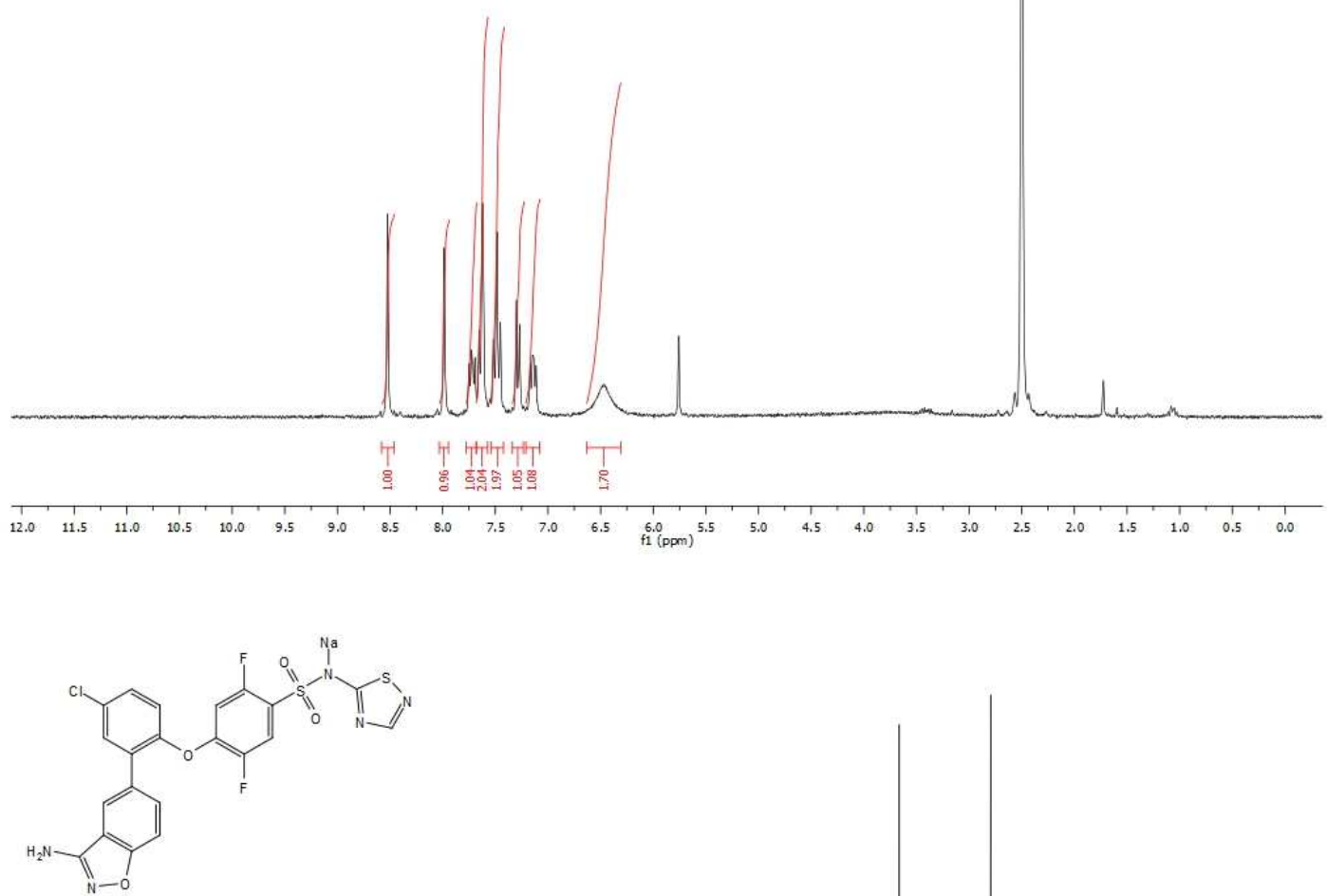

3a in DMSO- $\mathrm{d}_{6} / 300 \mathrm{MHz}$

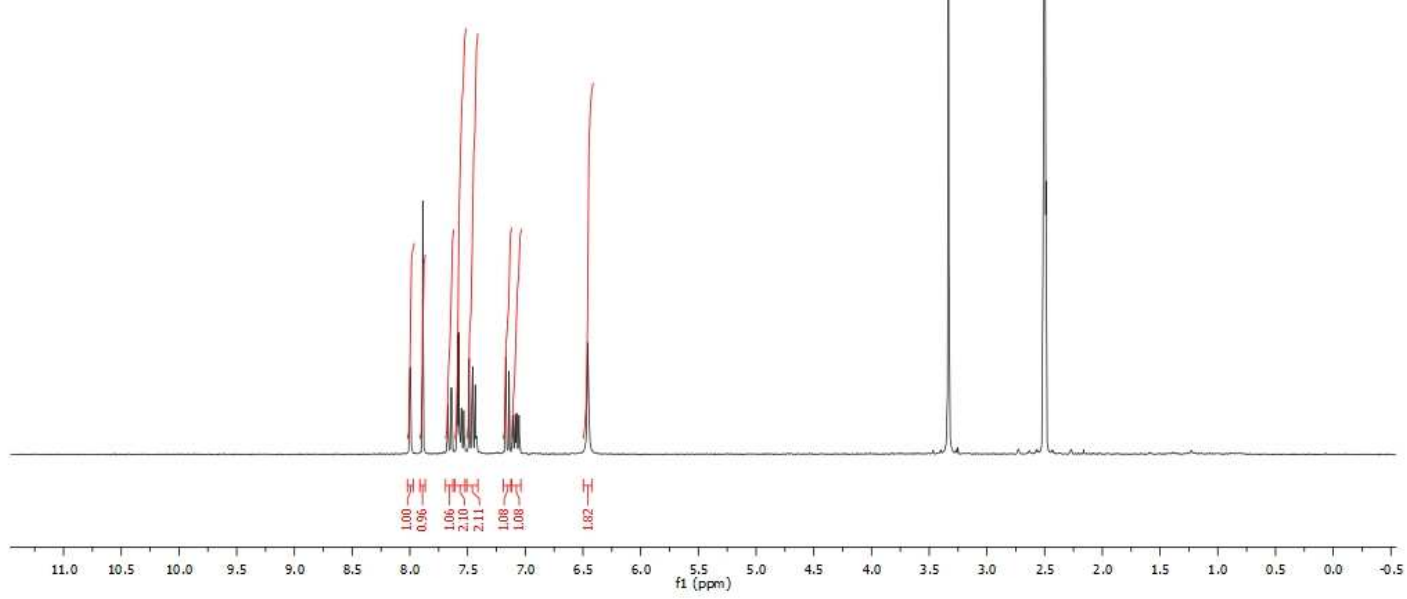




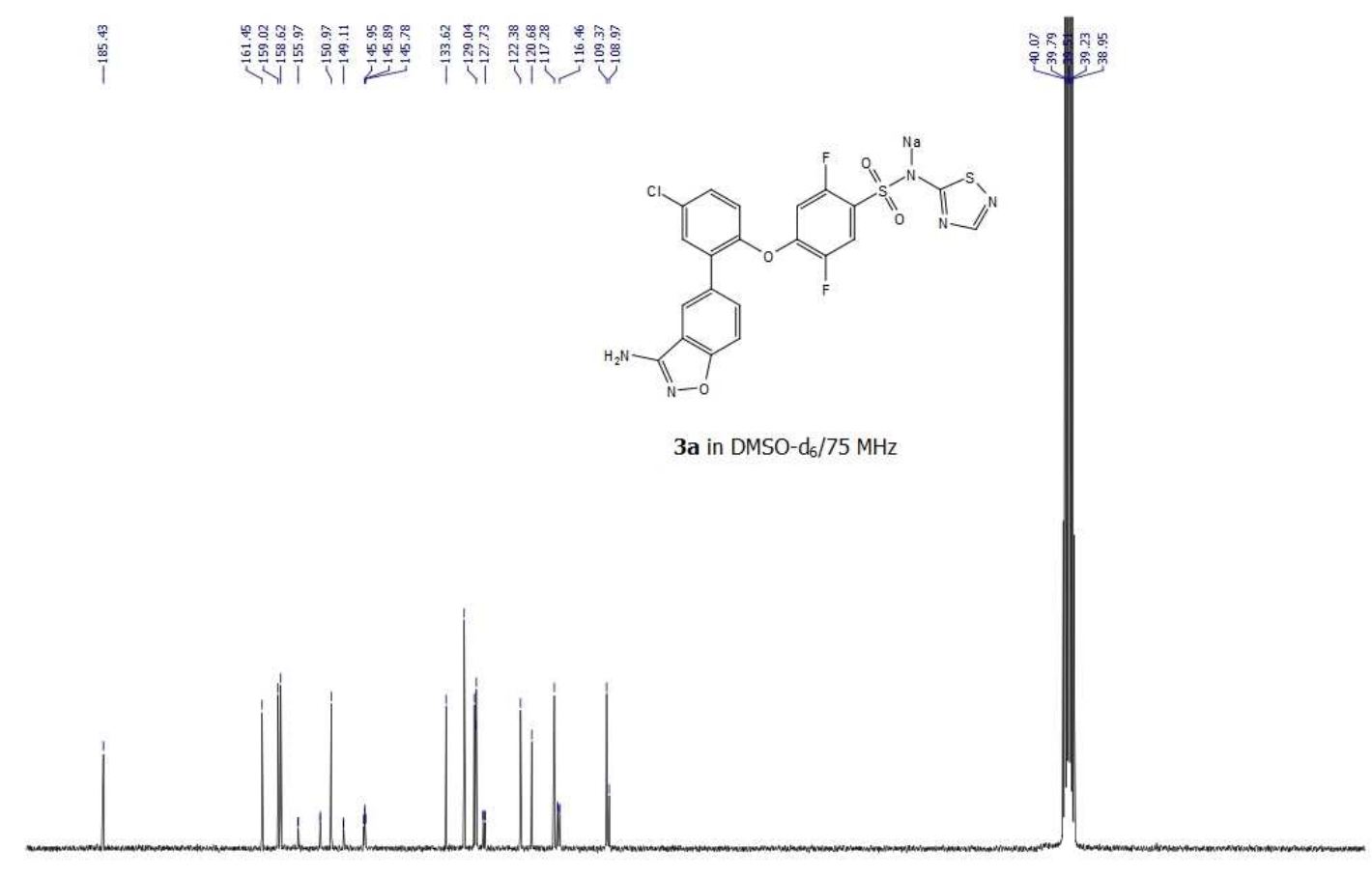




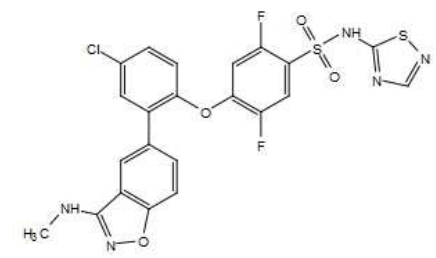

10 in DMSO- $d_{6} / 300 \mathrm{MHz}$
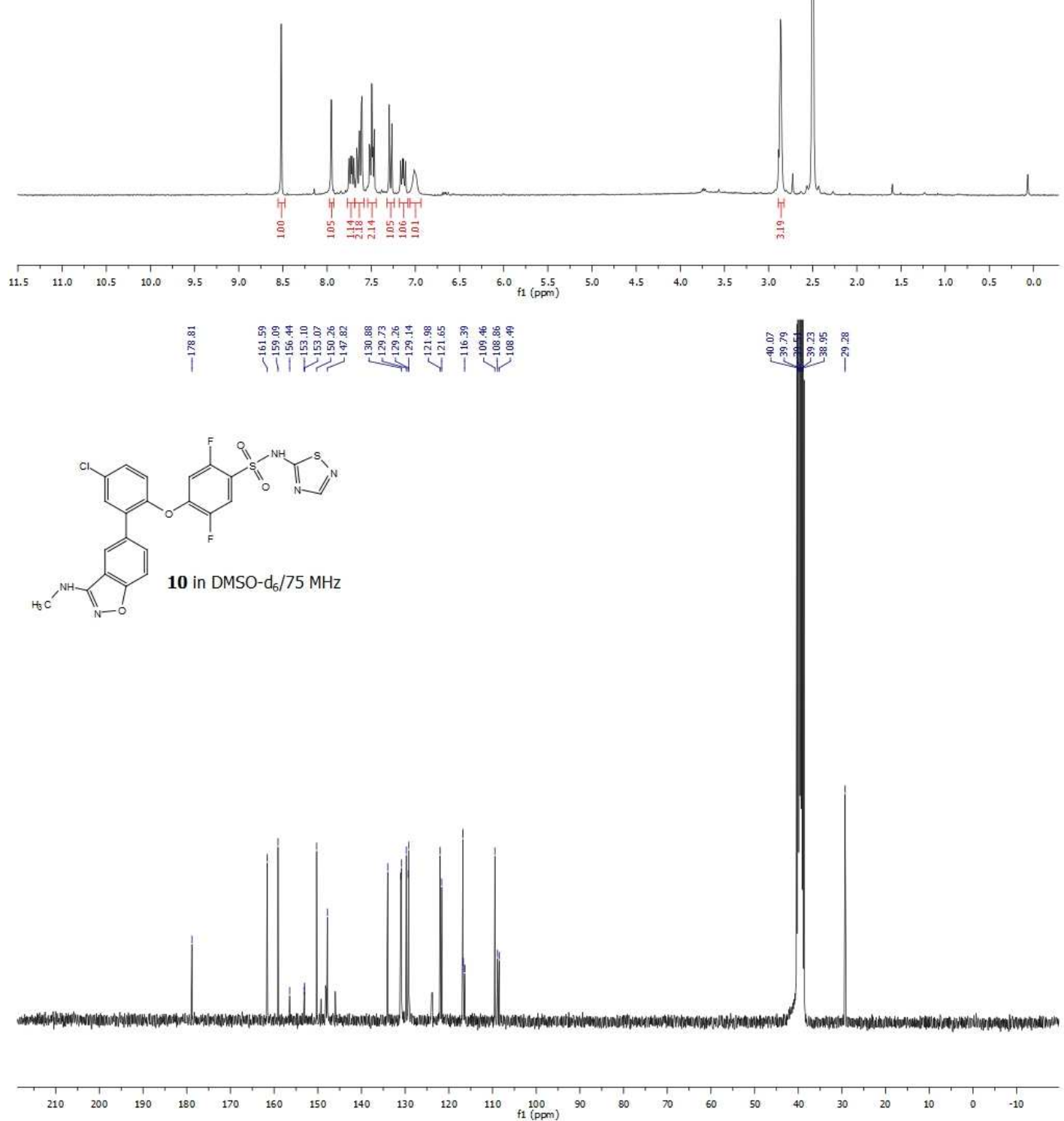

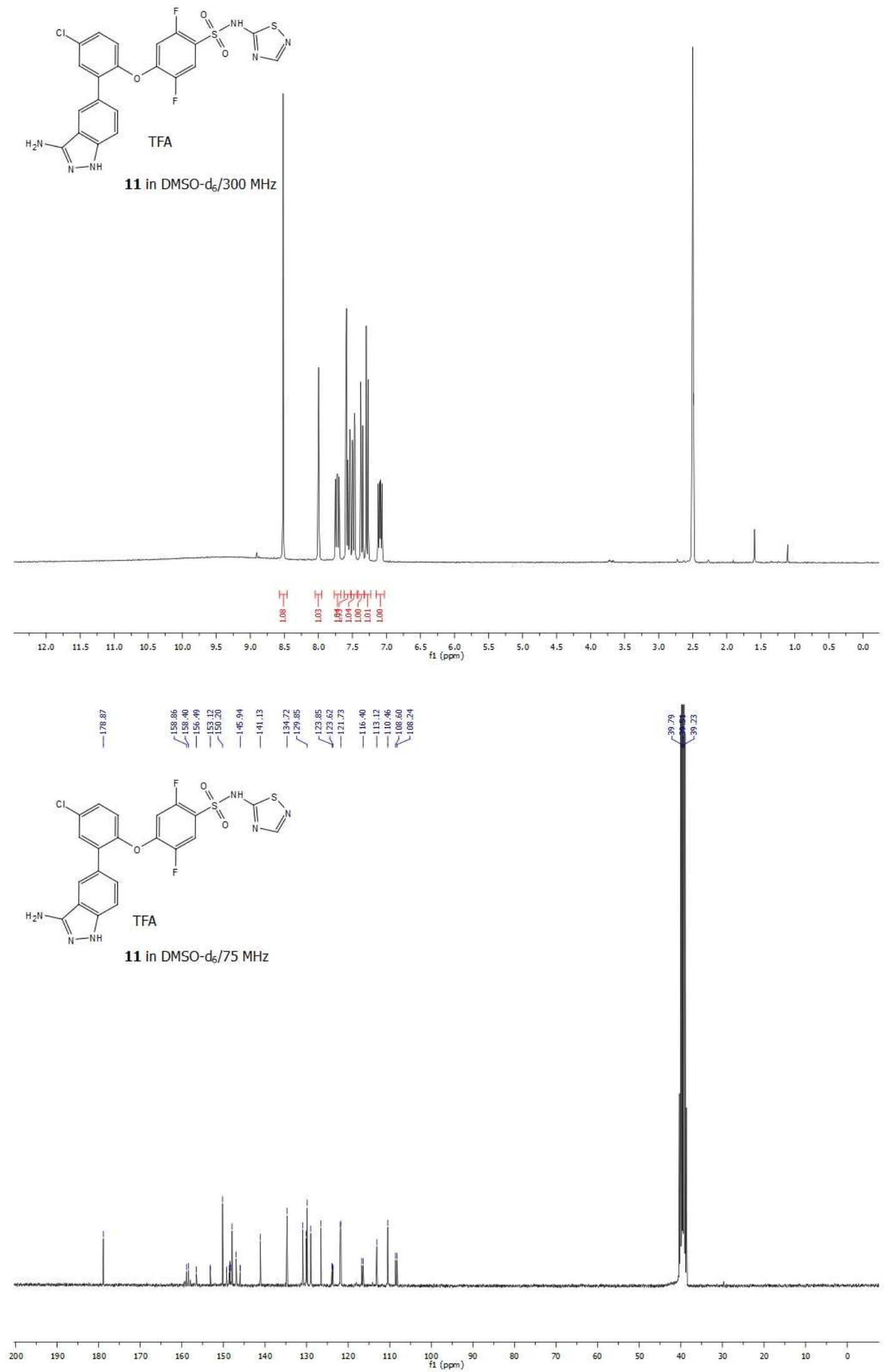


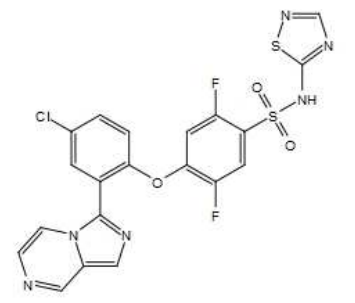

12 in DMSO- $\mathrm{d}_{6} / 300 \mathrm{MHz}$
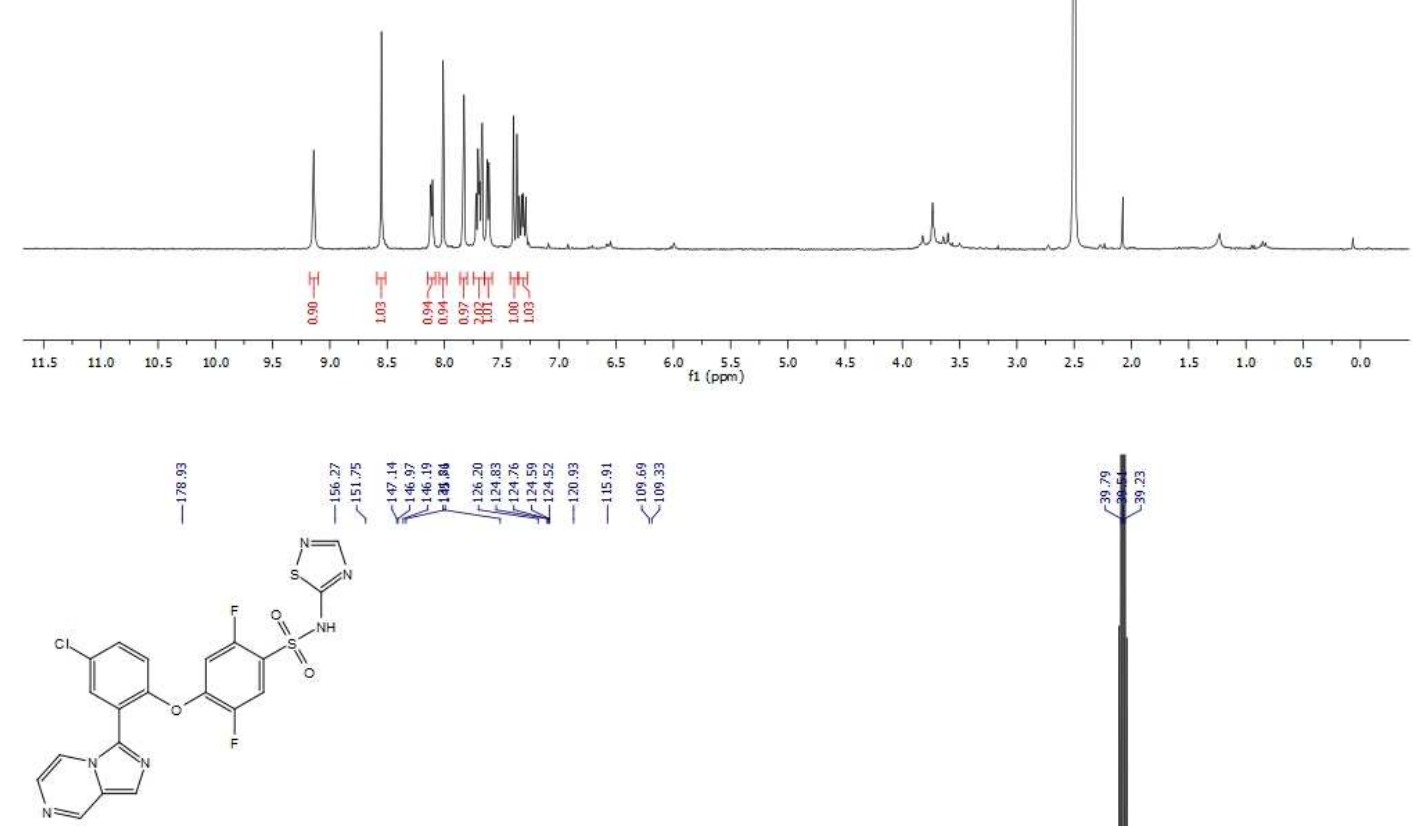

12 in DMSO- $d_{6} / 75 \mathrm{MHz}$
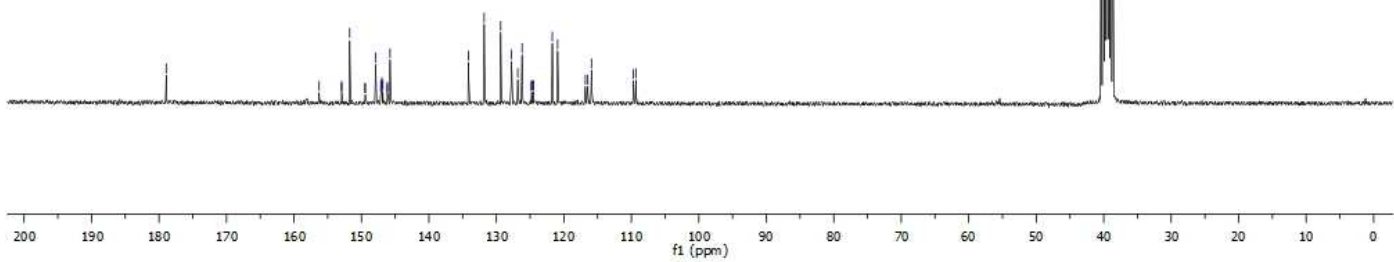


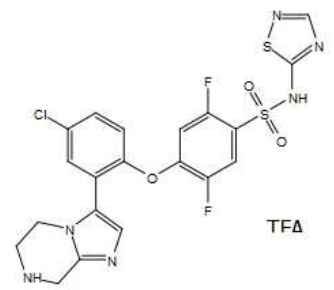

13 in DMSO- $d_{6} / 300 \mathrm{MHz}$

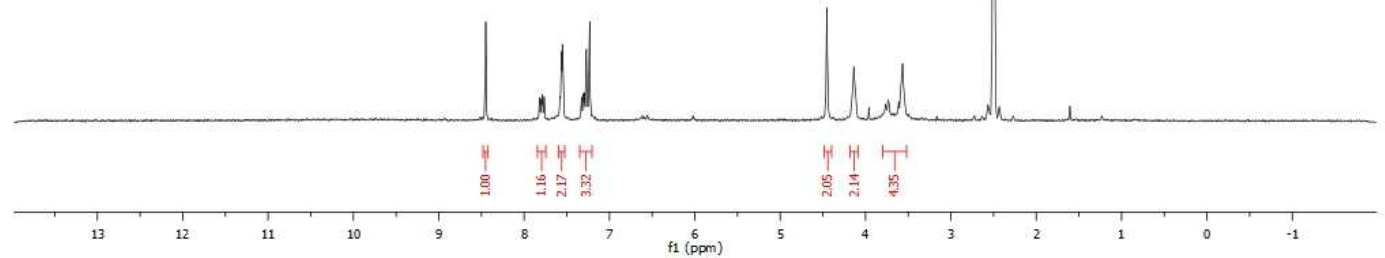



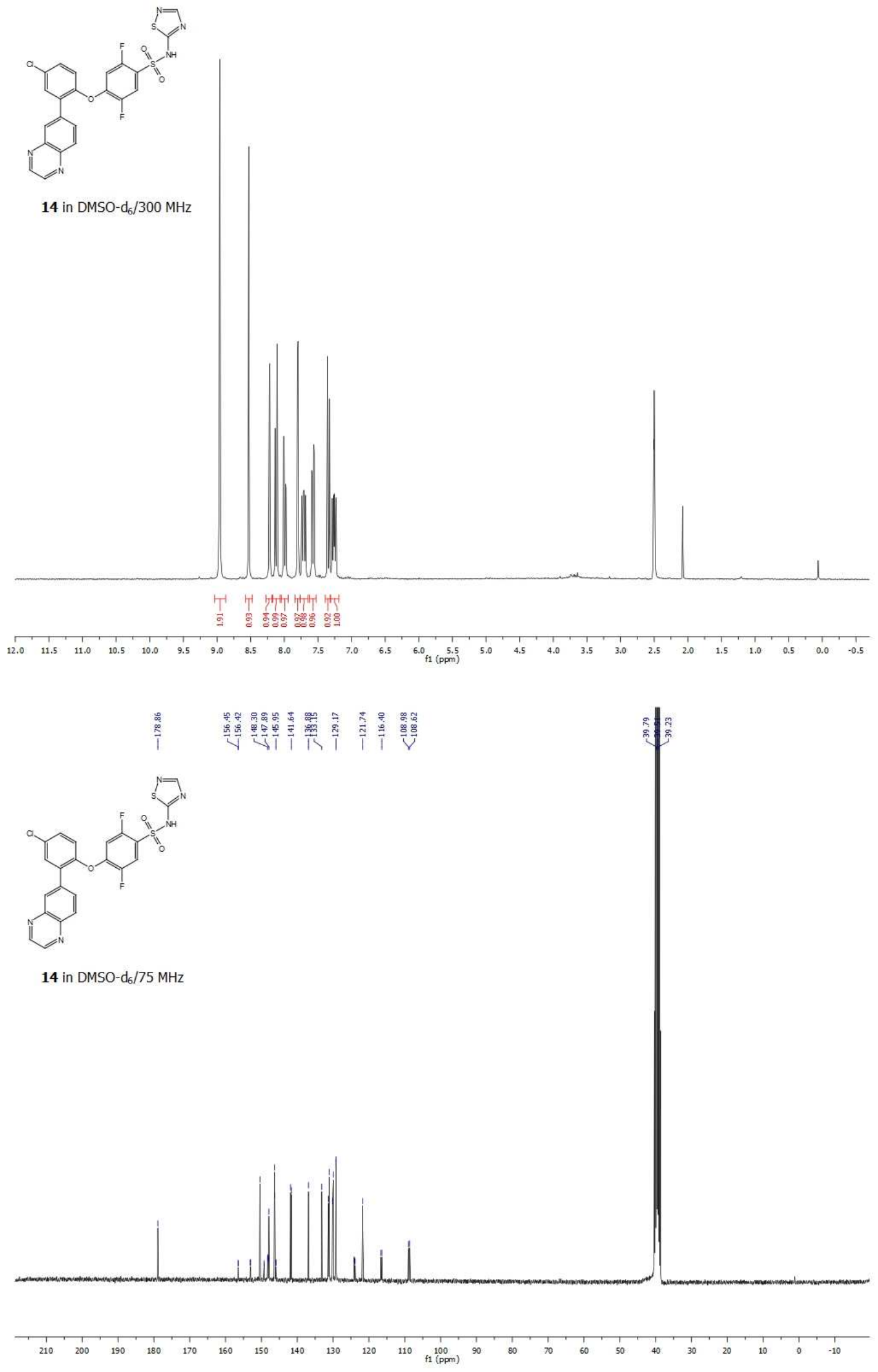

42 


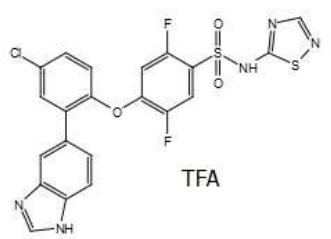

15 in DMSO-d $\mathrm{d}_{6} / 300 \mathrm{MHz}$

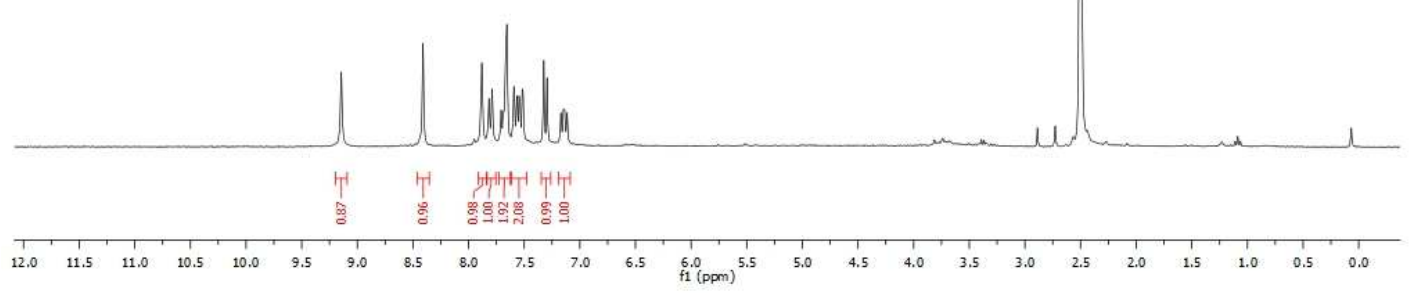

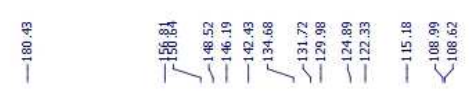

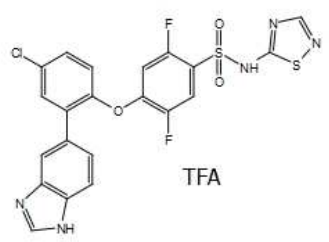

15 in DMSO- $\mathrm{d}_{6} / 300 \mathrm{MHz}$

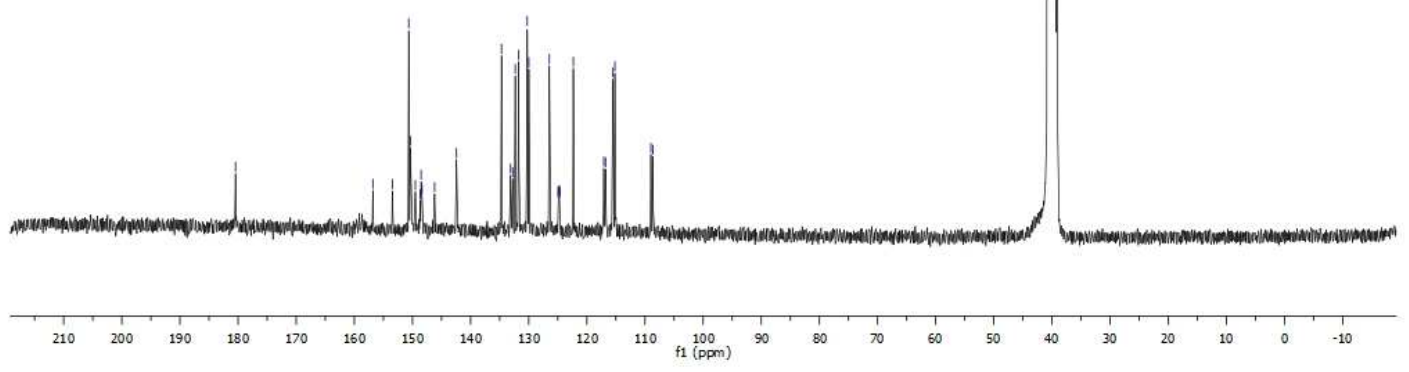

43 

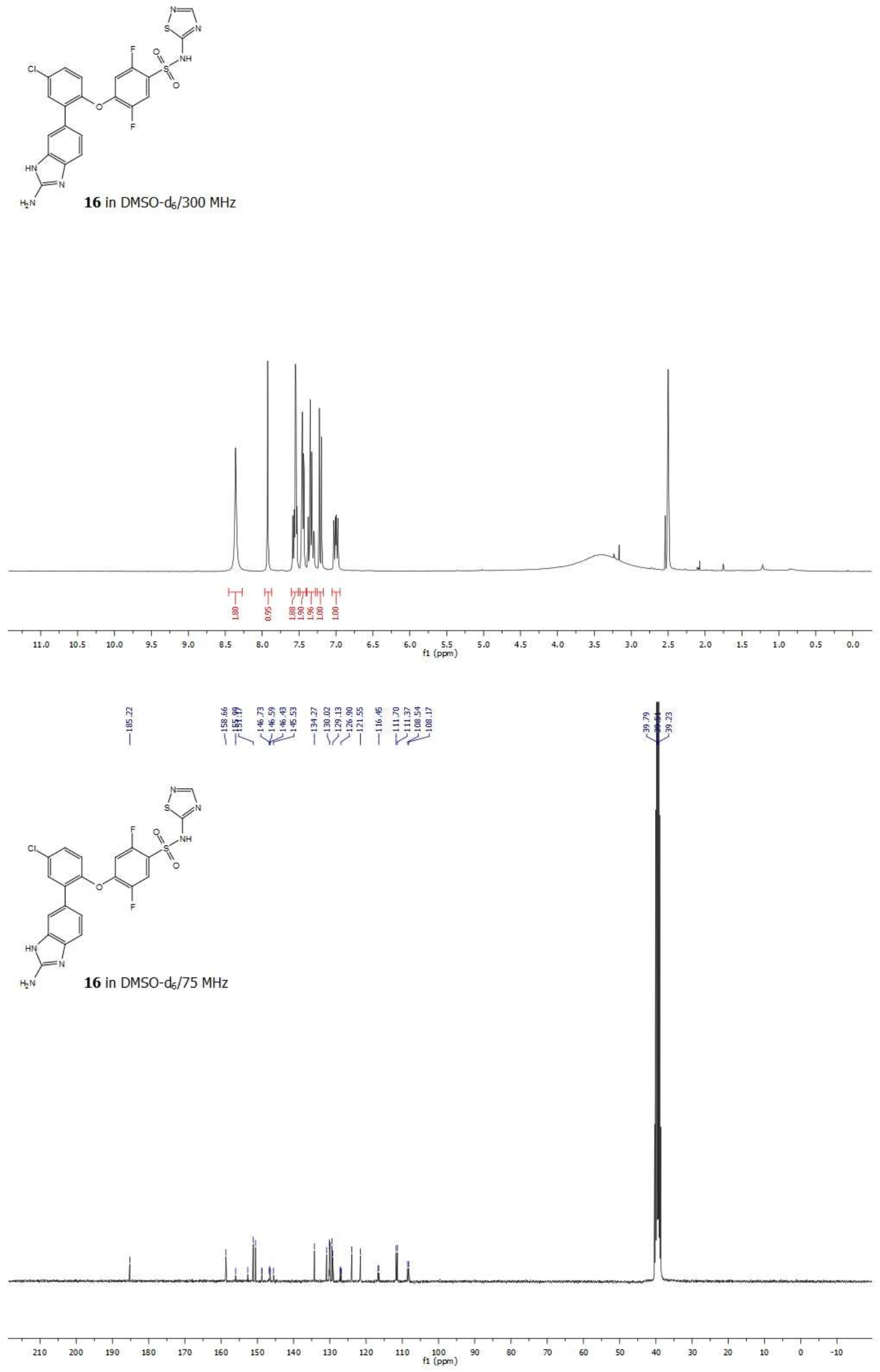

44 

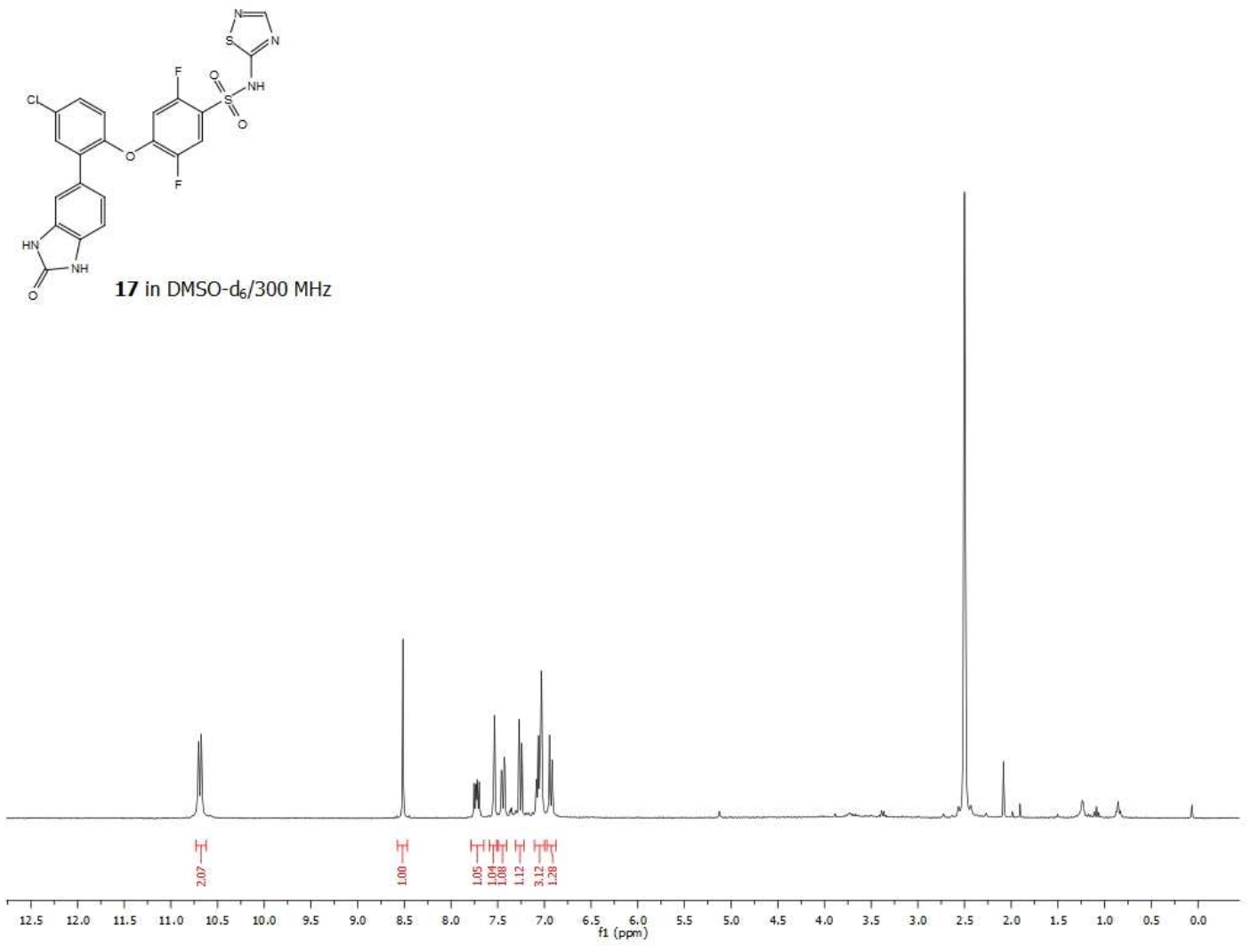

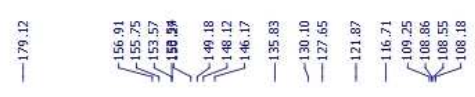
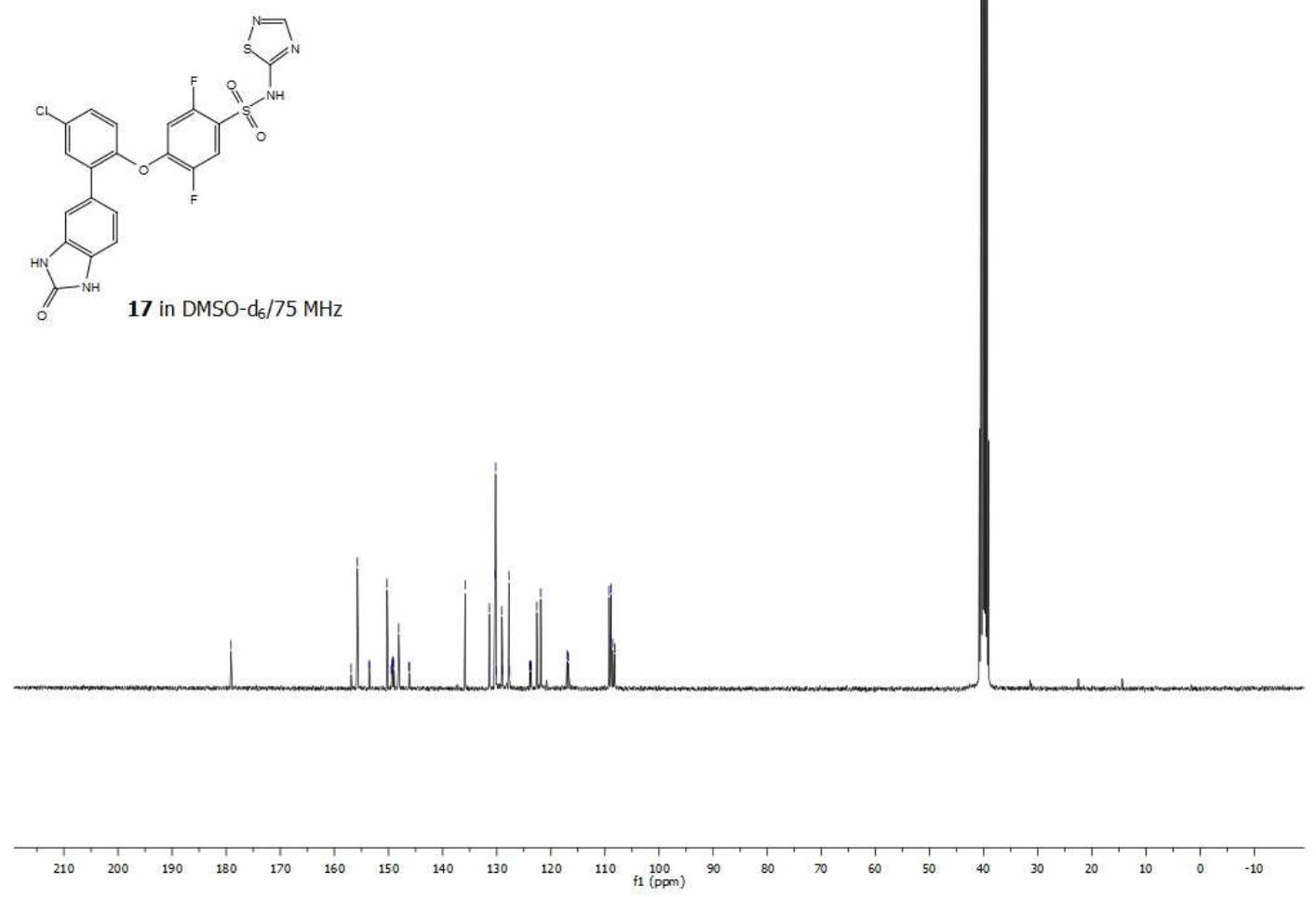

45 


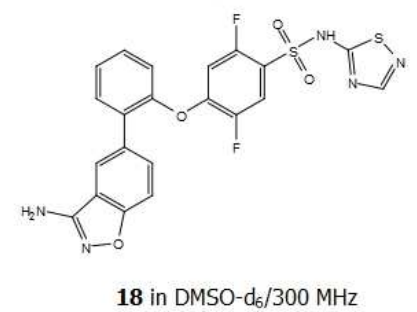

18 in DMSO- $\mathrm{d}_{6} / 300 \mathrm{MHz}$

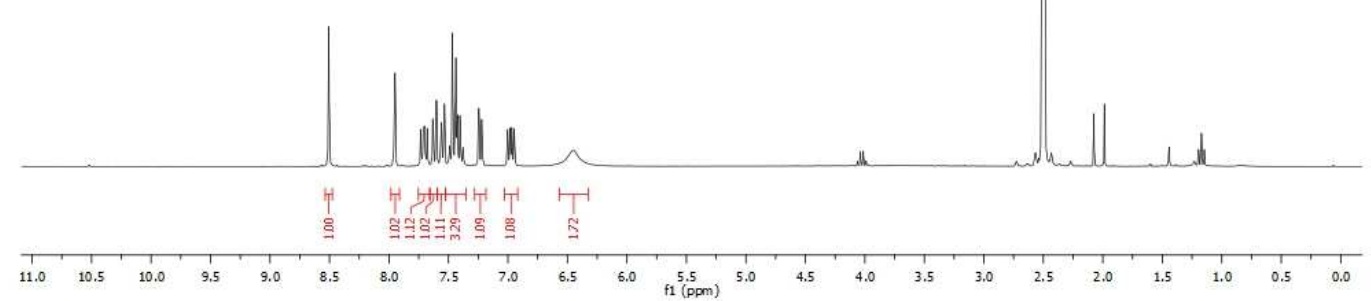

प一

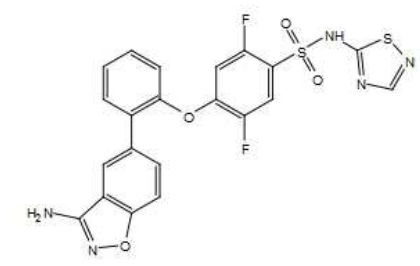

18 in DMSO- $d_{6} / 75 \mathrm{MHz}$

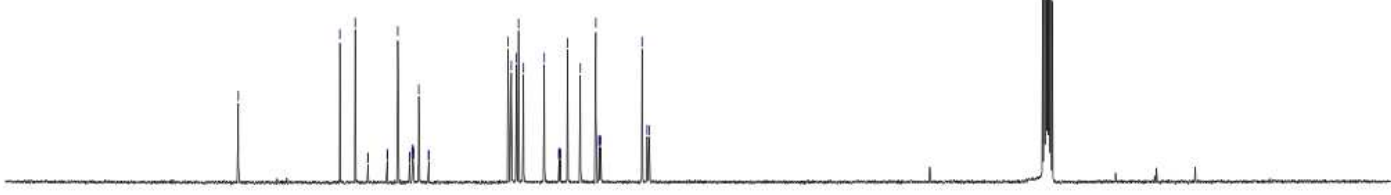

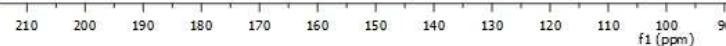



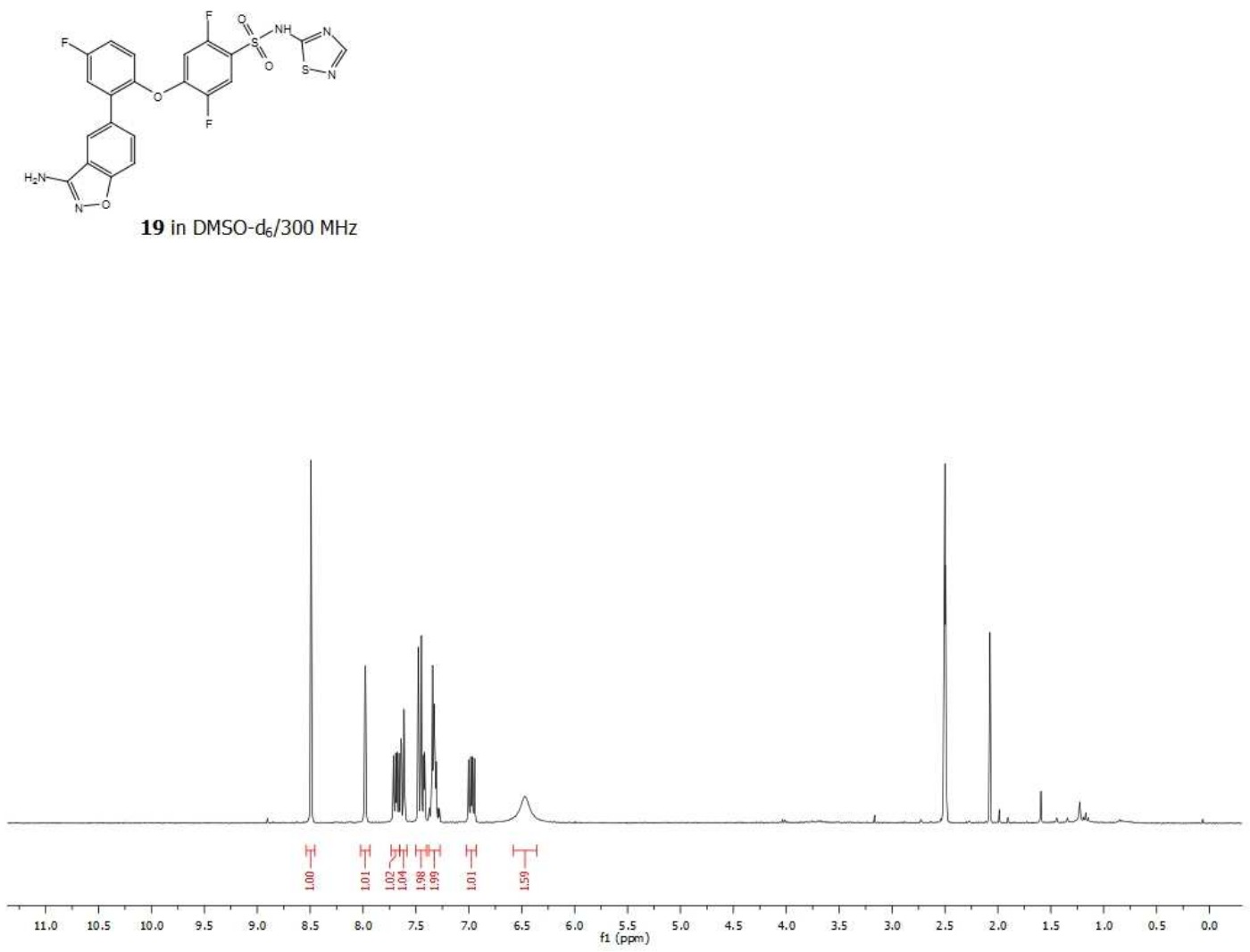

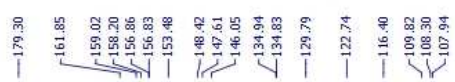

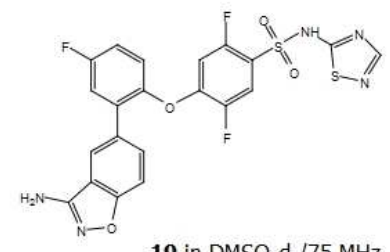

19 in DMSO- $\mathrm{d}_{6} / 75 \mathrm{MHz}$

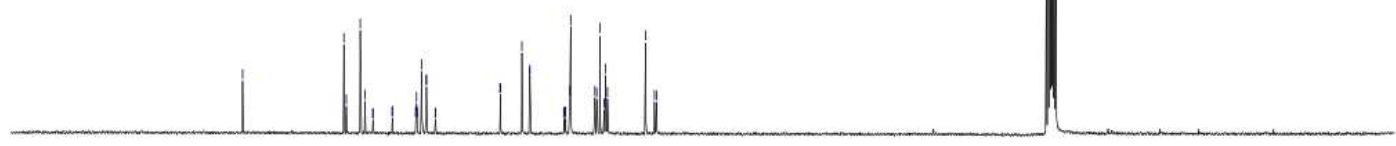

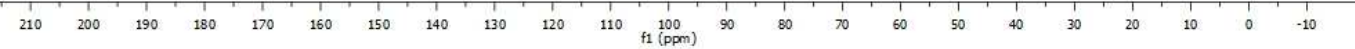




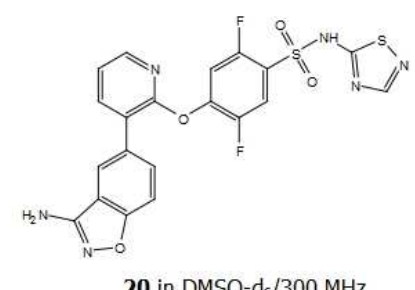

20 in DMSO- $\mathrm{d}_{6} / 300 \mathrm{MHz}$

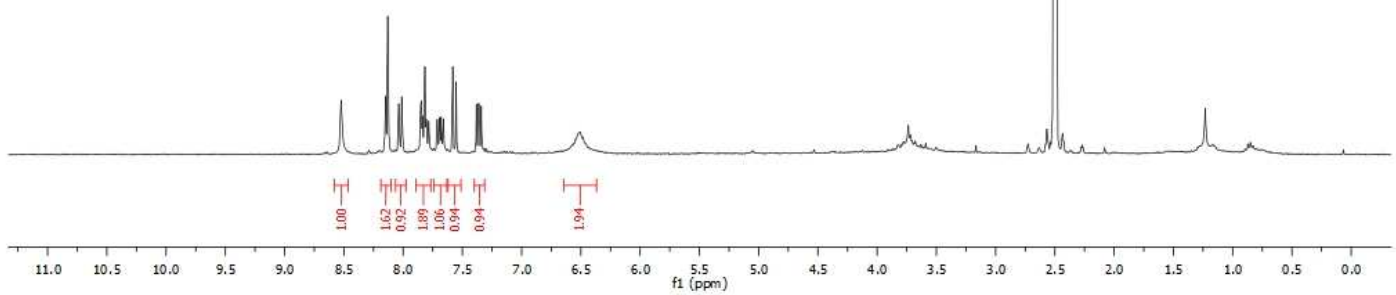



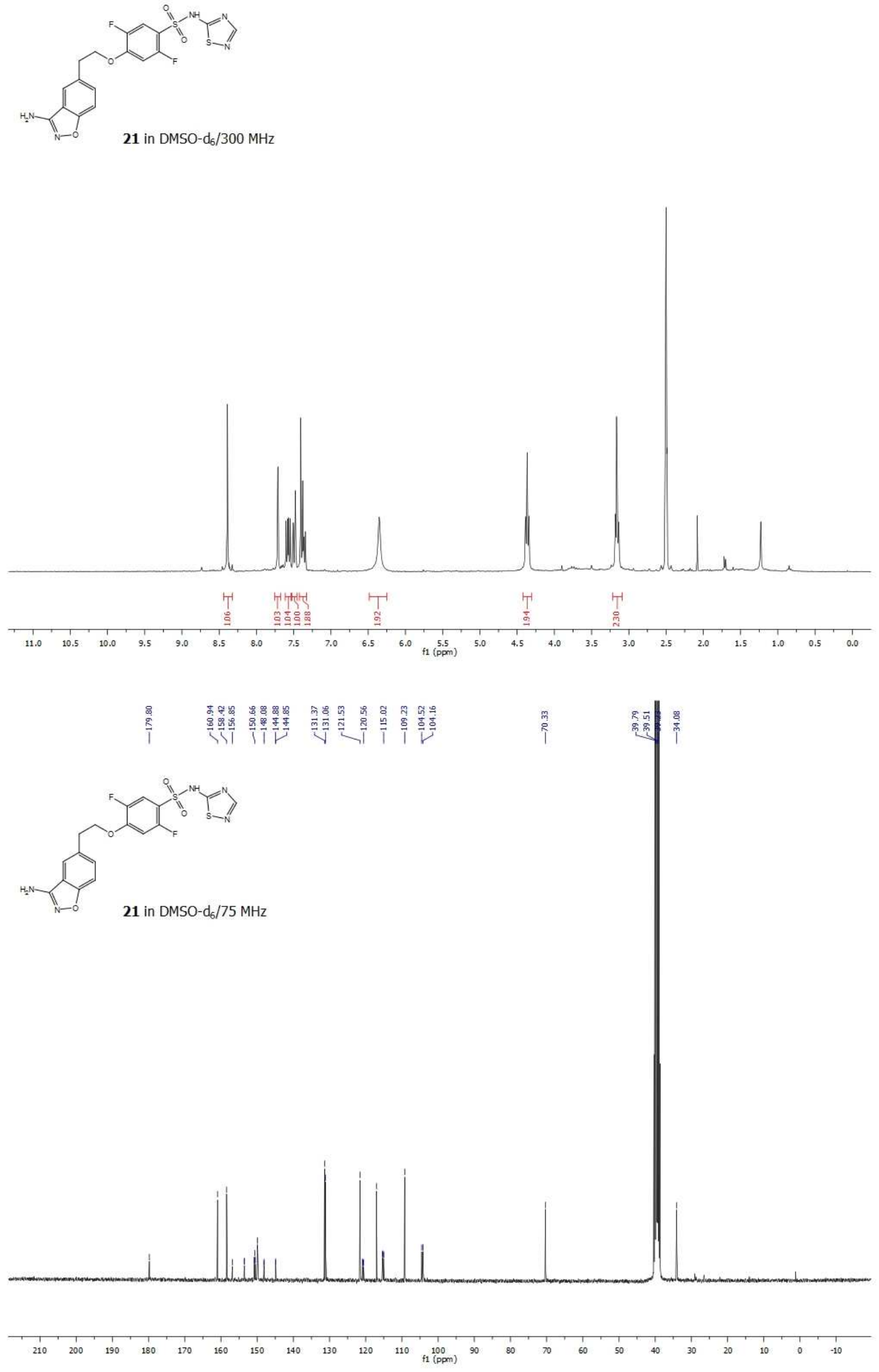

49 

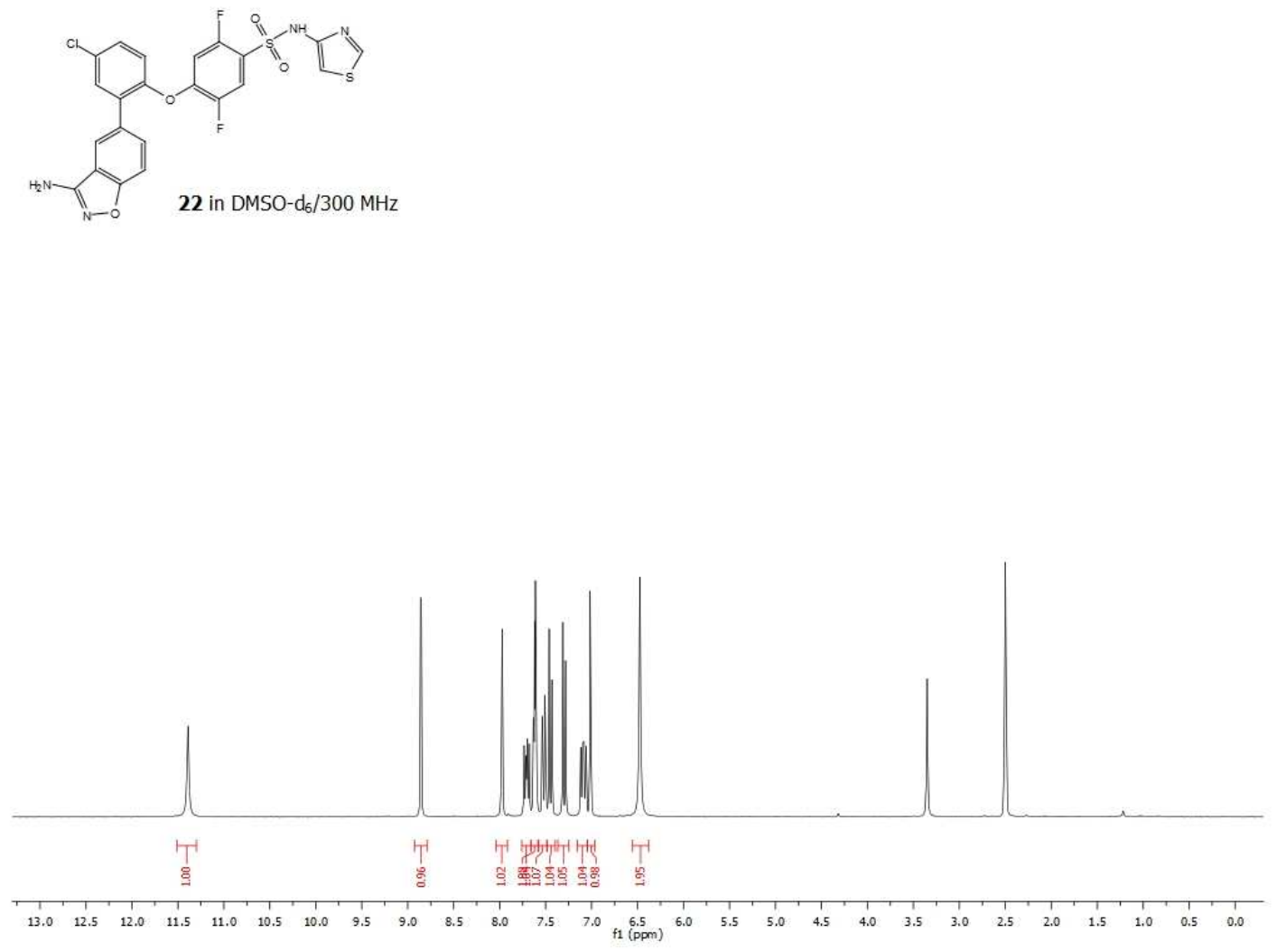

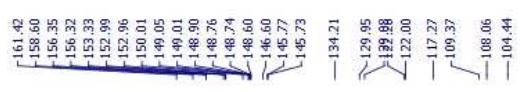
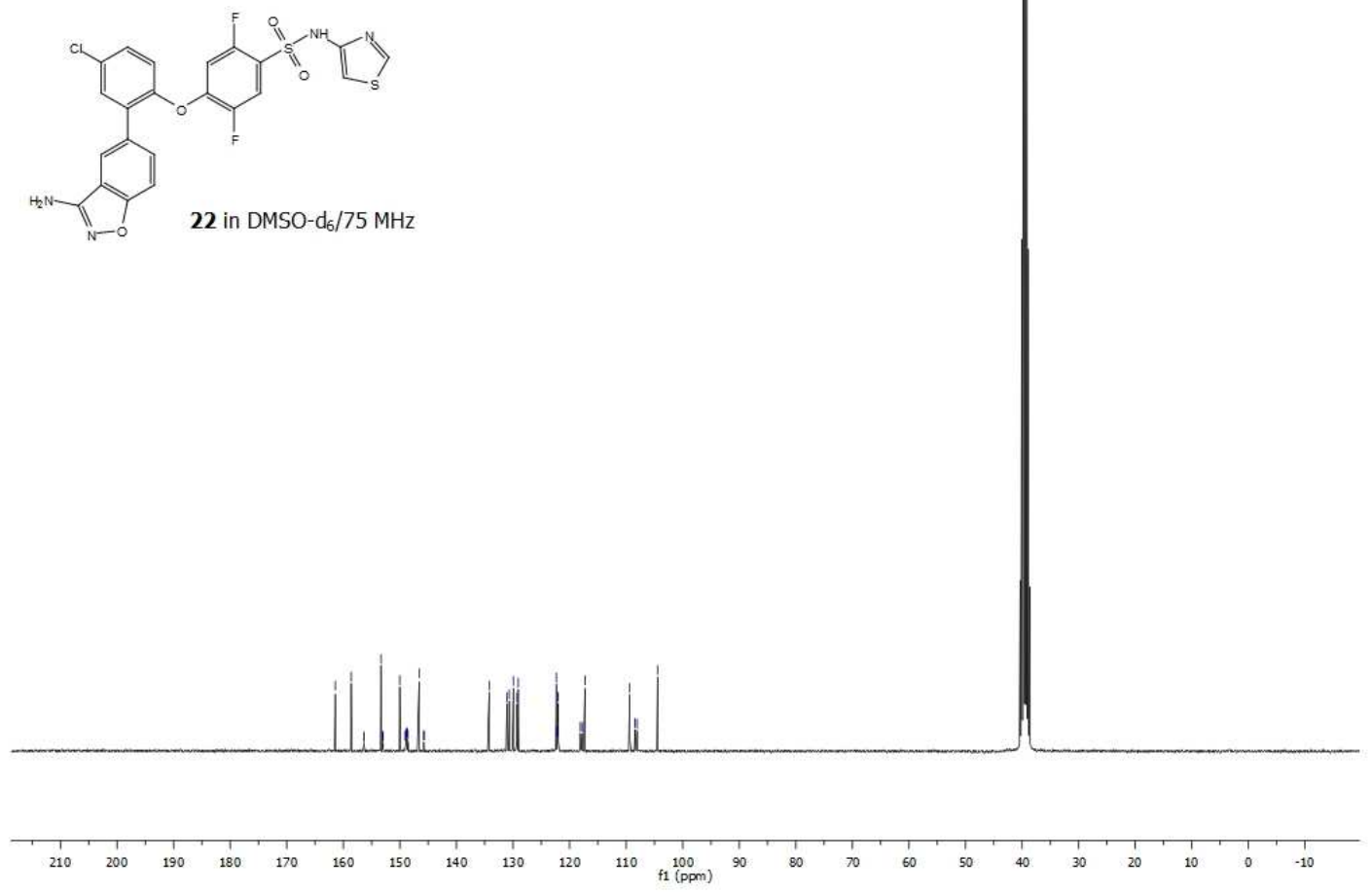

50 

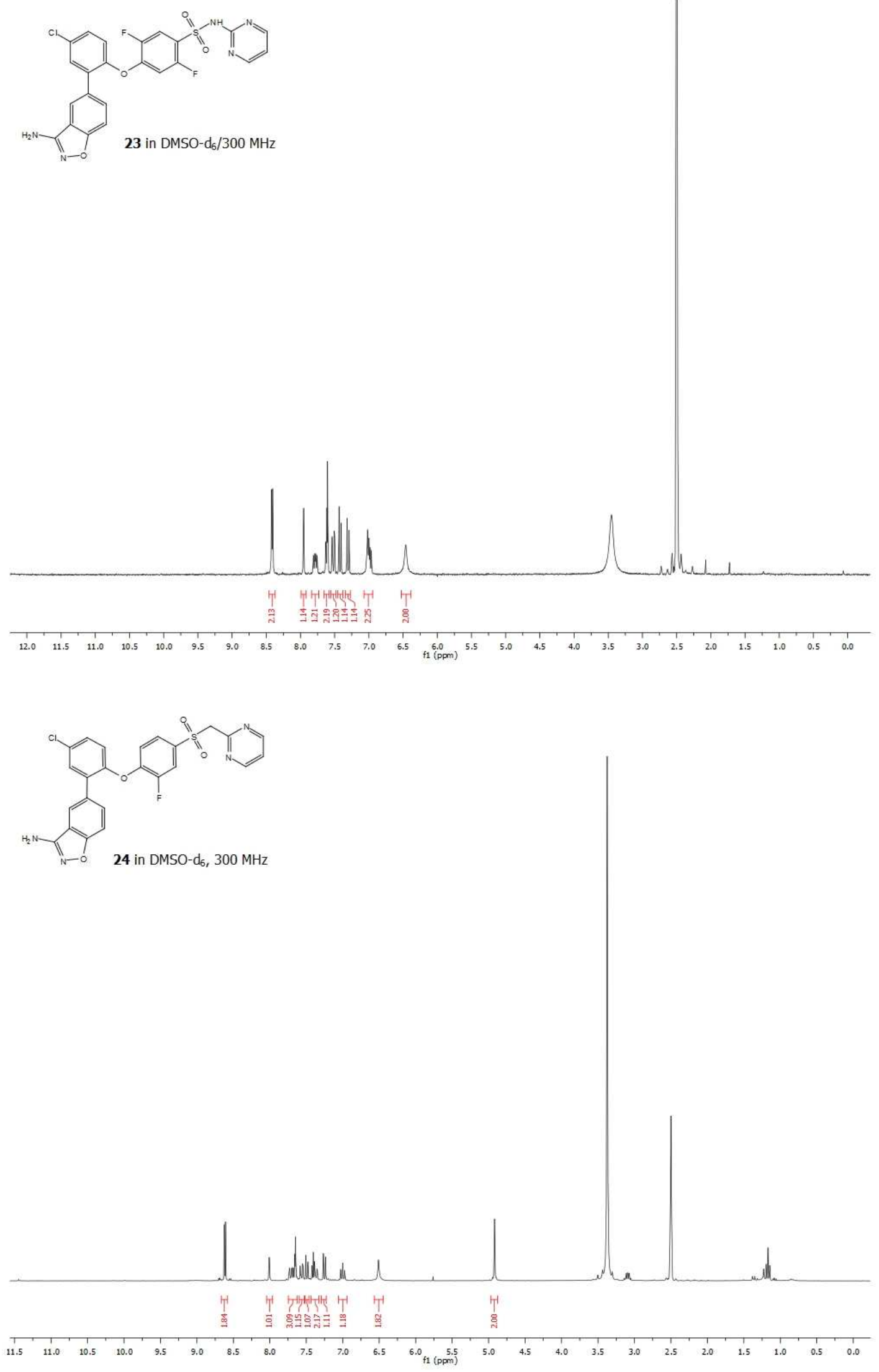

51 